\title{
WestVirginiaUniversity
}

THE RESEARCH REPOSITORY @ WVU

Graduate Theses, Dissertations, and Problem Reports

2006

\section{Hygrothermal effects on free vibration characteristics of rotating composite beams}

\author{
Sandeep Vennam \\ West Virginia University
}

Follow this and additional works at: https://researchrepository.wvu.edu/etd

\section{Recommended Citation}

Vennam, Sandeep, "Hygrothermal effects on free vibration characteristics of rotating composite beams" (2006). Graduate Theses, Dissertations, and Problem Reports. 1789.

https://researchrepository.wvu.edu/etd/1789

This Thesis is protected by copyright and/or related rights. It has been brought to you by the The Research Repository @ WVU with permission from the rights-holder(s). You are free to use this Thesis in any way that is permitted by the copyright and related rights legislation that applies to your use. For other uses you must obtain permission from the rights-holder(s) directly, unless additional rights are indicated by a Creative Commons license in the record and/ or on the work itself. This Thesis has been accepted for inclusion in WVU Graduate Theses, Dissertations, and Problem Reports collection by an authorized administrator of The Research Repository @ WVU. For more information, please contact researchrepository@mail.wvu.edu. 


\title{
Hygrothermal Effects on Free Vibration Characteristics of Rotating Composite Beams
}

\author{
Sandeep Vennam
}

\author{
Thesis submitted to the \\ College of Engineering and Mineral Resources \\ at the West Virginia University \\ in partial fulfillment of the requirements \\ for the degree of \\ Master of Science \\ in \\ Mechanical Engineering
}

Nithi T. Sivaneri, Ph.D., Chair

Kenneth H. Means, Ph.D

Charles F. Stanley, Ph.D

Department of Mechanical and Aerospace Engineering

Morgantown, West Virginia

2006

Keywords: Composite Materials, Rotating Beam, Hygrothermal, Finite Element Method 


\section{ABSTRACT \\ Hygrothermal Effects on Free Vibration Characteristics of Rotating Composite Beams}

\section{Sandeep Vennam}

Free vibration characteristics of a rotating composite cantilever beams subjected to a hygrothermal environment is studied using the finite element analysis. The problem is formulated using a First Order Shear Deformation theory (FSDT) for composite materials. The finite element formulation is based on variational principles and the equations are solved by a code generated using MATLAB. Hygrothermal effects are incorporated using empirical relations degrading the material stiffness property of the matrix depending on the temperature and moisture concentration. The dynamic analysis of a rotating composite beam are validated by comparing with that available in literature and the hygrothermal incorporation is validated by replicating results from literature for the case of bending deflection.

The influence of hygrothermal environments on the natural frequency of the beam is studied by conducting a parametric study. The hygrothermal effect on the natural frequency is minimal on the first two bending modes but more pronounced on the higher modes. As the rotating speed increases the hygrothermal effect is reduced. 


\section{ACKNOWLEDGEMENTS}

I would like to express my heartfelt and sincere gratitude to my research advisor Dr. Nithi Sivaneri, without whom this project would not have come to fruition. It is his invaluable guidance and support that helped me fulfill my graduation requirement. I would like to thank my committee members Dr. Kenneth Means and Dr. Charles Stanley for their valuable suggestions. Further, I wish to express my heartfelt thanks to my parents, for their love and support. I wish to express my appreciation to all my friends and well-wishers for their support and encouragement. I am thankful for the divine grace and guidance of the Satguru. 


\section{TABLE OF CONTENTS}

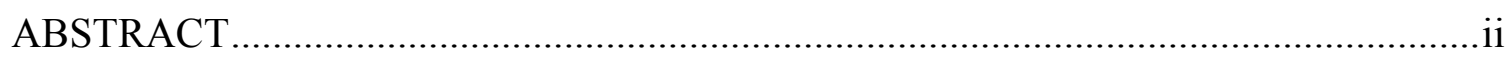

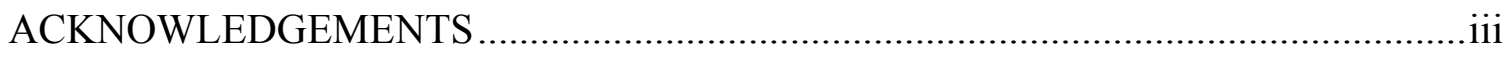

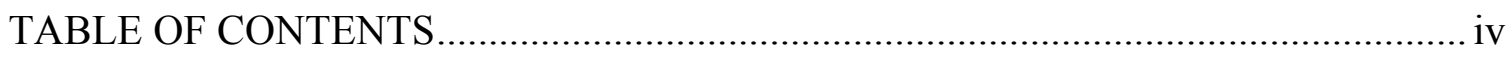

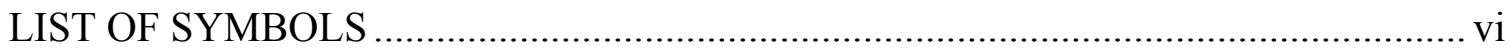

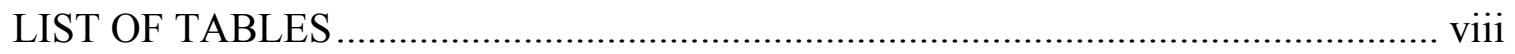

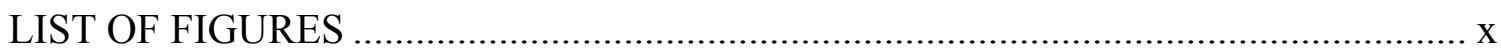

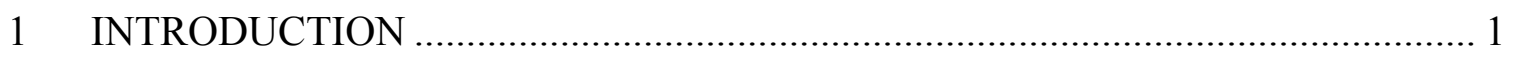

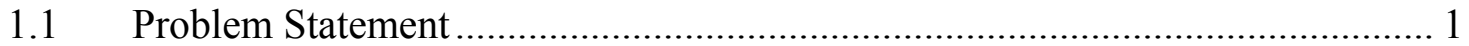

$1.2 \quad$ Laminated Composites....................................................................................... 1

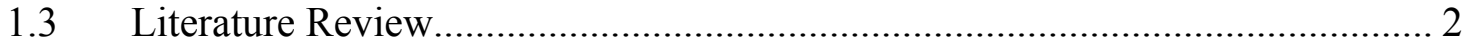

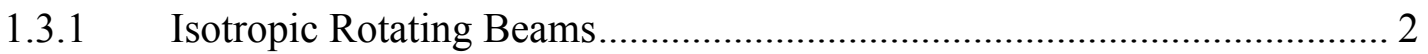

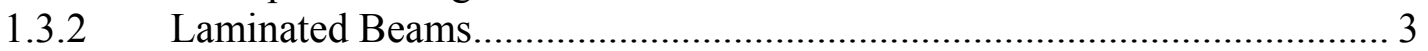

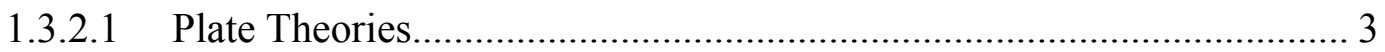

$1.4 \quad$ Need for present research...................................................................... 7

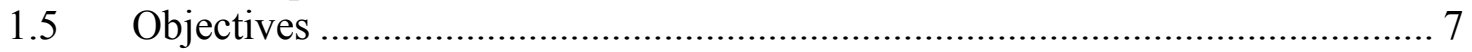

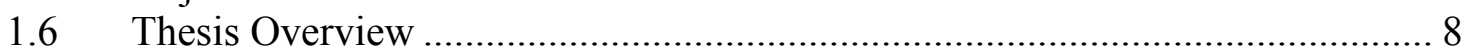

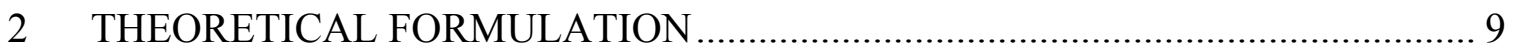

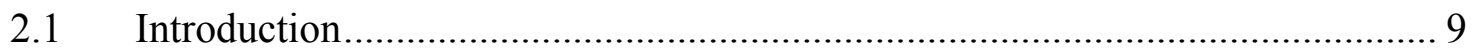

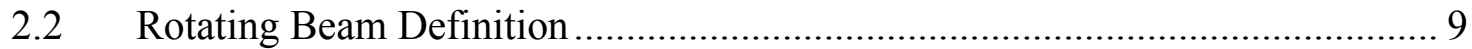

2.2.1 Lay-up Configuration........................................................................ 10

2.2.2 Force and Moment Resultants ............................................................. 11

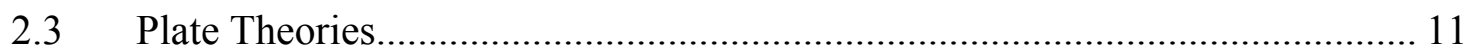

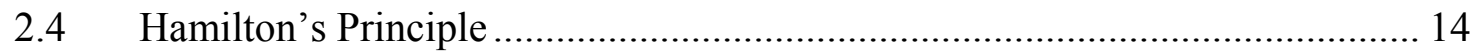

2.4.1 Kinematics Equations of a composite plate ............................................. 14

2.4.2 Virtual Strain Energy for a Plate........................................................ 16

2.4.3 Constitutive Equations ............................................................................ 17

2.4.4 Reduction of Plate Equations to Beam .................................................. 18

2.4.5 Virtual Strain Energy for a Beam …………………………………..... 21

2.4.6 Virtual Kinetic Energy for a Beam ......................................................... 22

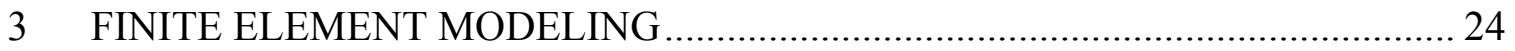

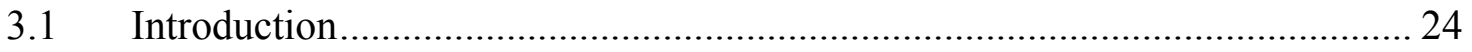

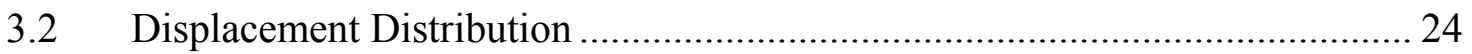

3.3 Element Stiffness Matrix Formulation........................................................... 29

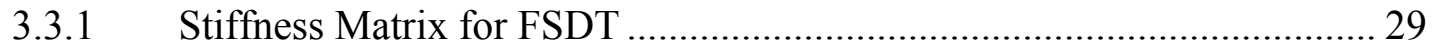

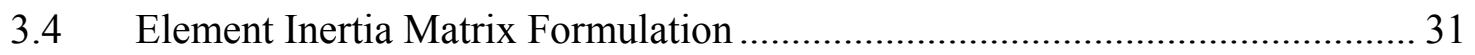

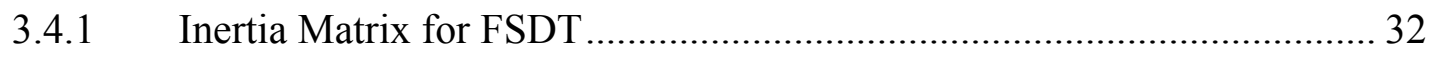

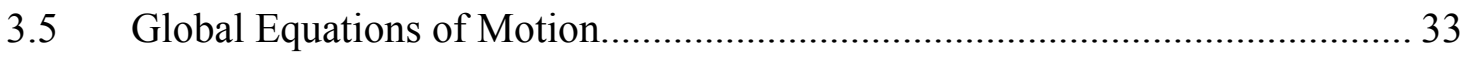


3.6 Gaussian Quadrature.............................................................................. 33

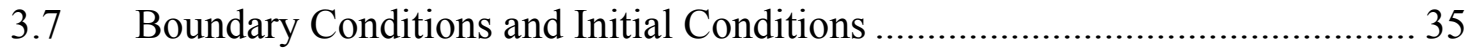

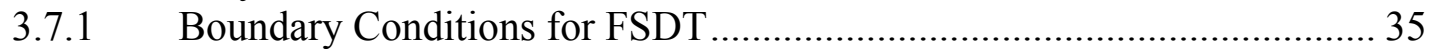

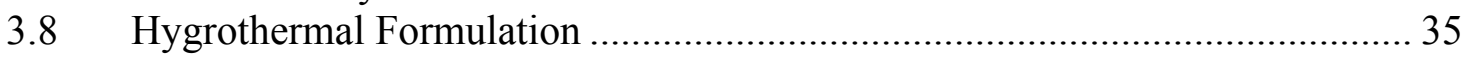

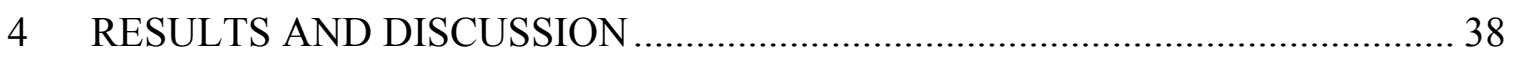

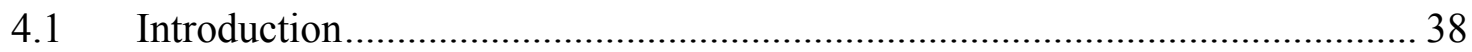

4.2 Isotropic Beam Comparison .......................................................................... 38

4.3 Non-Rotating Rectangular Composite Cantilever Beam ................................ 40

4.4 Rotating Rectangular Composite Cantilever Beam ......................................... 42

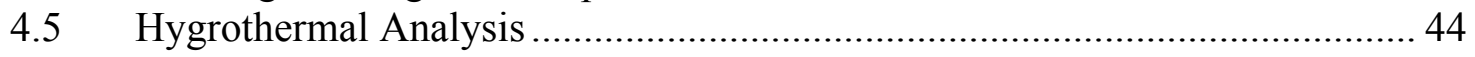

4.5.1 Large Deflection Bending of Composite Beams under Hygrothermal

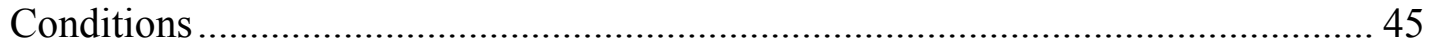

4.5.2 Hygrothermal Effects on Rotating Composite Cantilever Beams ............ 46

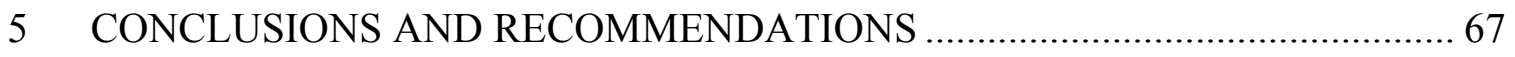

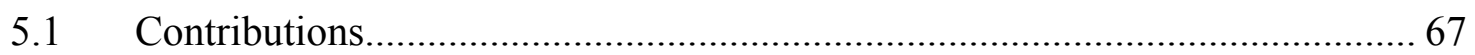

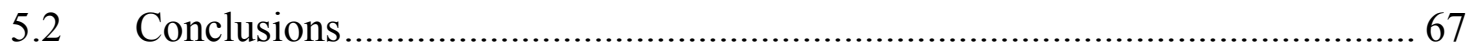

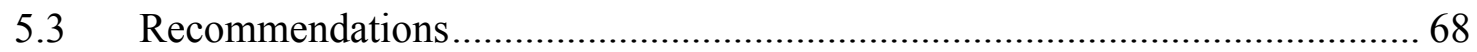

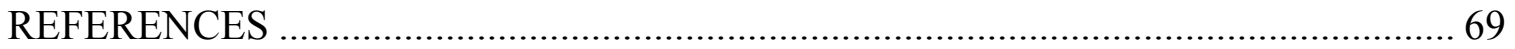

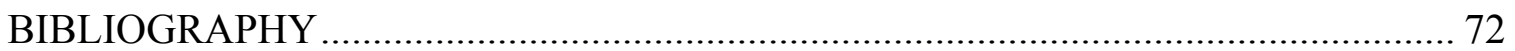




\section{LIST OF SYMBOLS}

$[A]$

$a_{i}, b_{j}$

$b$

$[B]$

$[D]$

E

$E_{1}$

$E_{2}$

$E_{f}$

$E_{m}$

$V_{f}$

$V_{m}$

$G_{12}$

$G_{f}$

$G_{m}$

$h$

$H_{i}, H_{L i}$

I

$I_{0}, I_{1}, I_{2}$

K

$\left[K_{x x}\right]$

$[K]$

$L$

$l_{e}$

$\left[M_{x x}\right]$

$[M]$

$M_{x}, M_{y}, M_{x y}$

$n$

$N_{x}, N_{y}, N_{x y}$

$P$

$P_{\text {HTM }}$

$P_{0}$

$\{q\}$

$Q_{x}, Q_{y}$

$\left[\bar{Q}^{k}\right]$

$\{Q\}$
- Axial stiffness matrix (N/m)

- Generalized coordinates

- Width of the beam (m)

- Bending-extension stiffness matrix $(\mathrm{N})$

- Bending stiffness matrix (Nm)

- Modulus of elasticity $\left(\mathrm{N} / \mathrm{m}^{2}\right)$

- Longitudinal modulus

- Transverse modulus

- Fiber modulus of elasticity $\left(\mathrm{N} / \mathrm{m}^{2}\right)$

- Matrix modulus of elasticity $\left(\mathrm{N} / \mathrm{m}^{2}\right)$

- Fiber volume fraction

- Matrix volume fraction

- In plane shear modulus

- Fiber in plane shear modulus

- Matrix in plane shear modulus

- Thickness of the beam (m)

- Hermitian and Lagrangian Shape functions

- Moment of Inertia $\left(\mathrm{m}^{4}\right)$

- Normal, coupled normal-rotary, and rotary inertia coefficients

- Shear correction factor

- Finite element stiffness matrix for composite material (N/m)

- Global stiffness matrix $(\mathrm{N} / \mathrm{m})$

- Length of the beam (m)

- Element length (m)

- Finite element inertia matrix for composite material

- Global Inertia matrix

- In plane moment resultants in $x y$ plane $(\mathrm{Nm})$

- Number of layers

- In plane force resultants in $x y$ plane $(\mathrm{N} / \mathrm{m})$

- Property to be measured

- Hygrothermal Mechanical Property

- Initial property

- Global displacements vector (m)

- Transverse shear force resultants $(\mathrm{N} / \mathrm{m})$

- Transformed reduced stiffness matrix of $k^{\text {th }}$ layer $\left(\mathrm{N} / \mathrm{m}^{2}\right)$

- Global load vector (N) 


\begin{tabular}{|c|c|}
\hline$[S]^{\mathrm{ij}}$ & - Partitions of reduced $[\mathrm{ABD}]$ matrix in formulation using FSDT \\
\hline$S_{i j}$ & - Element of reduced $[\mathrm{S}]$ matrix in formulation based on FSDT \\
\hline$t$ & - Time $(\mathrm{sec})$ \\
\hline$t_{k}$ & - Thickness of $k^{\text {th }}$ layer (m) \\
\hline$T$ & - Total kinetic energy $(\mathrm{Nm})$ \\
\hline$[T]^{i j}$ & - Partitions of reduced $[\mathrm{ABDEF}]$ matrix in formulation using \\
\hline $\begin{array}{l}T_{i j} \\
T_{g w r}\end{array}$ & $\begin{array}{l}\text { HSDT } \\
\text { - Elements of reduced }[\mathrm{T}] \text { matrix in formulation based on HSDT } \\
\text { - Glass transition temperature of wet resin }\end{array}$ \\
\hline$T_{g d r}$ & - Glass transition temperature of wet resin \\
\hline$u$ & - Axial deflection (m) \\
\hline$u_{0}, v_{0}, w_{0}$ & - Mid-plane displacements along $x, y$, and $z$ axis, respectively (m) \\
\hline$U$ & - Total strain energy $(\mathrm{Nm})$ \\
\hline$V$ & - Volume $\left(\mathrm{m}^{3}\right)$ \\
\hline$w_{b}, w_{s}$ & - Shear and bending components of transverse deflection (m) \\
\hline$w$ & - Transverse deflection (m) \\
\hline$W$ & - Work done (Nm) \\
\hline$x_{e}$ & - Element longitudinal axis \\
\hline$X, Y$ & - Global Axes \\
\hline$z$ & - Thickness coordinate \\
\hline$z_{k}$ & $\begin{array}{l}\text { - Distance to the top of the } k^{\text {th }} \text { layer from the mid-plane of a } \\
\text { laminate }(\mathrm{m})\end{array}$ \\
\hline$\overline{z_{k}}$ & $\begin{array}{l}\text { - Distance to the mid surface of the } k^{\text {th }} \text { layer from the mid-plane of } \\
\text { a laminate }(\mathrm{m})\end{array}$ \\
\hline $\bar{\Delta}$ & - Hamiltonian function \\
\hline$\Omega$ & $\begin{array}{l}\text { - Frequency of rigid-body rotational motion imparted to the beam } \\
(\mathrm{rad} / \mathrm{sec})\end{array}$ \\
\hline$\delta()$ & - Variation of ( ) \\
\hline$\varepsilon_{x}, \varepsilon_{y}, \varepsilon_{z}$ & - Normal strains in $x, y$, and $z$, directions, respectively \\
\hline$\phi_{x}, \phi_{y}$ & - Rotations about $x$ and $y$, respectively \\
\hline$\gamma_{x y}, \gamma_{y z}, \gamma_{x z}$ & - Engineering shear strains \\
\hline$\rho$ & - Mass Density $\left(\mathrm{Kg} / \mathrm{m}^{3}\right)$ \\
\hline$\xi$ & - Element non-dimensional coordinate \\
\hline()$^{T}$ & - Transpose of ( ) \\
\hline$\left.(\cdot),()^{\prime}\right)$ & - First and second partial derivatives with respect to time \\
\hline()$^{\prime},()^{\prime \prime}$ & - First and second partial derivatives with respect to $x$ \\
\hline()$^{y}$ & - Partial derivative with respect to $y$ \\
\hline
\end{tabular}




\section{LIST OF TABLES}

Table 3.1 Gauss integration points and weights................................ 34

Table 4.1 Material properties for steel beam with rectangular cross section..............39

Table 4.2 Summary of steel rotating cantilever beam response.......................39

Table 4.3 Material properties for Graphite/Epoxy composite beam...................41

Table 4.4 Natural frequency of Graphite/Epoxy composite beam with 300 fiber orientation.

Table 4.5 Natural frequency of Graphite/Epoxy composite beam with 150 fiber orientation. 41

Table 4.6 Material properties for Graphite/Epoxy composite beam...................42

Table 4.7 Constituent properties of S-Glass fiber and Epoxy matrix..................45

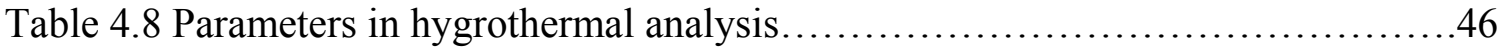

Table 4.9 Transverse deflections for clamped-clamped laminate due to transverse load in hygrothermal condition...................................46

Table 4.10 Parameters in hygrothermal analysis...............................47

Table 4.11 Constituent properties of S-Glass fiber and Epoxy matrix ..................48

Table 4.12 Material properties for S-Glass/Epoxy composite beam with $0 \%$ (dry conditions) and $2 \%$ moisture and $\mathrm{T}=900^{\circ} \mathrm{C}$ (hygrothermal condition)

Table 4.13 Material properties for S-Glass/Epoxy composite beam with $0 \%$ (dry condition) and $5 \%$ moisture and $\mathrm{T}=90 \circ \mathrm{C}$ (hygrothermal condition)

Table 4.14 Material properties for S-Glass/Epoxy composite beam with $0 \%$ (dry condition) and $5 \%$ moisture and $\mathrm{T}=52 \circ \mathrm{C}$ (hygrothermal condition)

Table 4.15 Influences of rotational speed and moisture content on natural frequencies of S-Glass/Epoxy beam, $[0] 24, \mathrm{~T}=90 \circ \mathrm{C}$ 
Table 4.16 Influences of rotational speed and moisture content on natural

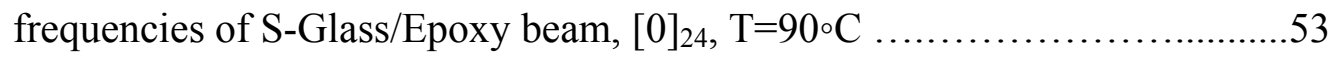

Table 4.17 Influences of rotational speed and moisture content on natural frequencies of S-Glass/Epoxy beam, $[15]_{24}, \mathrm{~T}=90{ }^{\circ} \mathrm{C} \ldots \ldots \ldots \ldots \ldots \ldots \ldots \ldots . \ldots \ldots$

Table 4.18 Influences of rotational speed and moisture content on natural frequencies of S-Glass/Epoxy beam, $[15] 24, \mathrm{~T}=90{ }^{\circ} \mathrm{C} \ldots \ldots \ldots \ldots \ldots \ldots \ldots \ldots . . . \ldots 5$

Table 4.19 Influences of rotational speed and moisture content on natural frequencies of S-Glass/Epoxy beam, [30]24, $\mathrm{T}=90{ }^{\circ} \mathrm{C} \ldots \ldots \ldots \ldots \ldots \ldots \ldots . \ldots \ldots$

Table 4.20 Influences of rotational speed and moisture content on natural frequencies of S-Glass/Epoxy beam, [30]24, T $=90^{\circ} \mathrm{C}$

Table 4.21 Influences of rotational speed and moisture content on natural frequencies of S-Glass/Epoxy beam, [45]24, $\mathrm{T}=90^{\circ} \mathrm{C}$

Table 4.22 Influences of rotational speed and moisture content on natural frequencies of S-Glass/Epoxy beam, [45]24, $\mathrm{T}=90^{\circ} \mathrm{C}$.

Table 4.23 Influences of rotational speed and moisture content on natural frequencies of S-Glass/Epoxy beam, $[0] 24, \mathrm{~T}=52^{\circ} \mathrm{C}$

Table 4.24 Influences of rotational speed and moisture content on natural frequencies of S-Glass/Epoxy beam, [15]24, T $=52^{\circ} \mathrm{C}$

Table 4.25 Influences of rotational speed and moisture content on natural frequencies of S-Glass/Epoxy beam, [30]24, $\mathrm{T}=52^{\circ} \mathrm{C}$

Table 4.26 Influences of rotational speed and moisture content on natural frequencies of S-Glass/Epoxy beam, [45]24, T $=52^{\circ} \mathrm{C}$

Table 4.27 Comparison of frequency results for FSDT and CLPT, for S-Glass/Epoxy Beam, [30]24, T=90 $\mathrm{C}$ 


\section{LIST OF FIGURES}

Figure 2.1 Coordinate systems for the rotating beam........................... 9

Figure 2.2 Composite lay-up configuration..................................... 10

Figure 2.3 Force and Moment Resultants on a flat plate [Barbero (1998)]..............11

Figure 2.4 Deformation of transverse normal for CLPT and FSDT [Reddy (1997)].....13

Figure 3.1 Element definition for formulation using

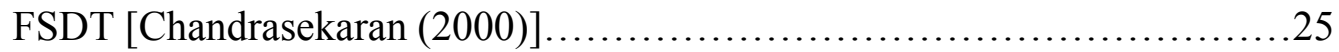

Figure 4.1 Frequency vs angular speed for graphite/epoxy beam $[15] 24 \ldots \ldots \ldots \ldots \ldots . . .43$

Figure 4.2 Frequency vs angular speed for graphite/epoxy beam $[0] 24 \ldots \ldots \ldots \ldots \ldots . .44$

Figure 4.3 Influences of rotational speed and moisture content on natural

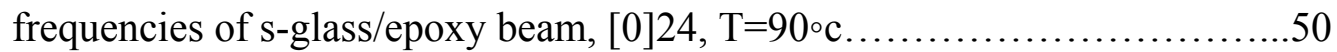

Figure 4.4 Influences of rotational speed and moisture content on natural

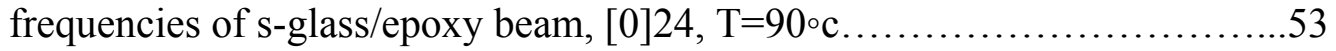

Figure 4.5 Influences of rotational speed and moisture content on natural

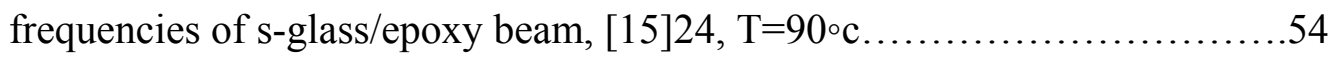

Figure 4.6 Influences of rotational speed and moisture content on natural

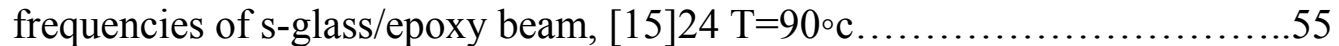

Figure 4.7 Influences of rotational speed and moisture content on natural

frequencies of s-glass/epoxy beam, $[30] 24, \mathrm{~T}=90{ }^{\circ} \mathrm{c} \ldots \ldots \ldots \ldots \ldots \ldots \ldots \ldots . .58$

Figure 4.8 Influences of rotational speed and moisture content on natural

frequencies of s-glass/epoxy beam, $[30] 24, \mathrm{~T}=90^{\circ} \mathrm{c}$.

Figure 4.9 Influences of rotational speed and moisture content on natural

frequencies of s-glass/epoxy beam, $[45] 24, \mathrm{~T}=90^{\circ} \mathrm{c}$.

Figure 4.10 Influences of rotational speed and moisture content on natural

frequencies of s-glass/epoxy beam, $[45] 24, \mathrm{~T}=90^{\circ} \mathrm{c}$.

Figure 4.11 Influences of rotational speed and moisture content on natural

frequencies of s-glass/epoxy beam, $[0] 24, \mathrm{~T}=52{ }^{\circ} \mathrm{c}$.

Figure 4.12 Influences of rotational speed and moisture content on natural

frequencies of s-glass/epoxy beam, $[15] 24, \mathrm{~T}=52^{\circ} \mathrm{c}$. 
Figure 4.13 Influences of rotational speed and moisture content on natural

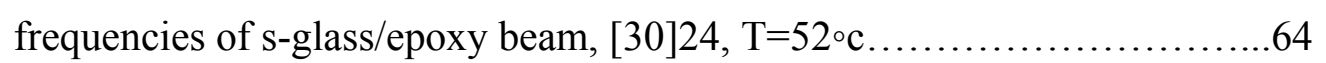

Figure 4.14 Influences of rotational speed and moisture content on natural

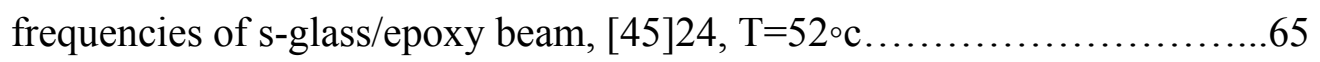




\section{INTRODUCTION}

\subsection{Problem Statement}

Applications such as turbine blades, propellers and helicopter rotor blades can be thought as rotating beams. Composite materials are increasingly being utilized in such applications. But composite materials are influenced by moisture and temperature conditions, thus it is important to analyze the fundamental part of dynamic behavior that is the free vibration characteristics of rotating cantilever composite beams under the influence of hygrothermal environment.

\subsection{Laminated Composites}

Composite materials are a combination of two or more materials called constituents. The characteristics of the composite materials depend on the constituents and the manner in which they are integrated. Constituents materials can be metallic, non metallic or a combination of both. Based on the kind of integration, composites are classified into three types namely fibrous composites, particulate composites and laminated composites. Advantages of composite materials are their high stiffness-toweight ratio and strength-to-weight ratio when compared to conventional metals.

Laminates are essentially sheets of material stacked together. A fiber-reinforced lamina is a sheet of composite material with fibers embedded in a matrix material. Desired strength and stiffness properties are achieved by laying/stacking lamina in a particular sequence. Laminated composites are generally classified into two types based on their lay-up architecture. They are symmetric and unsymmetric lay-ups. A laminate is 
said to be symmetric if it has the same number of layers with the same orientation and thickness located symmetrically about the mid-plane; otherwise it is unsymmetric.

Laminated composites have their planar dimensions comparatively larger than the thickness, rendering them to be treated as plates. Therefore, to study the behavior of composites, several laminate plate theories have been developed [Reddy (1985)]. When the width of the plate is small compared to the length it is treated as a beam. Reddy (1985) presented analytical solutions for a number of laminated beams and plate strips.

\subsection{Literature Review}

\subsubsection{Isotropic Moving Beams}

Sreeram (1995) and Sreeram and Sivaneri (1997) studied the response of a beam moving axially with respect to the supports using the finite element method.

Vibration behavior of rotating beams has been studied in the past. Several methods of analyses are found in the literature, namely numerical methods, transfer matrix method, the Rayleigh-Ritz method, the Ritz-Galerkin method, finite element methods etc. Bauer and Eidel (1988) have studied the free vibration behavior of a rotating uniform isotropic Euler beam. The vibration of the beam in the plane of rotation and

plane perpendicular to it are each described by an uncoupled partial differential equation with varying coefficients. The governing equations are solved approximately using the Ritz-Galerkin method.

Bhat (1986) has studied the transverse vibrations of a rotating uniform cantilever beam with a tip mass. The response of beam is predicted using beam characteristic 
orthogonal polynomials in the Rayleigh-Ritz method generated by Gram-Schmidt process.

Hodges and Rutkowski (1981) have implemented a variable-order finite element method (p-version) to analyze the free vibration characteristics of rotating beams. The purpose of the method is to improve accuracy by varying the order of the polynomial (pversion) or by using more elements (h-version) with reduced order polynomial shape function.

. Epps and Chandra (1996) have investigated experimentally and theoretically the influence of tip sweep on vibration behavior of rotating beams. Theoretical frequencies are calculated using the finite element method.

\subsubsection{Laminated Beams}

\subsubsection{Plate Theories}

Reddy (1985) has listed various theories that can be used for the analysis of composite plates. Earlier equivalent single layer theory in which every layer is considered as an elastic continuum with distinct material properties from adjacent layers is used for analysis. Lamination theories such as Classical Lamination Plate Theory (CLPT) and First-Order Shear-Deformation Theory (FSDT), based on methods such as Castigliano's theorem, Principle of minimum total potential energy and Variational principles have been developed considering the laminate to be in a state of plane stress. The CLPT has some disadvantages as it ignores transverse stress components and therefore was found to be inadequate for analysis of composite plates. This disadvantage could be overcome 
using a First order shear-deformation theory as it accounts for the transverse shear stresses.

Singh, Rao, and Iyengar (1991) studied the nonlinear vibration behavior of unsymmetric composite beams. The governing equations have been formulated using the classical lamination theory, first-order shear deformation theory and higher-order shear deformation theory based on Von Karman large-deflection theory to analyze large amplitude free vibration. The analysis is performed using elements having 8, 10 or 12 degrees of freedom per node. The behavior of isotropic and symmetric orthotropic laminates is studied. The equations are solved using direct numerical integration for various boundary conditions, lay-up sequences and slenderness ratios.

Abarcar and Cunniff (1972) have presented experimental and theoretical results pertaining to the vibrations characteristics of cantilever composite beams with rectangular cross section. They include the effect of rotary inertia and transverse shear in the theoretical evaluation using a flexibility approach. Frequency and mode shapes for graphite-epoxy and boron-epoxy beams with fiber orientation of 15 and 30 degrees have been determined experimentally and compared with the theoretical results.

Yildirim et al. (1999) studied the free vibration characteristics of symmetric crossply laminated composite beams using the transfer matrix approach. The rotary inertia, shear deformation and extensional deformation effects are considered. The effects of number of plies, slenderness ratio, width to height ratio and various boundary conditions, on both in-plane and out of plane free vibrations of rectangular beams is studied.

Stemple et, al. (1995) studied the vibration characteristics of rotating composite beams using the finite element approach, incorporating shear deformation and warping 
degrees of freedom into the finite element formulation. The effect of ply angle and rotational speed on the natural frequency of a cantilever box beam is studied and numerical results for beams with no coupling, extension-bending-torsion coupling and bending torsion coupling is presented.

Epps and Chandra (1996) have experimentally and theoretically investigated the influence of tip sweep on the natural frequency of rotating composite solid section beams. The theoretical study is done by linearized free vibration analysis of beams at their deformed state using the finite element method. Experimental results are determined for graphite-epoxy beams (24 plies) with different tip sweep and fiber orientation using invacuo rotor chamber. It is determined that with the increase in angle of the ply the torsional stiffness increases and the bending stiffness decreases; and with the increase in the sweep the first torsional frequency decreases, second does not vary and the third increases.

Hodges et al. (1996) have developed a geometrically non-linear finite element analysis for initially curved and twisted composite beams. A mixed finite element solution of intrinsic equations for arbitrary large deformation is presented by reducing a three dimensional beam problem into one or more two dimensional problems over the cross section and a non-linear one dimensional problem along the beam reference line. The results are compared with those available in literature and found to correlate with experimental data better than which have been achieved with standard deflection theory approach.

Chandrasekaran (2000) has studied the behavior of moving beams made of laminated composites using the finite element method based on the variational principle. 
The formulation is done for both the classical laminate plate theory and the first-order shear deformation theory. The boundary conditions are introduced via Lagrange multipliers. The finite element equations are then solved using Newmark's implicit method. The displacement response of the beam is studied for symmetric and unsymmetric laminates.

Chen and Chen (1988) have performed a free and force vibration analysis of laminated rectangular composite plates exposed to a steady-state hygrothermal environment. A finite element model formulated by Mindlin plate theory is used, which includes the transverse shear and normal deformation effects. A parametric study on graphite-epoxy laminated composite plate subjected to different moisture and temperate levels, boundary condition and fiber orientations is done. It is concluded that the hygrothermal environment has a degrading effect on the natural frequency of laminated plates.

Shen et al. (2004) have studied the effects of hygrothermal condition on the dynamic response of shear deformable laminated plates resting on elastic foundation. A Finite element model with the governing equations based on a higher order shear deformation theory is developed. The hygrothermal effects are incorporated using a micro-macro mechanical model wherein the material property is considered to be dependant on the temperature and moisture and provided explicitly in terms of fiber and matrix properties. The study concludes that with the increase in moisture and temperature the deflections and bending moments increased, but the frequencies decreased.

Upadhyay and Lyons (2000 a\&b) have studied the effects of hygrothermal conditions on large deflection bending of asymmetric PMC laminates. The governing 
equations are formulated based on Von Karman large deflection theory. The hygrothermal effects are incorporated by degrading the strength and stiffness related properties of the constituents due to hygrothermal conditioning based on empirical relations of Chamis (1983).

\subsection{Need for present research}

Composite materials are replacing conventional materials because of their better engineering properties such as strength to weight ratio and stiffness to weight ratio. Though composite materials have advantages they are readily affected by moisture and temperature conditions more than conventional metals. Some of the applications where composite materials are used and are subjected to hygrothermal environment are rotating elements such as compressor blades, propellers etc. Most basic or simplified idealization of such elements is beams. Therefore it is important to analyze the dynamic response of rotating composite beams subjected to hygrothermal environment.

\subsection{Objectives}

The Objectives of the thesis are:

- To formulate a finite element model for a composite rotating beam and analyze its dynamic behavior. The formulation would be based on a first-order shear deformation theory and the variational method. 
- To generate a MATLAB code to solve the finite element equations for the composite rotating beam with different lay-up configurations. The beam is assumed to make a uniform rotating motion with the specified rotational speed.

- To conduct hygrothermal analysis of rotating solid section beams made of PMC laminate and compare the fundamental frequencies under dry and wet conditions.

- To conduct a parametric study about the influence of hygrothermal conditions

\subsection{Thesis Overview}

Chapter two deals with the composite lay-up configuration, introduction to plate theories (CLPT, FSDT) and the displacement distributions, formulation of the governing equations for FSDT.

Chapter three details the finite element formulation of the stiffness and inertia matrices, Gaussian integration procedure and schemes used for solving the governing equations, Hygrothermal effects formulation and implementation.

Chapter four presents the results in the form of the free vibration response of a composite rotating beam under the influence of hygrothermal conditions.

Chapter five contains the conclusions of the present work and recommendations for future work. 


\section{THEORETICAL FORMULATION}

\subsection{Introduction}

In many applications, composite beams are taking the place of conventional materials. As mentioned in the previous sections there are several plate theories for analyzing composite plates. This chapter emphasizes in formulating the governing equations of a rotating composite beam from such plate theories.

\subsection{Rotating Beam Definition}

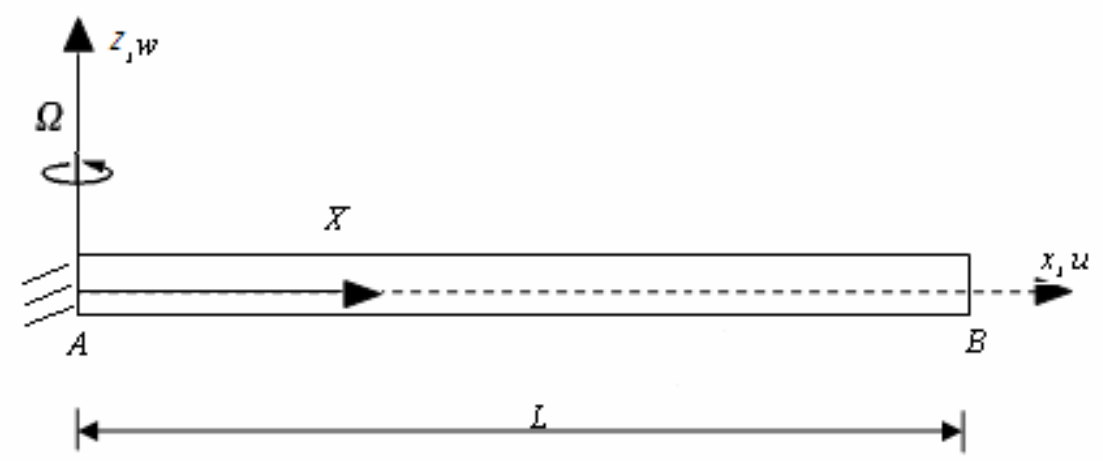

Figure 2.1 Coordinate systems for the rotating beam

A cantilever beam rotating perpendicular to its longitudinal axis is described in this section. Consider a beam $A B$ of length $L$ and mass per unit length $\mathrm{m}$ as shown in Figure 2.1. The beam is cantilevered at point $A$, which is the origin for an inertial frame $(X, Z)$ with the $Z$ - axis normal to the beam axis. The beam rotates with a constant angular velocity of $\Omega \mathrm{rad} / \mathrm{s}$ about the $Z$-axis. A moving coordinate frame $(x, z)$ with its origin at $A$ is attached to the beam and rotates with the beam. The beam undergoes an axial 
deformation, $u$, along the $x$-axis and a transverse deformation, $w$, along the $z$-axis. The rotating motion induces an axial force $N_{x}$ which is a function of $x$ as given by

$$
N_{x}=\frac{1}{2} m \Omega^{2}\left(L^{2}-x^{2}\right)
$$

\subsubsection{Lay-up Configuration}

The stacking sequence and naming convention of a composite laminate is as represented in Figure 2.2. The total thickness of the laminate is represented by $h$, which is equal to the sum of the thicknesses of all layers. $z_{k}$ represents the $z$-coordinate of the top of the $k^{\text {th }}$ layer from a reference plane located at the mid-surface of the composite. The quantity $\overline{z_{k}}$ represents the $z$-coordinate of the middle surface of the $k^{\text {th }}$ layer with thickness of the $k^{\text {th }}$ layer being $t_{k}$.

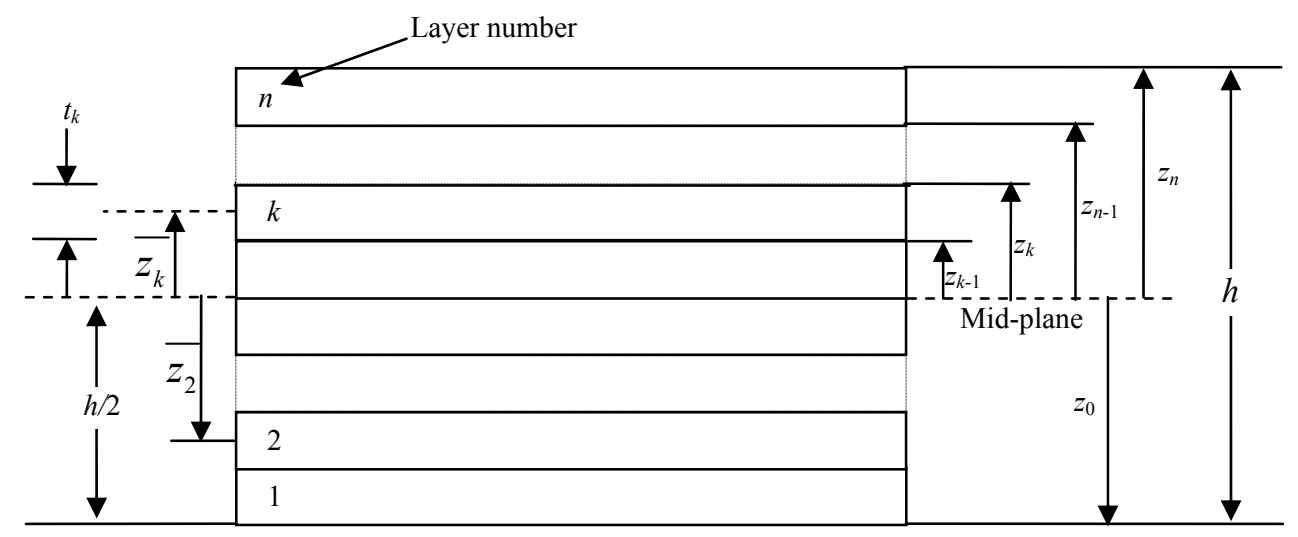

Figure 2.2 Composite lay-up configuration 


\subsubsection{Force and Moment Resultants}
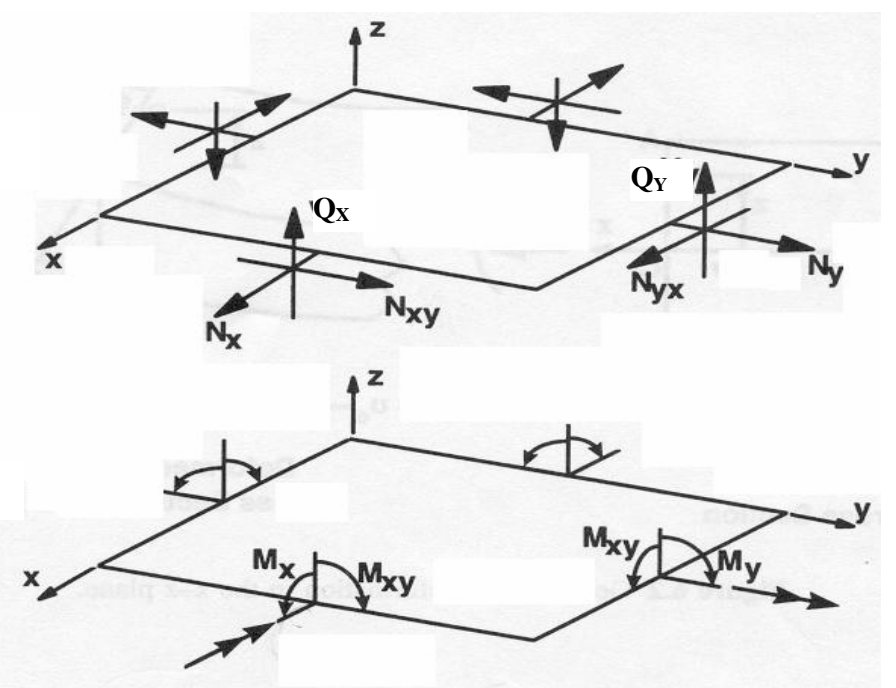

Figure 2.3 Force and Moment Resultants on a flat plate [Barbero (1998)]

Figure 2.3 shows the positive directions for force and moment resultants. The inplane force resultants acting along the $x$ and $y$ directions are represented by $N_{x}, N_{y}$, and $N_{x y}$. The moment resultants are represented by $M_{x}, M_{y}$, and $M_{x y}$ and the transverse shear force resultants by $Q_{x}$ and $Q_{y}$.

\subsection{Plate Theories}

Composite laminates are treated as plate elements because of the magnitude of planar dimensions being larger compared to their thickness. Based on the assumption of kinematics deformation or stress state, the composite plate elements are sometimes analyzed using equivalent single layer theories. The most commonly used equivalent single layer plate theories are the Classical Laminate Plate Theory (CLPT) and Firstorder Shear Deformation Theory (FSDT). The Classical laminate plate theory for 
composite laminates is an extension of the classical plate theory of isotropic materials. Kirchoff's hypotheses are used in the derivation of the plate stiffness and compliance equations. The assumptions, as stated by Reddy (1997), for CLPT are:

1. Straight lines perpendicular to the mid-surface (transverse normals) before deformation remain straight after deformation.

2. The transverse normals do not experience elongation. $\left(\varepsilon_{z z}=0\right)$

3. The transverse normals rotate such that they remain perpendicular to the midsurface after deformation. $\left(\varepsilon_{x z}=0\right.$ and $\left.\varepsilon_{y z}=0\right)$

In addition to Kirchoff's hypothesis, the following assumptions are also used:

4. The layers are perfectly bonded together.

5. The material of each layer is linearly elastic and has two planes of material symmetry (i.e., orthotropic).

6. Each layer is of uniform thickness.

7. The strains and displacements are small.

8. The transverse shear stresses on the top and bottom surfaces of the laminate are zero.

In the case of CLPT, the effects of transverse shear are neglected since transverse shear strains $\left(\gamma_{x z}\right.$ and $\left.\gamma_{y z}\right)$ are assumed to be zero. This assumption may render CLPT inadequate for the dynamic analysis of a beam even with a high slenderness ratio. To consider the effect of transverse shear, the First-order shear-deformation theory (FSDT) can be used. In FSDT the transverse normal is assumed to be straight but not perpendicular to the mid-surface after deformation and therefore transverse shear strains 
are not zero. The transverse normal inextensible, keeping the deformations independent of function of the thickness co-ordinate $z$.

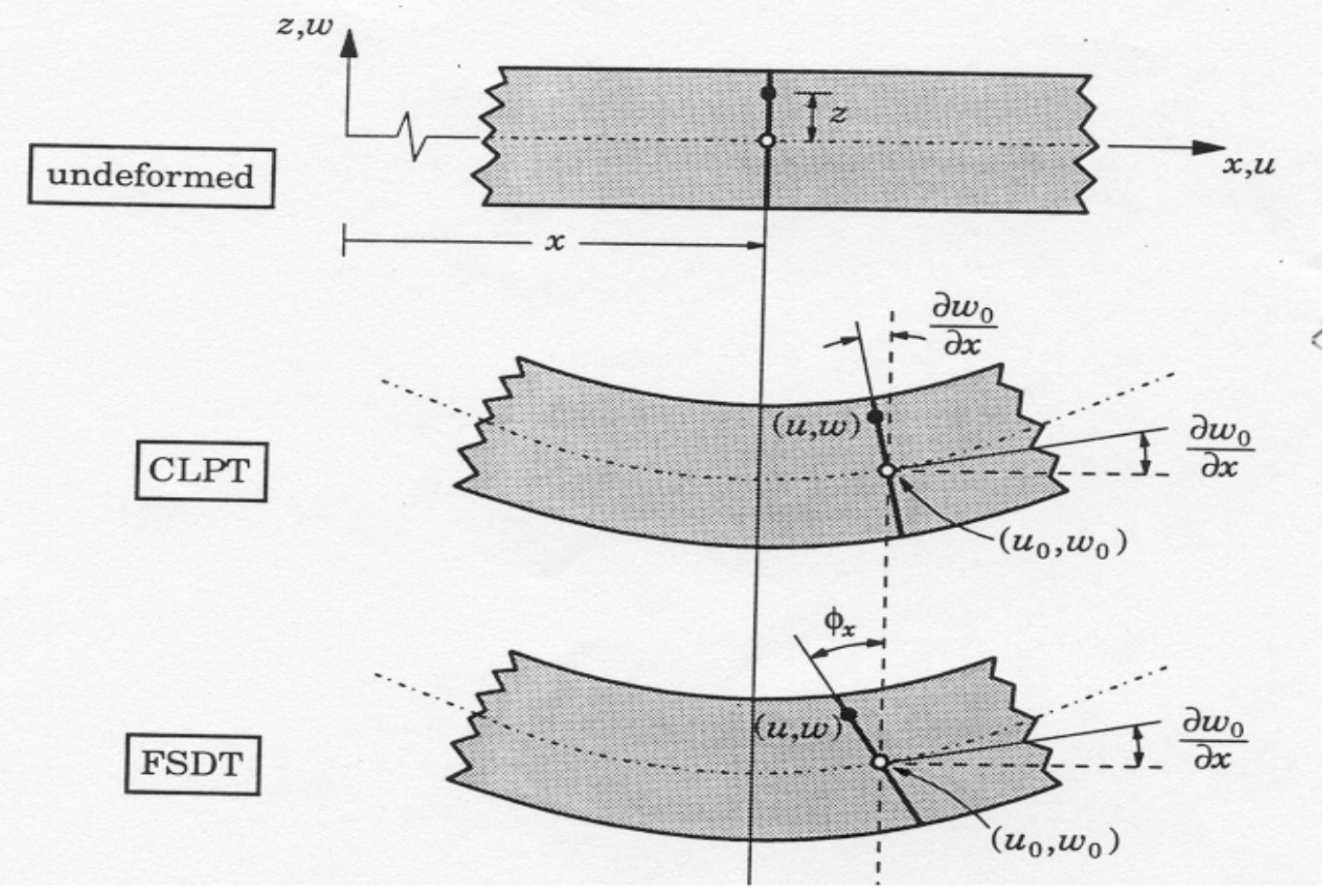

Figure 2.4 Deformation of transverse normal for CLPT and FSDT [Reddy (1997)]

In FSDT, the displacement field $(u, v, w)$ in the $(x, y, z)$ directions, respectively, can be expressed as [Reddy (1997)]:

$$
\begin{aligned}
& u(x, y, z, t)=u_{0}(x, y, t)+z \phi_{x}(x, y, t) \\
& v(x, y, z, t)=v_{0}(x, y, t)+z \phi_{y}(x, y, t) \\
& w(x, y, z, t)=w(x, y, t)=w_{b}(x, y, t)+w_{s}(x, y, t)
\end{aligned}
$$

where $u_{0}$ and $v_{0}$ represent the inplane displacements at the midplane. $\phi_{x}$ and $\phi_{\mathrm{y}}$ are the rotations of a transverse normal about the $y$ and $x$ axes, respectively (see Figure 2.4). The bending deformation $w$ is independent of thickness coordinate and consists of a pure bending component, $w_{b}$ and a shear component, $w_{s}$. 


\subsection{Hamilton's Principle}

The governing equations of the problem is derived from Hamilton's principle,

$\Delta=\int_{t_{1}}^{t_{2}}(\delta U-\delta T-\delta W) d t=0$

Where $\delta U$ is the virtual strain energy, $\delta T$ is the virtual kinetic energy, $\delta W$ is the virtual work and $\mathrm{t}$ is the time co-ordinate.

\subsubsection{Kinematics Equations of a composite plate}

The nonlinear kinematic equations are given by [Reddy (1997)],

$$
\begin{aligned}
& \varepsilon_{x}=\frac{\partial u}{\partial x}+\frac{1}{2}\left(\frac{\partial w}{\partial x}\right)^{2} \\
& \varepsilon_{y}=\frac{\partial v}{\partial y}+\frac{1}{2}\left(\frac{\partial w}{\partial y}\right)^{2} \\
& \gamma_{x y}=\left(\frac{\partial u}{\partial y}+\frac{\partial v}{\partial x}+\frac{\partial w}{\partial x} \frac{\partial w}{\partial y}\right) \\
& \gamma_{y z}=\left(\frac{\partial v}{\partial z}+\frac{\partial w}{\partial y}\right) \\
& \gamma_{x z}=\left(\frac{\partial u}{\partial z}+\frac{\partial w}{\partial x}\right)
\end{aligned}
$$

Substituting Eq. (2.2) into Eq. (2.4) we get,

$$
\begin{aligned}
& \varepsilon_{x}=\frac{\partial u_{0}}{\partial x}+\frac{1}{2}\left(\frac{\partial w}{\partial x}\right)^{2}+z \frac{\partial \phi_{x}}{\partial x} \\
& \varepsilon_{y}=\frac{\partial v_{0}}{\partial y}+\frac{1}{2}\left(\frac{\partial w}{\partial y}\right)^{2}+z \frac{\partial \phi_{y}}{\partial y}
\end{aligned}
$$


$\gamma_{x y}=\frac{\partial u_{0}}{\partial y}+\frac{\partial v_{0}}{\partial x}+\frac{\partial w}{\partial x} \frac{\partial w}{\partial y}+z\left(\frac{\partial \phi_{x}}{\partial y}+\frac{\partial \phi_{y}}{\partial x}\right)$

$\gamma_{y z}=\phi_{y}+\frac{\partial w}{\partial y}$

$\gamma_{z x}=\phi_{x}+\frac{\partial w}{\partial x}$

From Figure 2.4, the transverse normal rotations at the midplane, $\phi_{x}$ and $\phi_{\mathrm{y}}$ can be written

as,

$$
\begin{gathered}
\phi_{x}=\frac{\partial u_{0}}{\partial z}=-\frac{\partial w_{b}}{\partial x} \\
\phi_{y}=\frac{\partial v_{0}}{\partial z}=-\frac{\partial w_{b}}{\partial y}
\end{gathered}
$$

Then $\phi_{x}+\frac{\partial w}{\partial x}=-\frac{\partial w_{b}}{\partial x}+\frac{\partial w_{b}}{\partial x}+\frac{\partial w_{s}}{\partial x}=\frac{\partial w_{s}}{\partial x}$

Similarly, $\phi_{y}+\frac{\partial w}{\partial y}=\frac{\partial w_{s}}{\partial y}$

The strains of Eq. (2.5) can also be written as,

$$
\begin{aligned}
& \varepsilon_{x}=\varepsilon_{x}^{(0)}+z \varepsilon_{x}^{(1)} \\
& \varepsilon_{y}=\varepsilon_{y}^{(0)}+z \varepsilon_{y}^{(1)} \\
& \gamma_{x y}=\gamma_{x y}^{(0)}+z \gamma_{x y}^{(1)} \\
& \gamma_{y z}=\gamma_{y z}^{(0)} \\
& \gamma_{z x}=\gamma_{z x}^{(0)}
\end{aligned}
$$


where,

$\varepsilon_{x}^{(0)}=\frac{\partial u_{0}}{\partial x}+\frac{1}{2}\left(\frac{\partial w_{b}}{\partial x}\right)^{2}+\frac{1}{2}\left(\frac{\partial w_{s}}{\partial x}\right)^{2}$

$\varepsilon_{x}^{(1)}=-\frac{\partial^{2} w_{b}}{\partial x^{2}}$

$\varepsilon_{y}^{(0)}=\frac{\partial v_{0}}{\partial x}+\frac{1}{2}\left(\frac{\partial w_{b}}{\partial y}\right)^{2}+\frac{1}{2}\left(\frac{\partial w_{s}}{\partial y}\right)^{2}$

$\varepsilon_{y}^{(1)}=-\frac{\partial^{2} w_{b}}{\partial y^{2}}$

$\gamma_{x y}^{(0)}=\frac{\partial u_{0}}{\partial y}+\frac{\partial v_{0}}{\partial x}+\left(\frac{\partial w_{b}}{\partial x}+\frac{\partial w_{s}}{\partial x}\right)\left(\frac{\partial w_{b}}{\partial y}+\frac{\partial w_{s}}{\partial y}\right)$

The term $\left(\frac{\partial w_{b}}{\partial x}+\frac{\partial w_{s}}{\partial x}\right)\left(\frac{\partial w_{b}}{\partial y}+\frac{\partial w_{s}}{\partial y}\right)$ in the above expression is neglected in further

considerations to avoid nonlinearity in the governing equations.

$$
\begin{aligned}
& \gamma_{x y}^{(1)}=-2 \frac{\partial^{2} w_{b}}{\partial x \partial y} \\
& \gamma_{y z}^{(0)}=\frac{\partial w_{s}}{\partial y} \\
& \gamma_{x z}^{(0)}=\frac{\partial w_{s}}{\partial x}
\end{aligned}
$$

\subsubsection{Virtual Strain Energy for a Plate}

The total virtual strain energy of a plate is given by,

$$
\delta U=\iiint_{V}\left[\sigma_{x} \delta \varepsilon_{x}+\sigma_{y} \delta \varepsilon_{y}+\tau_{x y} \delta \gamma_{x y}+\tau_{y z} \delta \gamma_{y z}+\tau_{x z} \delta \gamma_{x z}\right] d V
$$


where $\delta \varepsilon_{x}, \delta \varepsilon_{y}, \delta \gamma_{x y}, \delta \gamma_{y z}$, and $\delta \gamma_{x z}$ are the virtual strains and $V$ is the volume of the plate.

Deducing the volume integral in (2.10) into an integral over the thickness coordinate $z$ and an area integral in the $x, y$ directions,

$$
\begin{aligned}
& \delta U=\iint_{A} \int_{-\frac{h}{2}}^{\frac{h}{2}}\left[\sigma_{x} \delta \varepsilon_{x}+\sigma_{y} \delta \varepsilon_{y}+\tau_{x y} \delta \gamma_{x y}+\tau_{y z} \delta \gamma_{y z}+\tau_{x z} \delta \gamma_{x z}\right] d A d z \\
& \left(N_{x}, N_{y}, N_{x y}\right)=\int_{-\frac{h}{2}}^{-\frac{h}{2}}\left(\sigma_{x}, \sigma_{y}, \tau_{x y}\right) d z \\
& \left(M_{x}, M_{y}, M_{x y}\right)=\int_{-\frac{h}{2}}^{-\frac{h}{2}}\left(\sigma_{x}, \sigma_{y}, \tau_{x y}\right) z d z \\
& \left(Q_{x}, Q_{y}\right)=\int_{-\frac{h}{2}}^{-\frac{h}{2}}\left(\tau_{x z}, \tau_{y z}\right) d z
\end{aligned}
$$

Defining the stress resultants as in (2.12) the strain energy equation of the beam reduces to:

$\delta U=\iint_{A}\left[\begin{array}{l}N_{x} \delta \varepsilon_{x}^{(0)}+M_{x} \delta \varepsilon_{x}^{(1)}+N_{y} \delta \varepsilon_{y}^{(0)}+M_{y} \delta \varepsilon_{y}^{(1)}+N_{x y} \delta \gamma_{x y}^{(0)}+M_{x y} \delta \gamma_{x y}^{(1)}+Q_{x} \delta \gamma_{z x}^{(0)} \\ +Q_{y}\end{array}\right] d A$

\subsubsection{Constitutive Equations}

The relation between the stress resultants and strains are given by [Reddy (1997)]:

$$
\begin{aligned}
& \left\{\begin{array}{c}
\{N\} \\
\{M\}
\end{array}\right\}=\left[\begin{array}{ll}
{[A]} & {[B]} \\
{[B]} & {[D]}
\end{array}\right]\left\{\begin{array}{l}
\left\{\varepsilon^{(0)}\right\} \\
\left\{\varepsilon^{(1)}\right\}
\end{array}\right\} \\
& \{Q\}=[A]\left\{\gamma^{(0)}\right\}
\end{aligned}
$$

Vectors $\{N\}$ and $\{M\}$ denote the force and moment resultant vectors. Vector $\{Q\}$ represents the transverse force resultants. Matrices $[A],[B]$ and $[D]$ contain the extension 
stiffness, bending-extension coupling and bending stiffness coefficients terms, respectively. The coefficient matrices in Eq. (2.14) are obtained from,

$$
\left(A_{i j}, B_{i j}, D_{i j}\right)=\sum_{k=1}^{n} \int_{z_{k-1}}^{z_{k}} \bar{Q}_{i j}^{(k)}\left(1, z, z^{2}\right) d z
$$

The matrices A, B, D in Eq. (2.14) are of the order $3 \times 3$ with the stiffness coefficients defined for $i, j=1,2,6$. Matrices in Eq. (2.15) are obtained from,

$$
\left(A_{i j}\right)=\sum_{k=1}^{n} \int_{z_{k-1}}^{z_{k}} \bar{Q}_{i j}^{(k)} d z
$$

The $\bar{Q}_{i j}^{(k)}$ represents the off-axis material stiffness coefficients of the $k^{\text {th }}$ layer. where $[A]$ is a $2 \times 2$ matrix with $i, j=4,5$.

\subsubsection{Reduction of Plate Equations to Beam}

For composite materials plate theories are developed first rather than beam theories. The beam theories are systematically reduced from the plate theories. The following procedure of reducing the plate equations to beam equations is in similar lines to the work done by Nagappan (2004). This process is adapted for FSDT and is outlined in this section.

For beams the lateral resultant forces are negligible. Therefore, $N_{y}, M_{y}$ are set to zero in Eq. (2.14). Similarly $Q_{y}$ is set to zero in Eq. (2.15). Rearranging and partitioning Eq. (2.14) we get, 


$$
\left\{\begin{array}{c}
N_{x} \\
N_{x y} \\
M_{x} \\
M_{x y} \\
0 \\
0
\end{array}\right\}=\left[\begin{array}{cccc|cc}
A_{11} & A_{16} & B_{11} & B_{16} & A_{12} & B_{12} \\
A_{16} & A_{66} & B_{16} & B_{66} & A_{26} & B_{26} \\
B_{11} & B_{16} & D_{11} & D_{16} & B_{12} & D_{12} \\
B_{16} & B_{66} & D_{16} & D_{66} & B_{26} & D_{26} \\
\hline A_{12} & A_{26} & B_{12} & B_{26} & A_{22} & B_{22} \\
B_{12} & B_{26} & D_{12} & D_{26} & B_{22} & D_{22}
\end{array}\right]\left\{\begin{array}{c}
\varepsilon_{x}^{(0)} \\
\gamma_{x y}^{(0)} \\
\varepsilon_{x}^{(1)} \\
\gamma_{x y}^{(1)} \\
\varepsilon_{y}^{(0)} \\
\varepsilon_{y}^{(1)}
\end{array}\right\}
$$

Introducing notations for the partitions we get,

$\left\{\begin{array}{c}\{\bar{N}\} \\ \{0\}\end{array}\right\}=\left[\begin{array}{ll}{\left[S^{11}\right]} & {\left[S^{12}\right]} \\ {\left[S^{21}\right]} & {\left[S^{22}\right]}\end{array}\right]\left\{\begin{array}{c}\{\bar{\varepsilon}\} \\ \left\{\overline{\varepsilon_{y}}\right\}\end{array}\right\}$

Where

$$
\left[S^{21}\right]=\left[S^{12}\right]^{T}
$$

Expanding Eq. (2.19) we get,

$$
\begin{aligned}
& \{\bar{N}\}=\left[S^{11}\right]\{\bar{\varepsilon}\}+\left[S^{12}\right]\left\{\overline{\varepsilon_{y}}\right\} \\
& \{0\}=\left[S^{21}\right]\{\overline{\bar{\varepsilon}}\}+\left[S^{22}\right]\left\{\overline{\varepsilon_{y}}\right\}
\end{aligned}
$$

Eliminating $\left\{\bar{\varepsilon}_{y}\right\}$ in Eq. (2.21) we get,

$$
\{\bar{N}\}=[S]\{\bar{\varepsilon}\}
$$

where $[S]=\left[\left[S^{11}\right]-\left[S^{12}\right]\left[S^{22}\right]^{-1}\left[S^{21}\right]\right]$

In a similar way Eq. (2.15) can be rearranged by setting $Q_{y}=0$,

$$
\left\{\begin{array}{c}
Q_{x} \\
0
\end{array}\right\}=K\left[\begin{array}{ll}
A_{55} & A_{45} \\
A_{45} & A_{44}
\end{array}\right]\left\{\begin{array}{c}
\gamma_{x z}^{(0)} \\
\gamma_{y z}^{(0)}
\end{array}\right\}
$$

Introducing the notations, $w_{s}^{\prime}=\frac{\partial w_{s}}{\partial x}$ and $w_{s}^{y}=\frac{\partial w_{s}}{\partial y}$ [Nagappan (2004)] in Eq. (2.9), the strain vector in Eq. (2.24) becomes,

$$
\left[\begin{array}{ll}
\gamma_{x z}^{(0)} & \gamma_{y z}^{(0)}
\end{array}\right]=\left[\begin{array}{ll}
w_{s}^{\prime} & w_{s}^{y}
\end{array}\right]
$$


For $A_{i j} \quad(i, j=4,5)$

$Q_{x}$

$Q_{y}$

Substituting Eq. (2.25) into Eq. (2.24) we get,

$$
\left\{\begin{array}{c}
Q_{x} \\
0
\end{array}\right\}=K\left[\begin{array}{ll}
A_{55} & A_{45} \\
A_{45} & A_{44}
\end{array}\right]\left\{\begin{array}{c}
\left\{w_{s}^{\prime}\right\} \\
\left\{w_{s}^{y}\right\}
\end{array}\right\}
$$

The second equation in (2.27) is manipulated to eliminate $\mathrm{w}_{\mathrm{s}}^{\mathrm{y}}$ and then written in terms of $w_{s}^{\prime}$ as

$Q_{x}=K A^{*} w_{s}^{\prime}$

where

$$
A^{*}=K\left(A_{55}-\frac{A_{45}^{2}}{A_{44}}\right)
$$

The K represents a shear correction factor. Since the transverse shear strains are represented as a constant through the laminate thickness, it implies the transverse shear stresses will also be constant. According to elementary theory of homogeneous beams the transverse shear stress varies parabolically through the thickness of the beam. In composite laminated beams and plates, the transverse shear stress varies at least quadratically through the thickness of the layer. This discrepancy between the actual stress state and the constant stress state predicted by FSDT is often corrected in computing the transverse shear force resultants i.e. the left hand side of Eq. (2.28) by multiplying the shear co-efficient matrix by a parameter $K$ which is the shear correction co-efficient. The factor $K$ is computed such that the strain energy due to transverse shear stresses equals the strain energy due to the true transverse stresses predicted by three- 
dimensional elasticity theory and the value for a rectangular cross section is taken to be as $5 / 6$.

\subsubsection{Virtual Strain Energy for a Beam}

For a beam of rectangular cross section of width $b$ and length $L$, the Eq. (2.13) changes into a line integral along $x$ as

$\delta U=b \int_{0}^{L}\left[N_{x} \delta \varepsilon_{x}^{(0)}+M_{x} \delta \varepsilon_{x}^{(1)}+N_{x y} \delta \gamma_{x y}^{(0)}+M_{x y} \delta \gamma_{x y}^{(1)}+Q_{x} \delta \gamma_{z x}^{(0)}\right] d x$

The $\delta U$ can be written in terms of the deformation quantities and using the following notation [Nagappan (2004)]

$$
\begin{gathered}
()^{\prime}=\frac{\partial()}{\partial x} \\
()^{y}=\frac{\partial()}{\partial y} \\
()^{\prime \prime}=\frac{\partial^{2}()}{\partial x^{2}} \\
()^{\prime y}=\frac{\partial^{2}()}{\partial x \partial y} \\
\gamma_{0}=\frac{\partial u_{0}}{\partial y}+\frac{\partial v_{0}}{\partial x} \\
\delta U=b \int_{0}^{L}\left[N_{x}\left(\delta u_{0}^{\prime}+w_{b}^{\prime} \delta w_{b}^{\prime}+w_{s}^{\prime} \delta w_{s}^{\prime}\right)-M_{x} \delta w_{b}^{\prime \prime}+N_{x y} \delta \gamma_{0}-2 M_{x y} \delta w_{b}^{\prime y}+Q_{x} w_{s}^{\prime}\right] d x
\end{gathered}
$$




\subsubsection{Virtual Kinetic Energy for a Beam}

The virtual kinetic energy expression is given by [Nagappan (2004)],

$\delta T=\iiint_{V} \rho[\dot{u} \delta \dot{u}+\dot{v} \delta \dot{v}+\dot{w} \delta \dot{w}] d V$

where $(\cdot)=\frac{\partial()}{\partial t}$. Substituting for the displacements from Eq. (2.2) and making use of

Eqs. (2.6) and (2.31) we get,

$\delta T=\iiint_{V} \rho\left[\begin{array}{l}\left(\dot{u}_{0}-z \dot{w}_{b}^{\prime}-\right)\left(\delta \dot{u}_{0}-z \delta \dot{w}_{b}^{\prime}\right)+\left(\dot{v}_{0}-z \dot{w}_{b}^{y}\right)\left(\delta \dot{v}_{0}-z \delta \dot{w}_{b}^{y}\right) \\ +\left(\dot{w}_{b}+\dot{w}_{s}\right)\left(\delta \dot{w}_{b}+\delta \dot{w}_{s}\right)\end{array}\right] d V$

where $\rho$ is the mass density and $\left({ }^{\bullet}\right)$ represents partial derivative with respect to time.

The $\dot{v}_{0}$ and $\delta \dot{v}_{0}$ terms are left out for a beam and the expression becomes,

$\delta T=\iiint_{V} \rho\left[\left(\dot{u}_{0}-z \dot{w}_{b}^{\prime}\right) \delta \dot{u}_{0}-\left(z \dot{u}_{0}-z^{2} \dot{w}_{b}^{\prime}\right) \delta \dot{w}_{b}^{\prime}+\left(z^{2} \dot{w}_{b}^{y}\right) \delta \dot{w}_{b}^{y}+\left(\dot{w}_{b}+\dot{w}_{s}\right) \delta \dot{w}_{b}+\left(\dot{w}_{b}+\dot{w}_{s}\right) \delta \dot{w}_{s}\right] d V$

Isolating the $\delta T$ term in Hamilton's principle [Eq. (2.3)] and integrating by parts with respect to $t$, and grouping all time boundary terms and denoting them as $(\ldots)_{t_{1}}^{t_{2}}$, we get, $-\int_{t_{1}}^{t_{2}} \delta T d t$
$=\iiint_{V}\left\{\int_{t_{1}}^{t_{2}} \rho\left[\left(\cdots \ddot{u}_{t_{1}}^{t_{2}}-z \ddot{w}_{b}^{\prime}\right) \delta u-\left(z \ddot{u}_{0}-z^{2} \dot{w}_{b}^{\prime}\right) \delta w_{b}^{\prime}+\left(z^{2} \ddot{w}_{b}^{y}\right) \delta w_{b}^{y}+\left(\ddot{w}_{b}+\ddot{w}_{s}\right) \delta w_{b}+\left(\ddot{w}_{b}+\ddot{w}_{s}\right) \delta w_{s}\right] d t\right\} d V$

Since the inertia matrix is independent of the time boundary terms they can be removed from quantities $\delta T$ equation. Since the variational quantities no longer contain time derivatives they can moved out of the time integral. The volume integral can be split into integrals over thickness, length and width. 
$-\delta T=b \int_{0}^{L} d x \int_{-\frac{h}{2}}^{\frac{h}{2}} \rho\left[\left(\ddot{u}_{0}-z \ddot{w}_{b}^{\prime}\right) \delta u-\left(z \ddot{u}_{0}-z^{2} \ddot{w}_{b}^{\prime}\right) \delta w_{b}^{\prime}+\left(z^{2} \ddot{w}_{b}^{y}\right) \delta w_{b}^{y}+\left(\ddot{w}_{b}+\ddot{w}_{s}\right) \delta w_{b}+\left(\ddot{w}_{b}+\ddot{w}_{s}\right) \delta w_{s}\right] d z$

The thickness integral can be further reduced using,

$$
I_{i}=\int_{-h / 2}^{h / 2} \rho(z)^{i} d z \quad(\mathrm{i}=0,1,2)
$$

where the $I_{i}$ represent inertia coefficients. The $I_{0}, I_{1}$ and $I_{2}$ are the normal, coupled normal-rotary, and rotary inertia coefficients, respectively. 


\section{FINITE ELEMENT MODELING}

\subsection{Introduction}

The finite element method is a numerical procedure used in analyzing structural engineering problems, where the continuum is solved by discretizing the domain. There are several methods in formulating the finite element equations, some of these methods are based on energy considerations and the variational method. Energy methods are based on the principle of conservation of energy where the total energy of a conservative system is constant. In the variational method, scalar quantities such as work, energy are considered, resulting in both the governing equations and the boundary conditions are established directly.

\subsection{Displacement Distribution}

In the present analysis, a finite element based on h-p version formulation chandrasekaran (2000) is used. The beam is divided into four elements with each element consisting of three internal nodes and two end nodes. Lagrangian and Hermitian interpolation functions are used to derive the shape functions. Lagrangian interpolation functions are used to ensure $C^{0}$ continuity in certain degrees of freedom, while Hermitian interpolation functions are used for $C^{1}$ continuity in other. The internal nodes do not have slope degrees of freedom as slope continuity is automatically assumed. The end nodes have both displacement and slope degrees of freedom for the variables with $C^{1}$ continuity. 


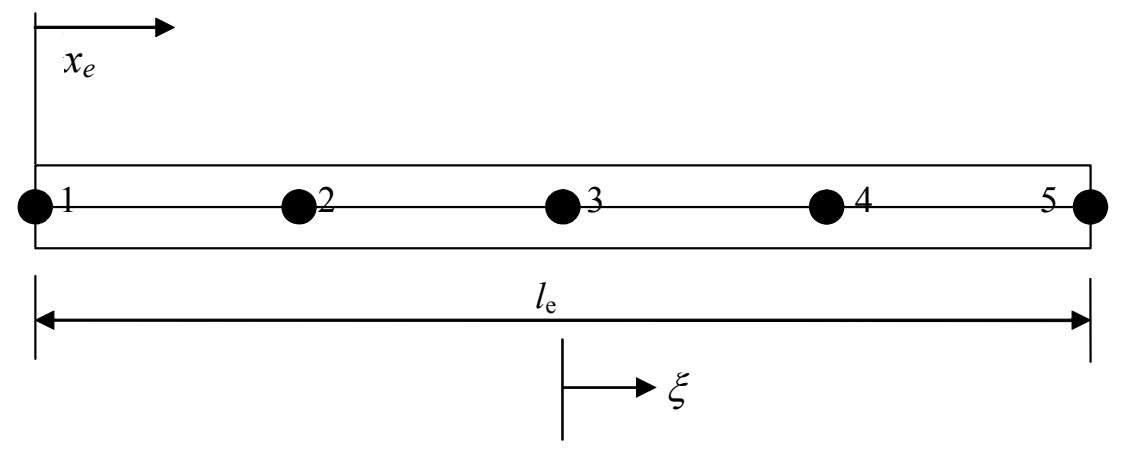

DOF at end nodes $(1,5): u, \gamma, w_{b}, w_{b}^{\prime}, w_{s}, w_{s}^{\prime}, w_{b}^{y}$

DOF at internal nodes $(2,3,4): u, \gamma, w_{b}, w_{s}, w_{b}^{y}$

\section{Figure 3.1 Element definition for formulation using FSDT [Chandrasekaran (2000)]}

Figure 3.1 shows a composite beam element of length $l_{e}$ with 2 end nodes and 3 internal nodes. The independent variable is $x_{e}$ measured from the left end of the beam. The dependent variables are:

$$
\begin{aligned}
& u=\text { axial deformation at the midplane } \\
& w_{b}=\text { transverse bending deformation } \\
& w_{\mathrm{s}}=\text { transverse shear deformation } \\
& \gamma=\left(\frac{\partial u}{\partial y}+\frac{\partial v}{\partial x}\right)_{z=0}=\text { mid-plane shear strain } \\
& w_{b}^{y}=\frac{\partial w_{b}}{\partial y}=\text { twist angle associated with bending deformation }
\end{aligned}
$$

"At the end nodes, slope continuity $\left(C^{1}\right)$ is maintained for the variables $w_{b}$ and $w_{s}$. The other variables, namely $u, \gamma, w_{b}^{y}$ obey only $C^{0}$ continuity. The slopes of these quantities represent forces (for $u$ and $\gamma$ ) and moments (for $w_{b}^{y}$ ) and forcing slope continuity will not allow for the freedom of a discontinuity in the corresponding force or 
a moment. Thus the element has seven degrees of freedom at each end node and five degrees of freedom at each internal node." [Nagappan (2004)].

A natural or intrinsic coordinate, $\xi$, is defined, with its origin at the center of the element. This non-dimensional coordinate, $\xi$, ranges from -1 to +1 . The transformation between the two coordinates is given by,

$$
\begin{aligned}
& x_{e}=\frac{l_{e}}{2}(\xi+1) \\
& d x_{e}=\frac{l_{e}}{2}(d \xi)
\end{aligned}
$$

The distribution for $\mathrm{u}$ and $w_{b}$, is assumed to be,

$$
\begin{aligned}
& u(\xi)=\sum_{i=0}^{4} a_{i} \xi^{i} \\
& w_{b}(\xi)=\sum_{j=0}^{6} b_{j} \xi^{j}
\end{aligned}
$$

These equations can be written in matrix notations as,

$$
\begin{aligned}
& u(\xi)=\left\lfloor\xi^{i}\right\rfloor\left\{a_{i}\right\} \quad i=0-4 \\
& w_{b}(\xi)=\left\lfloor\xi^{j}\right\rfloor\left\{b_{j}\right\} j=0-6
\end{aligned}
$$

where $a_{i}$ and $b_{j}$ are generalized coordinates, which can be derived from the following conditions.

$$
\begin{aligned}
& u(-1)=u_{1} \\
& u(-1 / 2)=u_{2} \\
& u(0)=u_{3} \\
& u(1 / 2)=u_{4} \\
& u(1)=u_{5}
\end{aligned}
$$

Solving the five equations and substituting in the first of Eq. (3.3) we get, 


$$
u(\xi)=\left\lfloor H_{L 1}(\xi) \ldots H_{L 5}(\xi)\right\rfloor\left\{\begin{array}{l}
u_{1} \\
\cdot \\
\cdot \\
\cdot \\
u_{5}
\end{array}\right\}
$$

where $H_{L 1}(\xi), H_{L 2}(\xi)$, etc are Lagrange shape functions and they only satisfy displacement continuity at the junction between 2 elements. The five Lagrangian polynomials are,

$$
\begin{aligned}
& H_{L 1}=\frac{1}{6} \xi-\frac{1}{6} \xi^{2}-\frac{2}{3} \xi^{3}+\frac{2}{3} \xi^{4} \\
& H_{L 2}=-\frac{4}{3} \xi+\frac{8}{3} \xi^{2}+\frac{4}{3} \xi^{3}-\frac{8}{3} \xi^{4} \\
& H_{L 3}=1-5 \xi^{2}+4 \xi^{4} \\
& H_{L 4}=\frac{4}{3} \xi+\frac{8}{3} \xi^{2}-\frac{4}{3} \xi^{3}-\frac{8}{3} \xi^{4} \\
& H_{L 5}=-\frac{1}{6} \xi-\frac{1}{6} \xi^{2}+\frac{2}{3} \xi^{3}+\frac{2}{3} \xi^{4}
\end{aligned}
$$

The generalized coordinate $b_{j}$ are based on the following conditions

$$
\begin{aligned}
& w_{b}(-1)=w_{b_{1}} \\
& \frac{l_{e}}{2} \frac{d w_{b}}{d \xi}(-1)=w_{b_{1}}{ }^{\prime} \\
& w_{b}(-1 / 2)=w_{b_{2}} \\
& w_{b}(0)=w_{b_{3}} \\
& w_{b}(1 / 2)=w_{b_{4}} \\
& w_{b}(1)=w_{b_{5}}
\end{aligned}
$$




$$
\frac{l_{e}}{2} \frac{d w_{b}}{d \xi}(1)=w_{b_{5}}^{\prime}
$$

Solving these seven equations for $b_{j}$ and substituting into the second of Eq. (3.3) we get,

$$
w_{b}(\xi)=\left\lfloor H_{1}(\xi) \ldots H_{7}(\xi)\right\rfloor\left\{\begin{array}{l}
w_{b_{1}} \\
w_{b_{1}}{ }^{\prime} \\
\cdot \\
\cdot \\
\cdot \\
w_{b_{5}}{ }^{\prime}
\end{array}\right\}
$$

where $H_{1}(\xi), H_{2}(\xi)$, etc., are Hermite shape functions and they satisfy inter-element displacement and slope continuities.

The seven Hermite polynomials are,

$$
\begin{aligned}
& H_{1}=\frac{1}{9}\left(\frac{17}{4} \xi-5 \xi^{2}-\frac{79}{4} \xi^{3}+\frac{47}{2} \xi^{4}+11 \xi^{5}-14 \xi^{6}\right) \\
& H_{2}=\frac{l_{e}}{6}\left(\frac{1}{4} \xi-\frac{1}{4} \xi^{2}-\frac{5}{4} \xi^{3}+\frac{5}{4} \xi^{4}+\xi^{5}-\xi^{6}\right) \\
& H_{3}=\frac{16}{9}\left(-\xi+2 \xi^{2}+2 \xi^{3}-4 \xi^{4}-\xi^{5}+2 \xi^{6}\right) \\
& H_{4}=1-6 \xi^{2}+9 \xi^{4}-4 \xi^{6} \\
& H_{5}=\frac{16}{9}\left(\xi+2 \xi^{2}-2 \xi^{3}-4 \xi^{4}+\xi^{5}+2 \xi^{6}\right) \\
& H_{6}=\frac{1}{9}\left(-\frac{17}{4} \xi-5 \xi^{2}+\frac{79}{4} \xi^{3}+\frac{47}{2} \xi^{4}-11 \xi^{5}-14 \xi^{6}\right) \\
& H_{7}=\frac{l_{e}}{6}\left(\frac{1}{4} \xi+\frac{1}{4} \xi^{2}-\frac{5}{4} \xi^{3}-\frac{5}{4} \xi^{4}+\xi^{5}+\xi^{6}\right)
\end{aligned}
$$




\subsection{Element Stiffness Matrix Formulation}

Stiffness matrix of an element is derived from the virtual strain energy expression of the beam presented in Section 2.4.5. The relation between virtual strain energy of an element and its stiffness matrix is written as,

$$
\delta U_{e}=\left\lfloor\delta q_{e}\right\rfloor\left[K_{e}\right]\left\{q_{e}\right\}
$$

where $U_{e}$ is the element strain energy,

$\left\{q_{e}\right\}$ is the vector of element degrees of freedom

$\left[K_{e}\right]$ is the element stiffness matrix.

The relation between real and virtual displacement fields for the axial and bending displacements are expressed as

$$
\begin{aligned}
& u(x)=\left\lfloor H_{L}\right\rfloor\left\{q_{u}\right\} \\
& \delta u(x)=\left\lfloor\delta q_{u}\right\rfloor\left\{H_{L}\right\} \\
& w_{b}(x)=\lfloor H\rfloor\left\{q_{w_{b}}\right\} \\
& \delta w_{b}(x)=\left\lfloor\delta q_{w_{b}}\right\rfloor\{H\}
\end{aligned}
$$

where $\left\{q_{u}\right\}$ and $\left\{q_{w_{b}}\right\}$ are the vectors of element nodal degrees of freedom for the variables $u$ and $w_{b}$ respectively. Stiffness matrix is constructed by comparing similar variables in the virtual strain energy expression, Eq. (2.32), and Eq. (3.10).

\subsubsection{Stiffness Matrix for FSDT [Nagappan (2004)]}

The element has 29 degrees of freedom. The independent variables are $u, \gamma, w_{b}$, $w_{s}, w_{b}^{y}$ with $C^{0}$ continuity for $u, \gamma$ and $w_{b}^{y}$, and $C^{1}$ continuity for $w_{b}$ and $w_{s}$. The element 
stiffness matrix is symmetric along its diagonal and is divided into twenty-five parts. The element stiffness matrix with its partitioned sub matrices is:

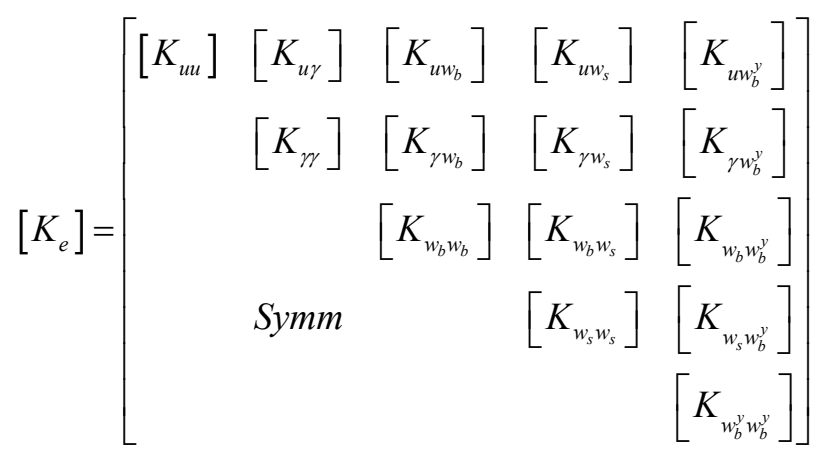

The expression for the sub matrices of the element stiffness matrix can be derived from the virtual strain energy expression. where

$$
\begin{aligned}
& {\left[K_{u u}\right]=b \int_{0}^{l_{e}} S_{11}\left\{H_{L}^{\prime}\right\}\left\lfloor H_{L}^{\prime}\right\rfloor d x_{e}} \\
& {\left[K_{u \gamma}\right]=b \int_{0}^{l_{e}} S_{12}\left\{H_{L}^{\prime}\right\}\left\lfloor H_{L}\right\rfloor d x_{e}} \\
& {\left[K_{u w_{b}}\right]=-b \int_{0}^{l_{e}} S_{13}\left\{H_{L}^{\prime}\right\}\left\lfloor H^{\prime \prime}\right\rfloor d x_{e}} \\
& {\left[K_{u w_{s}}\right]=[0]} \\
& {\left[K_{u w_{b}^{\prime}}\right]=-2 b \int_{0}^{l_{e}} S_{14}\left\{H_{L}^{\prime}\right\}\left\lfloor H_{L}^{\prime}\right\rfloor d x_{e}} \\
& {\left[K_{\gamma \gamma}\right]=b \int_{0}^{l_{e}} S_{22}\left\{H_{L}\right\}\left\lfloor H_{L}\right\rfloor d x_{e}} \\
& {\left[K_{\gamma w_{b}}\right]=-b \int_{0}^{l_{e}} S_{23}\left\{H_{L}\right\}\left\lfloor H^{\prime \prime}\right\rfloor d x_{e}} \\
& {\left[K_{\gamma w_{s}}\right]=[0]}
\end{aligned}
$$




$$
\begin{aligned}
& {\left[K_{\gamma w_{b}^{y}}\right]=-2 b \int_{0}^{l_{e}} S_{24}\left\{H_{L}\right\}\left\lfloor H_{L}^{\prime}\right\rfloor d x_{e}} \\
& {\left[K_{w_{b} w_{b}}\right]=b \int_{0}^{l_{e}} S_{33}\left\{H^{\prime \prime}\right\}\left\lfloor H^{\prime \prime}\right\rfloor d x_{e}+b \int_{0}^{l_{e}} N_{x}\left\{H^{\prime}\right\}\left\lfloor H^{\prime}\right\rfloor d x_{e}} \\
& {\left[K_{w_{b} w_{s}}\right]=[0]} \\
& {\left[K_{w_{b} w_{b}^{y}}\right]=2 b \int_{0}^{l_{e}} S_{34}\left\{H^{\prime \prime}\right\}\left\lfloor H_{L}^{\prime}\right\rfloor d x_{e}} \\
& {\left[K_{w_{s} w_{s}}\right]=b \int_{0}^{l_{e}} N_{x}\left\{H^{\prime}\right\}\left\lfloor H^{\prime}\right\rfloor d x_{e}+b \int_{0}^{l_{e}} A^{*}\left\{H^{\prime}\right\}\left\lfloor H^{\prime}\right\rfloor d x_{e}} \\
& {\left[K_{w_{s} w_{b}^{y}}\right]=[0]} \\
& {\left[K_{w_{b}^{y} w_{b}^{y}}\right]=4 b \int_{0}^{l_{e}} S_{44}\left\{H_{L}^{\prime}\right\}\left\lfloor H_{L}^{\prime}\right\rfloor d x_{e}}
\end{aligned}
$$

In the above expressions, the $[S]$ matrix is the reduced material stiffness of the beam from Eq (2.22) and $A^{*}$ from Eq (2.29)

\subsection{Element Inertia Matrix Formulation [Nagappan (2004)]}

The element inertia matrix is derived from the expression for the variation in total kinetic energy, $\delta T$, presented in Section 2.5.6. The relation between variational kinetic energy of an element and its inertia matrix $\left[M_{e}\right]$ can be represented as,

$$
-\delta T_{e}=\left\lfloor\delta q_{e}\right\rfloor\left[M_{e}\right]\left\{\ddot{q}_{e}\right\}
$$

Where $T_{e}$ is the element kinetic energy

$\left\{q_{e}\right\}$ is the vector of element degrees of freedom

$\left[M_{e}\right]$ is the element inertia matrix. 
The element inertia matrix is derived by comparing variables in $\mathrm{Eq}(3.11)$ and $\mathrm{Eq}(3.16)$.

\subsubsection{Inertia Matrix for FSDT}

The element inertia matrix for FSDT is derived following a similar procedure to the one for the element stiffness matrix. The dimensions and the number of sub matrices for the inertia matrix are similar to the element stiffness matrix:

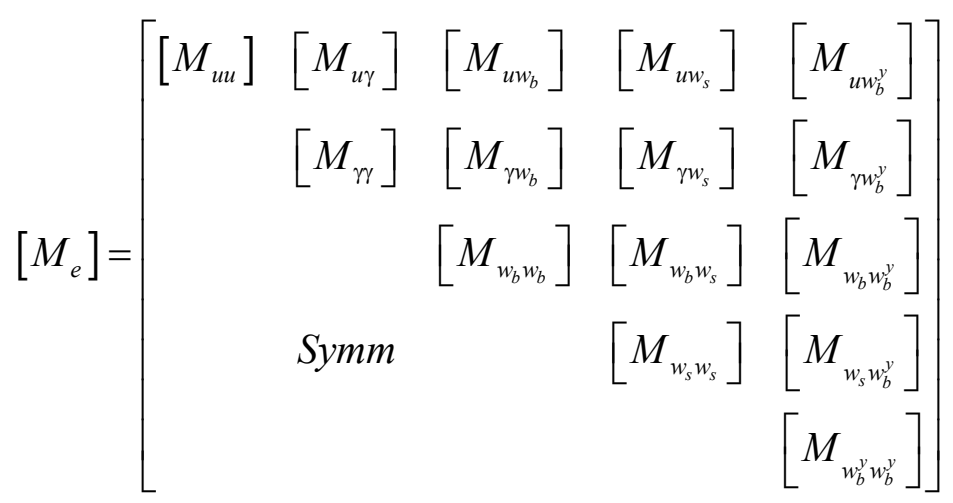

The expressions for the different sub matrices derived from the variational kinetic energy term are:

$$
\begin{aligned}
& {\left[M_{u u}\right]=b \int_{0}^{l_{e}} I_{0}\left\{H_{L}\right\}\left\lfloor H_{L}\right\rfloor d x_{e}} \\
& {\left[M_{u w_{b}}\right]=-b \int_{0}^{l_{e}} I_{1}\left\{H_{L}\right\}\left\lfloor H^{\prime}\right\rfloor d x_{e}} \\
& {\left[M_{w_{b} w_{b}}\right]=b \int_{0}^{l_{e}} I_{2}\left\{H^{\prime}\right\}\left\lfloor H^{\prime}\right\rfloor d x_{e}+b \int_{0}^{l_{e}} I_{0}\{H\}\lfloor H\rfloor d x_{e}} \\
& {\left[M_{w_{b} w_{s}}\right]=b \int_{0}^{l_{e}} I_{0}\{H\}\lfloor H\rfloor d x_{e}} \\
& {\left[M_{w_{s} w_{s}}\right]=\int_{0}^{l_{e}} I_{0}\{H\}\lfloor H\rfloor d x_{e}}
\end{aligned}
$$




$$
\begin{aligned}
& {\left[M_{w_{b}^{y} w_{b}^{y}}\right]=b \int_{0}^{l_{e}} I_{2}\left\{H_{L}\right\}\left\lfloor H_{L}\right\rfloor d x_{e}} \\
& {\left[M_{u \gamma}\right]=\left[M_{u w_{s}}\right]=\left[M_{u w_{b}^{y}}\right]=\left[M_{\gamma}\right]=\left[M_{\gamma w_{b}}\right]=[0]} \\
& {\left[M_{\gamma w_{s}}\right]=\left[M_{\gamma w_{b}^{y}}\right]=\left[M_{w_{b} w_{b}^{y}}\right]=\left[M_{w_{s} w_{b}^{y}}\right]=[0]}
\end{aligned}
$$

\subsection{Global Equations of Motion}

The element stiffness matrices and inertia matrices for all the elements are assembled to form the global stiffness matrix $[K]$ and the global inertial matrix $[M]$ respectively. The finite element equations of motion are given by:

$$
[M]\{\ddot{q}\}+[C]\{\dot{q}\}+[K]\{q\}=\{Q\}
$$

Where $[C]$ is the damping matrix, $\{q\}$ is the global displacement vector and $\{Q\}$ the global load vector. Since in the present analysis damping is not considered, the $[C]$ matrix is set to zero; further there is no external load present, therefore the load vector is a zero vector. Thus the equations of motion for the rotating beam reduce to:

$$
[M]\{\ddot{q}\}+[K]\{q\}=\{0\}
$$

\subsection{Gaussian Quadrature}

The Gaussian quadrature method is used for integration to calculate element inertial and mass matrices. In Gaussian quadrature, the positions of the sampling points and the weights are optimized. 
Gaussian quadrature requires $n$ sampling points to integrate a polynomial of order $(2 n-1)$ exactly. In the present case a seven point Gaussian quadrature scheme is used since highest order polynomial to be integrated is fourteen. Therefore the integration scheme is represented as,

$$
\int_{-1}^{1} f(\xi) d \xi=\sum_{j=1}^{n} w_{j} f\left(a_{j}\right)
$$

where $n$ is the number of sampling points, $a_{j}$ represent the $\xi$ coordinate at the sampling points and $w_{j}$ the corresponding weights. The sampling points and weights used are shown below

Table 3.1 Gauss integration points and weights [Nagappan (2004)]

\begin{tabular}{|l|l|}
\hline Sampling Points & Weights \\
\hline \pm 0.9491079123 & 0.1294849661 \\
\hline \pm 0.7415311855 & 0.0797053914 \\
\hline \pm 0.4058451513 & 0.3813005050 \\
\hline 0.0000000000 & 0.4179591836 \\
\hline
\end{tabular}

The stiffness and the inertia matrices are integrated after transforming the coordinates from $x_{e}$ to the non-dimensional coordinate $\xi$. 


\subsection{Boundary Conditions and Initial Conditions}

The boundary conditions used to solve the finite element equations of motion are listed below.

\subsubsection{Boundary Conditions for FSDT}

The boundary conditions used for the beam using FSDT are:

$$
\begin{array}{lll}
\text { Hinged Support } & : & u=w_{b}=w_{s}=w_{b}^{y}=0 \\
\text { Fixed Support } & : & u=w_{b}=w_{s}=w_{b}^{\prime}=w_{s}^{\prime}=w_{b}^{y}=0
\end{array}
$$

The implementation of boundary condition and the system of equations is solved by using a Gauss Elimination direct solution method.

\subsection{Hygrothermal Formulation}

The analysis of composite laminates undergoing the effect of hygrothermal exposure can be done in two ways, as indicated in the literature. They are

1. By considering the expansion strains caused due to moisture and temperature.

2. By degrading the strength and stiffness related properties of the constituents due to hygrothermal conditioning.

For the first one the effect is of a residual nature. Polymer matrix materials have higher thermal and moisture expansion coefficients than fibers. At elevated temperatures and moisture content the differential expansion/contraction between fiber and matrix materials leads to increase in complex miss matched thermal and expansion stresses in a PMC composites. These residual stresses induces thermal loading and in turn affect the vibration characteristics of the polymer matrix composites. 
In the second case the effect of increased hygrothermal conditioning is the degradation of the mechanical properties of a PMC ply. Matrix being hygroscopic and having higher expansion coefficient suffers more degradation, as evident from the literature the fiber properties remain almost unaffected. The degradation occurs in both the stiffness and strength values of the matrix and consequently in the corresponding values of the composite laminate.

In this present study the second procedure is used [Kavipurapu (2005)] to analyze the hygrothermal conditioning. The degraded properties of composite due to hygrothermal conditions are calculated by relations given by Chamis (1983). In that it is assumed that only matrix properties are affected by the raise in temperature and moisture content. According to Chamis, the relationship between the wet resin and dry resin mechanical properties are given as

$$
\frac{P_{H T M}}{P_{0}}=\left[\frac{T_{g w r}-T}{T_{g d r}-T_{0}}\right]^{0.5}
$$

Where $P$ is the property to be measured, HTM refers to hygrothermal mechanical condition, $T_{g w r}$ is wet resin glass transition temperature and $T_{g d r}$ dry resin glass transition temperature. $\mathrm{T}_{0}$ is room temperature and $\mathrm{T}$ is the temperature at which the property is to be measured.

The relation between the dry and wet resin glass transition temperature in terms of moisture content $(\mathrm{m})$, expressed in weight percent is given by

$$
T_{g w r}=\left(0.005 m^{2}-0.1 m+1.0\right) T_{g d r}
$$

The changed matrix property and elastic constants of the hygrothermal affected composite are calculated using the rule of mixtures given by. 


$$
\begin{aligned}
& E_{1}=E_{f} V_{f}+E_{m} V_{m} \\
& E_{2}=\frac{E_{f} E_{m}}{E_{f} V_{f}+E_{m} V_{m}} \\
& G_{12}=\frac{G_{m} G_{f}}{V_{m} G_{f}+G_{m} V_{f}}
\end{aligned}
$$

Where $E_{1}$ is the longitudinal modulus, $E_{2}$ is transverse modulus, $G_{12}$ is in plane shear modulus, $E_{f}, E_{m}, V_{f}, V_{m}, G_{f}, G_{m}$ are modulus of elasticity of fiber, modulus of elasticity of matrix, fiber volume fraction, matrix volume fraction, fiber in plane shear modulus and matrix in plane shear modulus respectively. 


\section{RESULTS AND DISCUSSION}

\subsection{Introduction}

A finite element code is written in MATLAB to generate the necessary numerical results based on the finite-element model formulated in the previous chapter of a composite rotating beam. Validation of the current problem is done by first generating results for isotropic, CLPT and FSDT cases without the hygrothermal effects and comparing with the existing results in the literature. For the case with of hygrothermal effects on rotating composite beam, there are no results available in the literature, and therefore an indirect method is used for validation. First the hygrothermal incorporation is validated by generating results for large deflection bending and comparing the results with the existing results in literature, this way the formulation for global inertia and stiffness matrix would be validated and then the same implementation is extended to the free vibration analysis of rotating composite beam.

\subsection{Isotropic Rotating Beam Comparison}

The free vibration response analysis of a rotating isotropic steel beam is performed. The geometric dimensions of the beam are length of the beam $(L)=1.0 \mathrm{~m}$, beam width $(b)=0.05 \mathrm{~m}$, beam height $(h)=0.06 \mathrm{~m}$. The material properties used in the calculation are given in Table 4.1 .

A cantilever beam with solid rectangular cross section undergoes a rigid body rotation about an axis perpendicular to its longitudinal direction with uniform rotational speed $\Omega$. The rotational speed $\Omega$ is converted to dimensionless parameter $\lambda$ by the following equation. 


$$
\lambda^{2}=\frac{\rho \Omega^{2} L^{4}}{E I}
$$

Where $\rho$ is mass density, $E$ is young's modulus, $I$ is the moment of inertia. The results from present study for dimensionless frequency $\mu$ as a function of dimensionless angular speed $\lambda$ are presented in Table 4.2. The corresponding results from Hodges and Rutkowski (1981) are presented in this table and the comparison of the two sets of the results show an excellent agreement.

Table 4.1 Material properties for steel beam with rectangular cross section

\begin{tabular}{|c|c|}
\hline Property & Dimensions \\
\hline Young's modulus $(E)$ & $200 \mathrm{GPa}$ \\
\hline Mass density $(\rho)$ & $7900 \mathrm{Kg} / \mathrm{m}^{3}$ \\
\hline Poisson's ratio $(v)$ & 0.3 \\
\hline
\end{tabular}

Table 4.2 Non-dimensional rotational frequency

\begin{tabular}{|c|c|c|c|c|c|c|}
\hline \multirow{2}{*}{$\mu$} & \multicolumn{3}{|c|}{ Present Study } & \multicolumn{3}{c|}{ Hodges and Rutkowski (1981) } \\
\cline { 2 - 7 } & $\begin{array}{c}\text { First } \\
\text { Mode }\end{array}$ & $\begin{array}{c}\text { Second } \\
\text { Mode }\end{array}$ & $\begin{array}{c}\text { Third } \\
\text { Mode }\end{array}$ & $\begin{array}{c}\text { First } \\
\text { Mode }\end{array}$ & $\begin{array}{c}\text { Second } \\
\text { Mode }\end{array}$ & $\begin{array}{c}\text { Third } \\
\text { Mode }\end{array}$ \\
\hline 0 & 3.5160 & 22.0344 & 61.6972 & 3.5160 & 22.0344 & 61.6972 \\
\hline 1 & 3.6816 & 22.1810 & 61.8417 & 3.6816 & 22.1810 & 61.8417 \\
\hline 2 & 4.1373 & 22.6149 & 62.2731 & 4.1373 & 22.6149 & 62.2731 \\
\hline 3 & 4.7973 & 23.3202 & 62.9849 & 4.7973 & 23.3202 & 62.9849 \\
\hline 4 & 5.5850 & 24.2733 & 63.9667 & 5.5850 & 24.2733 & 63.9667 \\
\hline 5 & 6.4495 & 25.4460 & 65.2050 & 6.4495 & 25.4460 & 65.2050 \\
\hline
\end{tabular}




\subsection{Non-Rotating Rectangular Composite Cantilever Beam}

The present analysis is used to obtain the natural frequency results of a nonrotating composite cantilever beam considered by Abarcar and Cunniff (1972). The geometric dimensions of the solid section rectangular beams considered by them are beam length $(L)=0.190 \mathrm{~m}$, beam width $(b)=0.0127 \mathrm{~m}$, beam height $(h)=0.003175 \mathrm{~m}$. and the material properties used in the calculation are given in Table 4.3. Abarcar and Cunniff (1972) considered unidirectional composite beams undergoing coupled transverse bending and torsional free vibrations. They presented theoretical and numerical results for beams with ply orientations of $15^{\circ}$ and $30^{\circ}$. The present validation case does not include torsional vibrations but includes first order shear deformation effects. The natural frequencies in cycles per sec $(\mathrm{Hz})$ for the first several modes are presented in the Table 4.4. The experimental and theoretical results from Abarcar and Cunniff (1972) are also shown in Table 4.4 for comparison. It should be noted that though their results correspond to coupled bending (B) and torsion (T) modes, the first four modes are almost exclusively bending modes while the fifth one is primarily a torsional mode. The present natural frequencies corresponding to the bending modes agree excellently with both the experimental and analytical results of Abarcar and Cunniff. In fact the present results are closer to their experimental results than their theoretical ones; this is probably due to the inclusion of first order shear effects in the

present model. The comparisons presented in Table 4.5 for the beam of $15^{\circ}$ fiber orientation lead to similar conclusions as that of the $30^{\circ}$ beam. 
Table 4.3 Material properties for Graphite/Epoxy composite beam

\begin{tabular}{|c|c|}
\hline Property & Dimensions \\
\hline Longitudinal Modulus $\left(E_{1}\right)$ & $129.1 \mathrm{GPa}$ \\
\hline Transverse Modulus $\left(E_{2}\right)$ & $9.408 \mathrm{GPa}$ \\
\hline Longitudinal Shear Modulus $\left(G_{12}\right)$ & $5.157 \mathrm{GPa}$ \\
\hline Transverse Shear Modulus $\left(G_{13}\right)$ & $4.304 \mathrm{GPa}$ \\
\hline Inter-laminar Shear Modulus $\left(G_{23}\right)$ & $2.541 \mathrm{GPa}$ \\
\hline Mass density $(\rho)$ & $1551 \mathrm{Kg} / \mathrm{m}^{3}$ \\
\hline Poisson's ratio $(v)$ & 0.3 \\
\hline
\end{tabular}

Table 4.4 Natural frequency of Graphite/Epoxy composite beam with $30^{\circ}$ fiber orientation

\begin{tabular}{|c|c|c|c|}
\hline \multirow{2}{*}{ Mode no. } & $\begin{array}{c}\text { Present Study } \\
\text { (FSDT) }\end{array}$ & \multicolumn{2}{|c|}{ Abarcar and Cunniff (1972) } \\
\cline { 3 - 4 } & 52.8 & Experimental & Analysis \\
\hline $1(\mathrm{FT})$ & 330.5 & 52.7 & 52.7 \\
\hline $2(\mathrm{FT})$ & 921.6 & 331.8 & 329.3 \\
\hline $3(\mathrm{FT})$ & 1794.9 & 924.7 & 915.9 \\
\hline $4(\mathrm{FT})$ & N/A & 1766.9 & 1767.0 \\
\hline $5(\mathrm{TF})$ & 2944.9 & 1827.4 & 1896.5 \\
\hline $6(\mathrm{FT})$ & & 2984.0 & 2901.4 \\
\hline
\end{tabular}

Table 4.5 Natural frequency of Graphite/Epoxy composite beam with $15^{\circ}$ fiber orientation

\begin{tabular}{|c|c|c|c|}
\hline \multirow{2}{*}{ Mode no. } & Present Study & \multicolumn{2}{|c|}{ Abarcar and Cunniff (1972) } \\
\cline { 3 - 4 } & (FSDT) & Experimental & Analysis \\
\hline $1(\mathrm{FT})$ & 82.5 & 82.5 & 80.8 \\
\hline $2(\mathrm{FT})$ & 514.6 & 511.3 & 501.5 \\
\hline $3(\mathrm{FT})$ & 1428.6 & 1423.4 & 1376.0 \\
\hline $4(\mathrm{TF})$ & N/A & 1526.9 & 1579.3 \\
\hline $5(\mathrm{FT})$ & 2764.9 & 2783.6 & 2648.7 \\
\hline $6(\mathrm{FT})$ & 4501.1 & 4364.6 & 4189.0 \\
\hline
\end{tabular}




\subsection{Rotating Rectangular Composite Cantilever Beam}

In this section the influence of rotational speed on the free vibration characteristics of a composite cantilever beam is studied. In this study graphite/epoxy beams of rectangular cross section with fiber orientation of $[0]_{24}$ and $[15]_{24}$ are used. The dimensions of the beam are length $(L)=.9525 \mathrm{~m}$, width $(b)=0.0254 \mathrm{~m}$, height $(h)=$ $0.0029718 \mathrm{~m}$ for $[0]_{24}$ and height $(h)=0.0032258 \mathrm{~m}$, for $[15]_{24}$ and the material properties are listed in Table 4.6. The rotating natural frequencies of the first four bending (B) modes are presented in Figure 4.1 for the $[15]_{24}$ beam and in Figure 4.2 for the $[0]_{24}$ case. The results from Hodges et al; (1996) also included in these two figures and the comparisons show excellent agreement.

Table 4.6 Material properties for graphite/epoxy composite beam

\begin{tabular}{|c|c|}
\hline Property & Dimensions \\
\hline Longitudinal Modulus $\left(E_{1}\right)$ & $1.42 \mathrm{GPa}$ \\
\hline Transverse Modulus $\left(E_{2}\right)$ & $9.80 \mathrm{GPa}$ \\
\hline Longitudinal Shear Modulus $\left(\mathrm{G}_{12}\right)$ & $6.14 \mathrm{GPa}$ \\
\hline Transverse Shear Modulus $\left(\mathrm{G}_{13}\right)$ & $6.14 \mathrm{GPa}$ \\
\hline Inter-laminar Shear Modulus $\left(\mathrm{G}_{23}\right)$ & $5.51 \mathrm{GPa}$ \\
\hline Mass density $(\rho)$ & $1551 \mathrm{Kg} / \mathrm{m}^{3}$ \\
\hline Poisson's ratio $(v)$ & 0.3 \\
\hline
\end{tabular}




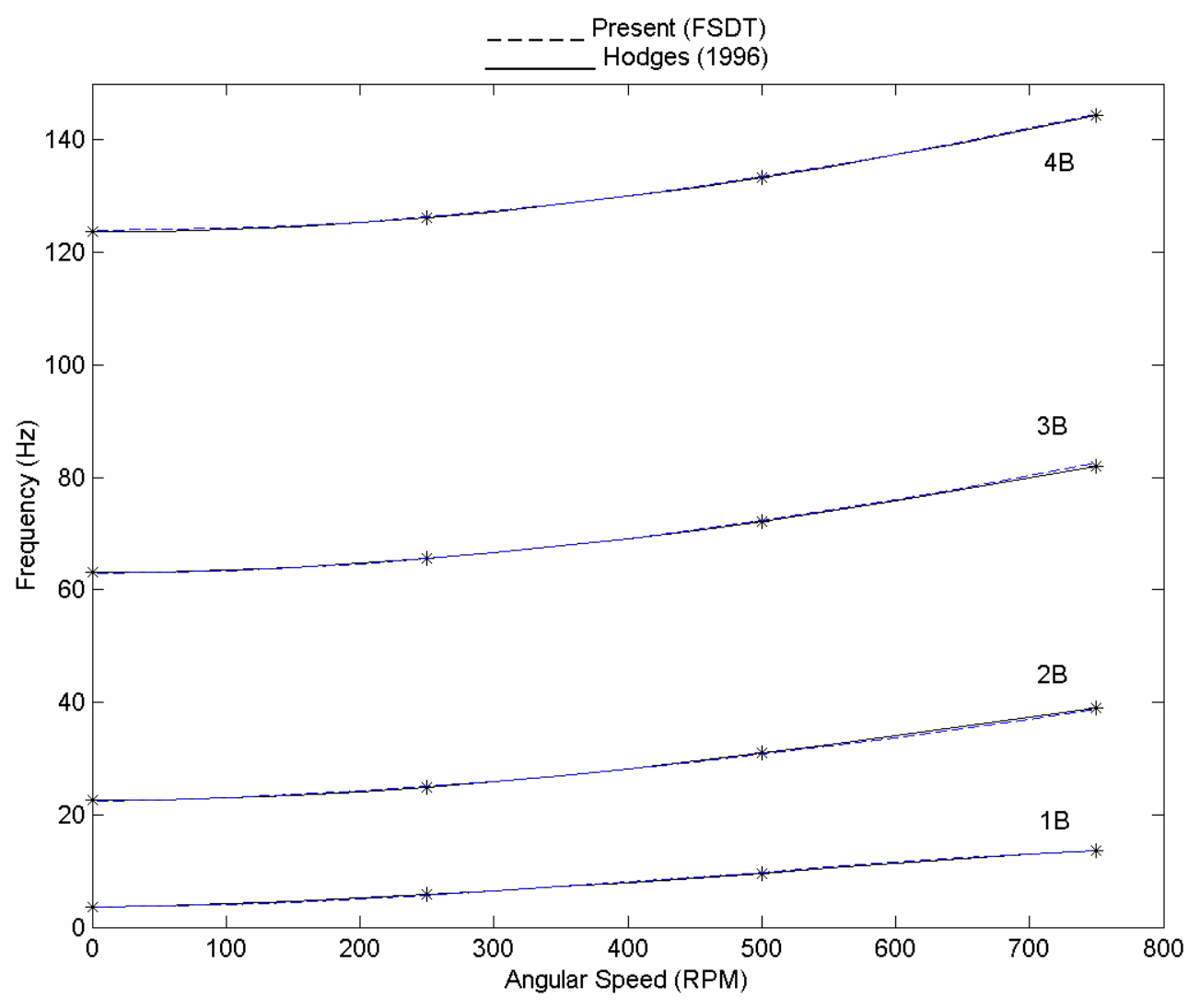

Figure 4.1 Frequency vs angular speed for graphite/epoxy beam [15 $]_{24}$ 


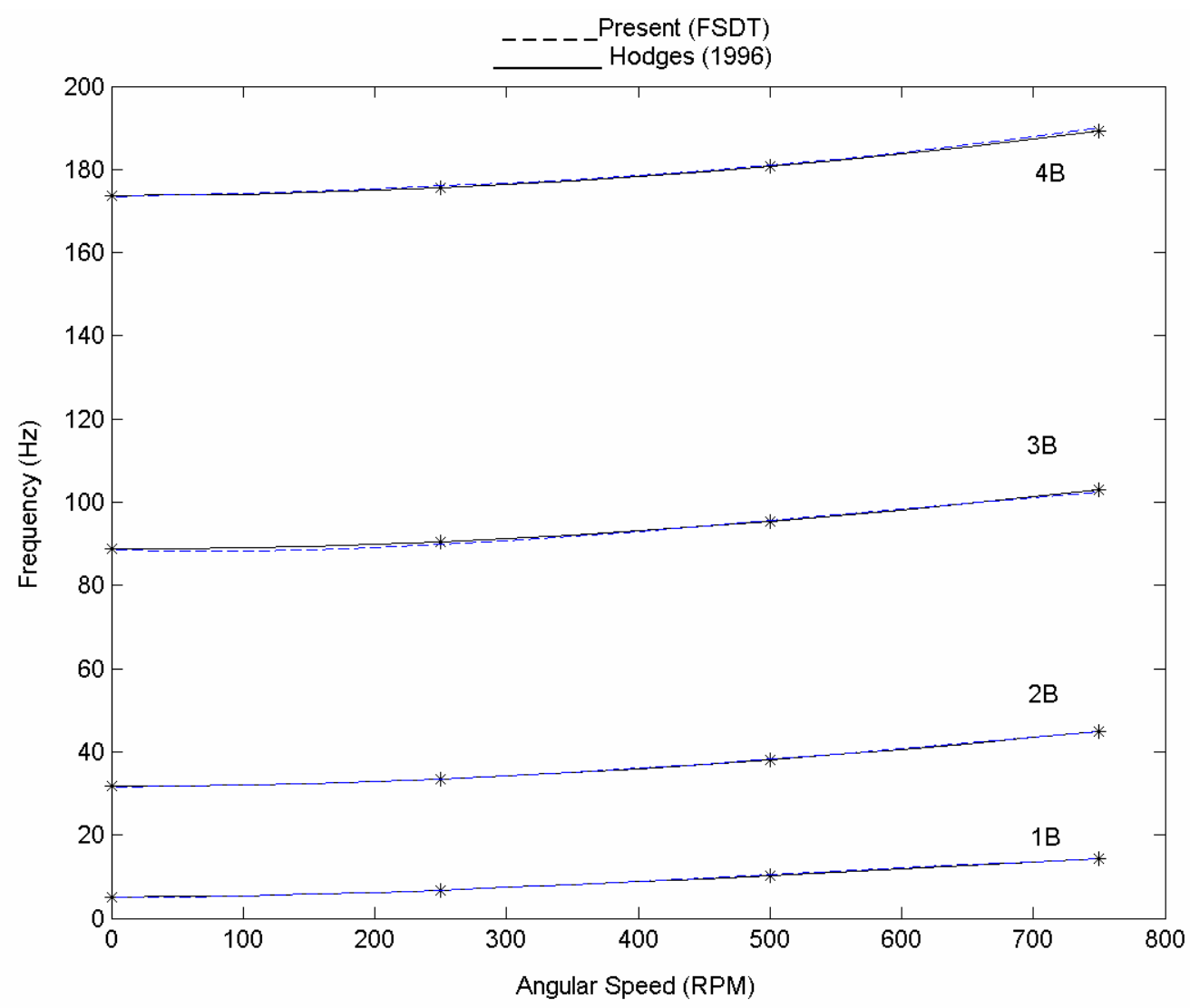

Figure 4.2 Frequency vs angular speed for graphite/epoxy beam $[0]_{24}$

\subsection{Hygrothermal Analysis}

In this section, the response of laminated composite beams to hygrothermal conditions is studied. Since no results are available in the literature for the hygrothermal effect on rotating composite beam, an indirect method is used for validation. First the hygrothermal incorporation is validated by generating results for a non rotating beam and comparing with available results in the literature.

In this study, the stiffness properties of the constituents are degraded by using the empirical relations proposed by Chamis (1983) as discussed in the previous sections. It is assumed that only matrix properties are affected by temperature change and moisture 
content. By using the rule of mixtures and changed properties of the matrix, updated elastic constants of the lamina and the laminate are calculated.

\subsubsection{Bending of Composite Beams under Hygrothermal Conditions}

The present analysis is used to obtain bending results of composite laminates subjected to a hygrothermal environment. Upadhyay and Lyons (2000a\&b) have presented results for cylindrical bending of asymmetric PMC laminates under hygrothermal conditions. In this study an asymmetric cross-ply laminate of $\left(0_{4} / 90_{4}\right)$ configuration is considered. The length, width and thickness of laminate are taken as 9 in., 1.5 in., and 0.04 in., respectively. The S-glass fiber and epoxy composite properties used here are similar to those taken by Cairns and Adams (1984). The material and hygrothermal properties are listed in Tables 4.7 and 4.8, respectively.

The analysis is carried out on laminates with clamped-clamped boundary conditions. The value of temperature and moisture conditions are taken to be $154.2{ }^{0} \mathrm{C}$ and $5 \%$ (by weight), respectively. The laminate is subjected to a uniform transverse load and the maximum transverse deflection is found. The present results and that of Upadhyay and Lyons (2000a\&b) are listed in Table 4.9. The comparison indicates excellent agreement thus validating the incorporation of the hygrothermal effects.

Table 4.7 Constituent properties of s-glass fiber and epoxy matrix

\begin{tabular}{|c|c|c|}
\hline Property & $\begin{array}{c}\text { Owens-Corning } \\
\text { S2 Glass Fiber }\end{array}$ & $\begin{array}{c}\text { Hercules 3501-6 } \\
\text { Epoxy Matrix (Dry) }\end{array}$ \\
\hline Modulus of Elasticity $(E)$ & $12.5 \times 10^{6} \mathrm{psi}$ & $0.62 \times 10^{6} \mathrm{psi}$ \\
\hline Shear Modulus $(\mathrm{G})$ & $5.12 \times 10^{6} \mathrm{psi}$ & $0.23 \times 10^{6} \mathrm{psi}$ \\
\hline Poisson's ratio $(v)$ & 0.22 & 0.34 \\
\hline
\end{tabular}


Table 4.8 Parameters in hygrothermal analysis

\begin{tabular}{|l|c|}
\hline \multicolumn{1}{|c|}{ Property } & Values \\
\hline Moisture Content, $\mathrm{m}$ & $5 \%$ \\
\hline Glass Transition Temperature of Dry Resin, $T_{\text {gdr }}$ & $420^{\circ} \mathrm{F}$ \\
\hline Temperature at which property to be measured, $\mathrm{T}$ & $154.2^{\circ} \mathrm{F}$ \\
\hline Temperature at which initial parameter is measured, $\mathrm{T}_{0}$ & $72^{\circ} \mathrm{F}$ \\
\hline Glass Transition Temperature of wet Resin, $T_{g w r}$ & $213.75^{\circ} \mathrm{C}$ \\
\hline Fiber Volume Fraction & 0.52 \\
\hline
\end{tabular}

Table 4.9 Transverse deflections of clamped-clamped laminate due to transverse load under Hygrothermal Condition

\begin{tabular}{|c|c|c|}
\hline $\begin{array}{c}\text { Transverse Load } \\
\text { (psi) }\end{array}$ & $\begin{array}{c}\text { Transverse Deflection } \\
\text { Present (FSDT) (inches) }\end{array}$ & Upadhyay \& Lyons (2000) \\
\hline 0.0072 & 0.012 & 0.012 \\
\hline 0.0145 & 0.024 & 0.024 \\
\hline 0.217 & 0.037 & 0.037 \\
\hline 0.0291 & 0.050 & 0.050 \\
\hline 0.0363 & 0.062 & 0.062 \\
\hline 0.0435 & 0.074 & 0.074 \\
\hline
\end{tabular}

\subsubsection{Hygrothermal Effects on Rotating Composite Cantilever Beams}

In the previous sections the rotating composite beam analysis and hygrothermal analysis are validated separately. In this section both the analysis are combined together and the free vibration response of the rotating composite cantilever beams under the influence of hygrothermal conditions is studied. The beam considered is an SGlass/Epoxy laminate. A parametric study is conducted by varying temperature, moisture content, ply-orientation and rotating speed.

The procedure of hygrothermal incorporation detailed in Section 3.9.3 is used, that is, degrading the matrix properties for hygrothermal/wet conditions by empirical 
relations and then using rule of mixtures to calculate the lamina property. The dimensions of the beam considered in the present study are length $(L)=0.190 \mathrm{~m}$, width $(b)=0.0127$ $\mathrm{m}$, height $(h)=0.003175 \mathrm{~m}$.

All the results presented correspond to a fiber volume fraction $V_{f}=0.6$ and the temperature for dry condition $(\mathrm{m}=0 \%)$ is taken to be $21{ }^{\circ} \mathrm{C}$. For the hygrothermal condition two cases of temperature $52{ }^{\circ} \mathrm{C}$ and $90{ }^{\circ} \mathrm{C}$ are considered. First results are generated for dry conditions and then results are generated for a moisture content of $2 \%$ and $5 \%$ with fiber orientation of $0,15,30,45$ degrees. The various properties used in this analysis are listed in Tables $4.10-4.14$. A comparison of frequency results for FSDT and CLPT are presented in the table 4.27 for beam with 30 fiber orientation, $5 \%$ moisture content and $52{ }^{\circ} \mathrm{C}$ temperature conditions.

Table 4.10 Parameters in Hygrothermal Analysis

\begin{tabular}{|l|c|}
\hline \multicolumn{1}{|c|}{ Property } & Dimensions \\
\hline Glass Transition Temperature of Dry Resin, $T_{g d r}$ & $216{ }^{\circ} \mathrm{C}$ \\
\hline Temperature at which property to be measured, $\mathrm{T}$ & $52{ }^{\circ} \mathrm{C}$ and $90^{\circ} \mathrm{C}$ \\
\hline Temperature at which initial parameter is measured, $\mathrm{T}_{0}$ & $21{ }^{\circ} \mathrm{C}$ \\
\hline $\begin{array}{l}\text { Glass Transition Temperature of wet Resin for } 2 \% \\
\text { moisture content, } T_{g w r}\end{array}$ & $177^{\circ} \mathrm{C}$ \\
\hline $\begin{array}{l}\text { Glass Transition Temperature of wet Resin for } 5 \% \\
\text { moisture content, } T_{g w r}\end{array}$ & $135^{\circ} \mathrm{C}$ \\
\hline
\end{tabular}


Table 4.11 Constituent Properties of S-glass fiber and epoxy Matrix

\begin{tabular}{|l|c|c|}
\hline \multicolumn{1}{|c|}{ Property } & $\begin{array}{c}\text { Owens-Corning } \\
\text { S2 Glass Fiber }\end{array}$ & $\begin{array}{c}\text { Hercules 3501-6 } \\
\text { Epoxy Matrix (Dry) }\end{array}$ \\
\hline Modulus of Elasticity $(E)$ & $86.2 \mathrm{GPa}$ & $3.45 \mathrm{GPa}$ \\
\hline Shear Modulus $(\mathrm{G})$ & $35.7 \mathrm{GPa}$ & $1.27 \mathrm{GPa}$ \\
\hline Poisson's ratio $(v)$ & 0.22 & 0.35 \\
\hline Density $(\rho)$ & $2491 \mathrm{Kg} / \mathrm{m}^{3}$ & $1265 \mathrm{Kg} / \mathrm{m}^{3}$ \\
\hline
\end{tabular}

Table 4.12 Material properties of S-glass/epoxy composite when dry and in hygrothermal environment ( $2 \%$ moisture)

\begin{tabular}{|c|c|c|}
\hline Property & $\begin{array}{c}\text { Dry } \\
\text { Condition } \\
\mathbf{T}=\mathbf{2 1}{ }^{\circ} \mathrm{C}, \mathbf{m}=\mathbf{0 \%}\end{array}$ & $\begin{array}{c}\text { Hygrothermal } \\
\text { Condition } \\
\mathbf{T}=\mathbf{9 0}{ }^{\circ} \mathrm{C}, \mathbf{m}=\mathbf{2} \%\end{array}$ \\
\hline Longitudinal Modulus $\left(E_{l}\right)$ & $53.1 \mathrm{GPa}$ & $52.64 \mathrm{GPa}$ \\
\hline Transverse Modulus $\left(\mathrm{E}_{2}\right)$ & $8.14 \mathrm{GPa}$ & $5.53 \mathrm{GPa}$ \\
\hline Longitudinal Shear Modulus $\left(\mathrm{G}_{12}\right)$ & $3.03 \mathrm{GPa}$ & $2.06 \mathrm{GPa}$ \\
\hline Poisson's ratio $\left(v_{12}\right)$ & 0.27 & 0.27 \\
\hline Transverse Shear Modulus $\left(\mathrm{G}_{13}\right)$ & $3.03 \mathrm{GPa}$ & $2.06 \mathrm{GPa}$ \\
\hline Inter-laminar Shear Modulus $\left(\mathrm{G}_{23}\right)$ & $3.98 \mathrm{GPa}$ & $2.74 \mathrm{GPa}$ \\
\hline Mass density $(\rho)$ & $2000 \mathrm{Kg} / \mathrm{m}^{3}$ & $2040 \mathrm{Kg} / \mathrm{m}^{3}$ \\
\hline
\end{tabular}

Table 4.13 Material properties of S-glass/epoxy composite when dry and in hygrothermal environment (5 \% moisture)

\begin{tabular}{|l|c|c|}
\hline \multicolumn{1}{|c|}{ Property } & $\begin{array}{c}\text { Dry } \\
\text { Condition } \\
\mathbf{T = 2 1}{ }^{\circ} \mathbf{C}, \mathbf{m}=\mathbf{0 \%}\end{array}$ & $\begin{array}{c}\text { Hygrothermal } \\
\text { Condition } \\
\mathbf{T}=\mathbf{9 0}{ }^{\circ} \mathrm{C}, \mathbf{m}=\mathbf{5 \%}\end{array}$ \\
\hline Longitudinal Modulus $\left(E_{1}\right)$ & $53.1 \mathrm{GPa}$ & $52.38 \mathrm{GPa}$ \\
\hline Transverse Modulus $\left(E_{2}\right)$ & $8.14 \mathrm{GPa}$ & $4.03 \mathrm{GPa}$ \\
\hline Longitudinal Shear Modulus $\left(G_{12}\right)$ & $3.03 \mathrm{GPa}$ & $1.50 \mathrm{GPa}$ \\
\hline Transverse Shear Modulus $\left(G_{13}\right)$ & $3.03 \mathrm{GPa}$ & $1.50 \mathrm{GPa}$ \\
\hline Inter-laminar Shear Modulus $\left(G_{23}\right)$ & $3.98 \mathrm{GPa}$ & $2.01 \mathrm{GPa}$ \\
\hline Mass density $(\rho)$ & $2000 \mathrm{Kg} / \mathrm{m}^{3}$ & $2100 \mathrm{Kg} / \mathrm{m}^{3}$ \\
\hline Poisson's ratio $\left(v_{12}\right)$ & 0.27 & 0.27 \\
\hline
\end{tabular}


Table 4.14 Material properties of S-glass/epoxy composite when dry and in hygrothermal environment (5\% moisture)

\begin{tabular}{|l|c|c|}
\hline \multicolumn{1}{|c|}{ Property } & $\begin{array}{c}\text { Dry } \\
\text { Condition } \\
\mathbf{T =} \mathbf{2 1} \mathbf{~}^{0} \mathbf{C}, \mathbf{m}=\mathbf{0 \%}\end{array}$ & $\begin{array}{c}\text { Hygrothermal } \\
\text { Condition } \\
\mathbf{T}=\mathbf{5 2}{ }^{0} \mathbf{C}, \mathbf{~ m}=\mathbf{5 \%}\end{array}$ \\
\hline Longitudinal Modulus $\left(E_{1}\right)$ & $53.1 \mathrm{GPa}$ & $52.62 \mathrm{GPa}$ \\
\hline Transverse Modulus $\left(E_{2}\right)$ & $8.14 \mathrm{GPa}$ & $5.41 \mathrm{GPa}$ \\
\hline Longitudinal Shear Modulus $\left(G_{12}\right)$ & $3.03 \mathrm{GPa}$ & $2.031 \mathrm{GPa}$ \\
\hline Transverse Shear Modulus $\left(G_{13}\right)$ & $3.03 \mathrm{GPa}$ & $2.031 \mathrm{GPa}$ \\
\hline Inter-laminar Shear Modulus $\left(G_{23}\right)$ & $3.98 \mathrm{GPa}$ & $2.175 \mathrm{GPa}$ \\
\hline Mass density $(\rho)$ & $2000 \mathrm{Kg} / \mathrm{m}^{3}$ & $2100 \mathrm{Kg} / \mathrm{m}^{3}$ \\
\hline Poisson's ratio $\left(v_{12}\right)$ & 0.27 & 0.27 \\
\hline
\end{tabular}

The results are presented in the form of plots of beam rotating natural frequencies as a function of angular speed. In the figures and tables, $1 \mathrm{~B}, 2 \mathrm{~B}, 3 \mathrm{~B}, 4 \mathrm{~B}$ indicate the first, second, third and fourth flap bending modes of the rotating beam, respectively. 


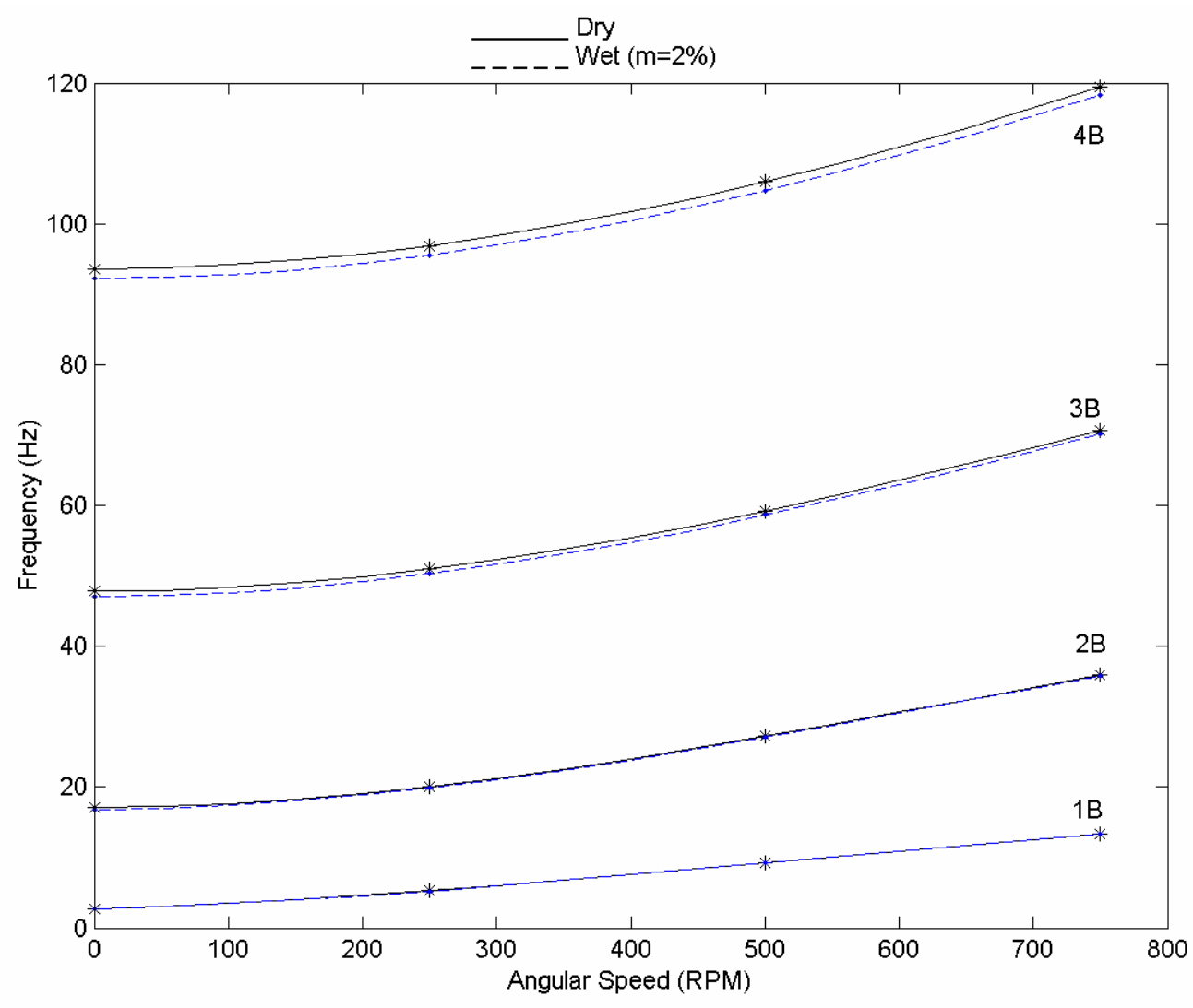

Figure 4.3 Influences of rotational speed and moisture content on natural frequencies of S-glass/epoxy beam, $[0]_{24}, \mathbf{T}=90{ }^{\circ} \mathrm{C}$

Table 4.15 Influences of rotational speed and moisture content on natural frequencies of S-glass/epoxy beam, $[0]_{24}, T=90{ }^{\circ} \mathrm{C}$

\begin{tabular}{|c|c|c|c|c|c|c|c|c|c|c|c|c|}
\hline \multirow{2}{*}{$\begin{array}{l}\text { Angular } \\
\text { Speed } \\
\text { (RPM) }\end{array}$} & \multicolumn{4}{|c|}{ Dry Condition (Hz) } & \multicolumn{4}{|c|}{$\begin{array}{c}\text { Hygrothermal (Hz) } \\
\text { m=2\% }\end{array}$} & \multicolumn{4}{|c|}{ \% Reduction } \\
\hline & 1B & $2 B$ & 3B & 4B & 1B & 2B & 3B & 4B & 1B & 2B & 3B & 4B \\
\hline $\mathbf{0}$ & 2.72 & 17.08 & 47.81 & 93.63 & 2.68 & 16.83 & 47.12 & 92.26 & 1.47 & 1.46 & 1.44 & 1.46 \\
\hline 250 & 5.26 & 20.1 & 50.93 & 96.89 & 5.23 & 19.89 & 50.27 & 95.56 & 0.57 & 1.04 & 1.29 & 1.37 \\
\hline 500 & 9.25 & 27.19 & 59.21 & 105.99 & 9.23 & 27.03 & 58.63 & 104.74 & 0.21 & 0.58 & 0.97 & 1.18 \\
\hline 750 & 13.36 & 35.93 & 70.67 & 119.39 & 13.34 & 35.8 & 70.15 & 118.23 & 0.15 & 0.36 & 0.73 & 0.97 \\
\hline
\end{tabular}


The natural frequencies for the first four modes under dry and wet (2\% moisture content at $90^{\circ} \mathrm{C}$ ) conditions as a function of the rotational speed is presented in Figure 4.3 and Table 4.15 for the case of the [0]24 beam. Considering all the 16 data points ( 4 modes at 4 speeds), the effect of the hygrothermal condition is minimal with the highest reduction in the natural frequency being less than $1.5 \%$. This insignificant effect of the hygrothermal environment on the natural frequencies of the beam can be explained as follows. The degradation of material stiffness properties due to an elevated moisture/temperature state is confined to the matrix in the present model, customary in the treatment of hygrothermal analyses. This being a beam of zero-degree ply orientation, the fiber material stiffness is the predominant contributor to the beam stiffness with the matrix playing a rather minor role. Further observation of the results indicates the following trends. The maximum effect is manifested in the non-rotating beam and as the rotational speed of the beam increases, the hygrothermal effects become smaller in all the four modes. This is attributed to the fact that the stiffness of the beam increases with the rotational speed due to the centrifugal effect and the reduction in beam stiffness due to material stiffness degradation caused by the hygrothermal environment becomes a smaller percentage of the total beam stiffness. For the non-rotating beam, the hygrothermal effect is essentially the same (about $1.45 \%$ ) in all the four modes whereas for a beam rotating at a constant speed (any of the three speeds considered) the effect increases gradually with the mode number.

Figure 4.4 and Table 4.16 show results for the case of 5\% moisture content with all other parameters same as the previous case. As expected, each of the natural 
frequency values for the $\mathrm{m}=5 \%$ case is lower than the corresponding value for the $\mathrm{m}=2 \%$ case due to the fact that there is more degradation at the higher moisture content. While the trends for the $5 \%$ case are similar to the trends discussed in the previous paragraph for the $2 \%$ case, the percentage reductions in the natural frequencies are all higher. Again the maximum reduction (about 3\%) is exhibited by the non-rotating beam. 


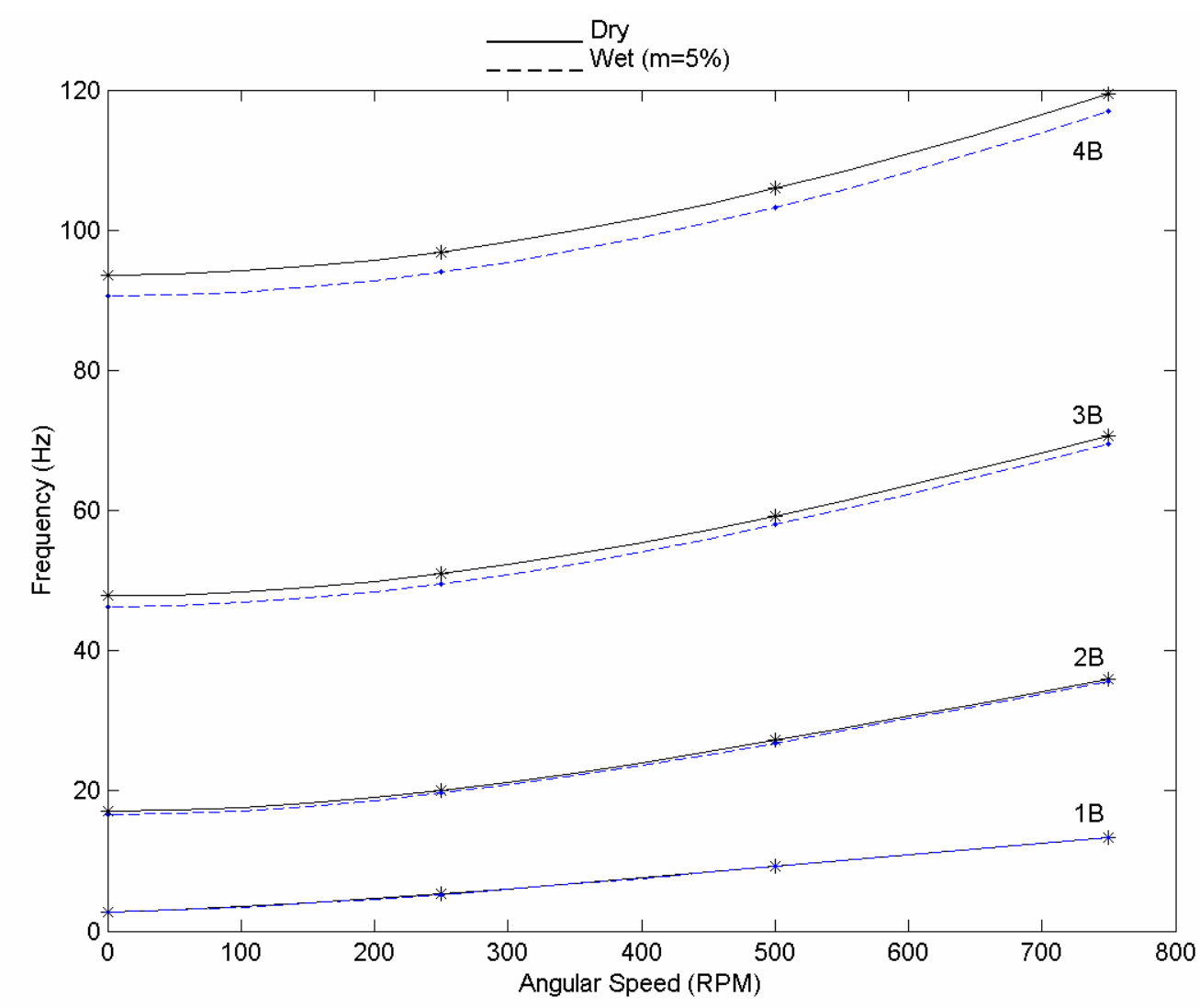

Figure 4.4 Influences of rotational speed and moisture content on natural frequencies of S-glass/epoxy beam, $[0]_{24}, T=90{ }^{\circ} \mathrm{C}$

Table 4.16 Influences of rotational speed and moisture content on natural frequencies of S-glass/Epoxy Beam, $[0]_{24}, \boldsymbol{T}=90{ }^{\circ} \mathrm{C}$

\begin{tabular}{|c|c|c|c|c|c|c|c|c|c|c|c|c|}
\hline \multirow{2}{*}{$\begin{array}{l}\text { Angular } \\
\text { Speed } \\
\text { (RPM) }\end{array}$} & \multicolumn{4}{|c|}{ Dry Condition (Hz) } & \multicolumn{4}{|c|}{$\begin{array}{c}\text { Hygrothermal }(\mathrm{Hz}) \\
\mathrm{m}=5 \%\end{array}$} & \multicolumn{4}{|c|}{ \% Reduction } \\
\hline & 1B & 2B & 3B & 4B & 1B & $2 B$ & 3B & 4B & 1B & 2B & 3B & 4B \\
\hline $\mathbf{0}$ & 2.72 & 17.08 & 47.81 & 93.63 & 2.64 & 16.55 & 46.31 & 90.65 & 2.94 & 3.10 & 3.14 & 3.18 \\
\hline 250 & 5.26 & 20.1 & 50.93 & 96.89 & 5.21 & 19.65 & 49.51 & 93.99 & 0.95 & 2.24 & 2.79 & 2.99 \\
\hline 500 & 9.25 & 27.19 & 59.21 & 105.99 & 9.21 & 26.84 & 57.96 & 103.29 & 0.43 & 1.29 & 2.11 & 2.55 \\
\hline 750 & 13.36 & 35.93 & 70.67 & 119.39 & 13.32 & 35.64 & 69.56 & 116.89 & 0.30 & 0.81 & 1.57 & 2.09 \\
\hline
\end{tabular}




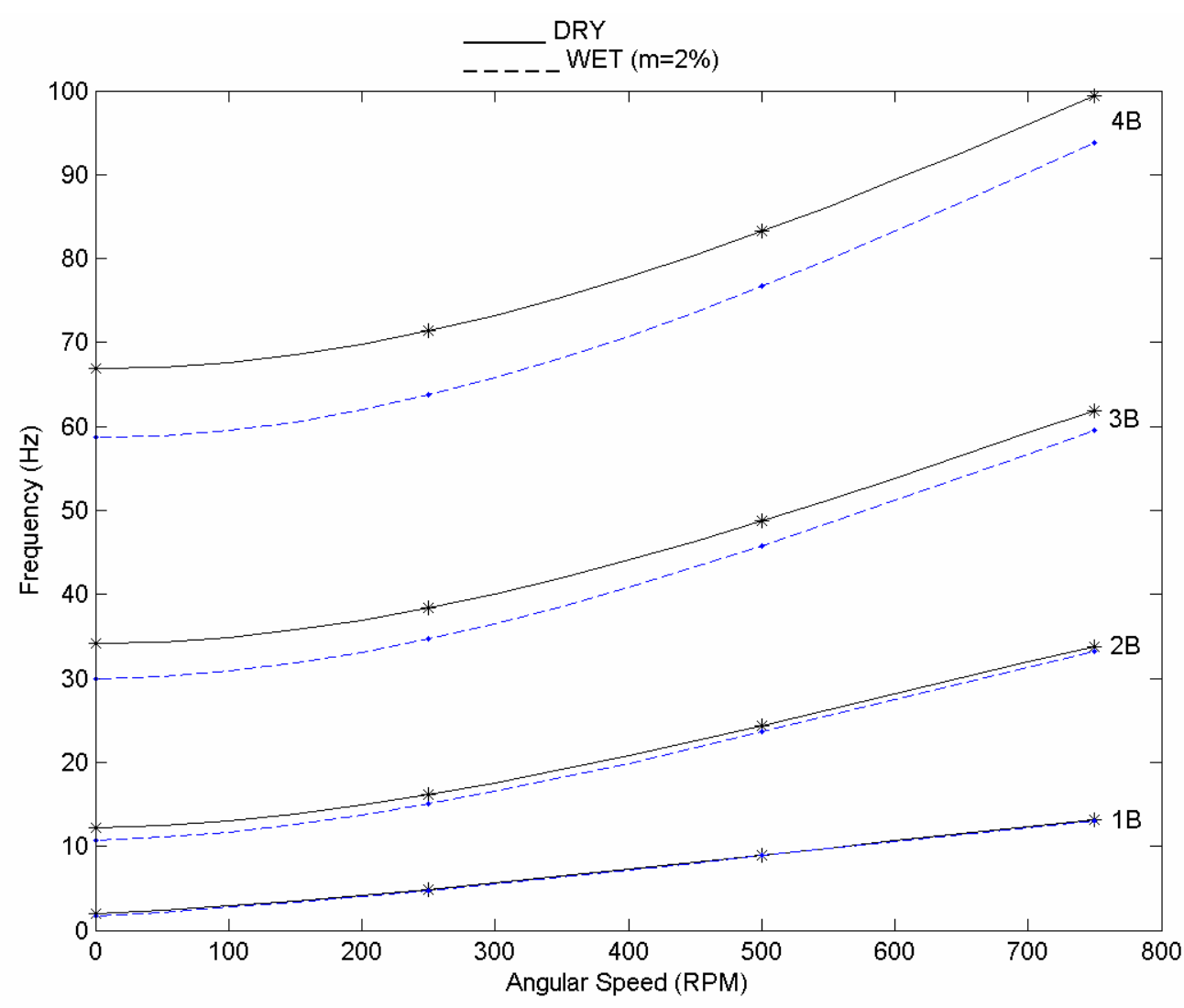

Figure 4.5 Influences of rotational speed and moisture content on natural frequencies of S-glass/epoxy beam, $[15]_{24}, \boldsymbol{T}=90^{\circ} \mathrm{C}$

Table 4.17 Influences of rotational speed and moisture content on natural frequencies of S-glass/epoxy beam, $[15]_{24}, T=90{ }^{\circ} C$

\begin{tabular}{|c|c|c|c|c|c|c|c|c|c|c|c|c|}
\hline \multirow{2}{*}{$\begin{array}{l}\text { Angular } \\
\text { Speed } \\
\text { (RPM) }\end{array}$} & \multicolumn{4}{|c|}{ Dry Condition (Hz) } & \multicolumn{4}{|c|}{$\begin{array}{c}\text { Hygrothermal (Hz) } \\
\text { m=2\% }\end{array}$} & \multicolumn{4}{|c|}{ \% Reduction } \\
\hline & 1B & 2B & 3B & 4B & 1B & 2B & 3B & $4 B$ & 1B & 2B & 3B & 4B \\
\hline $\mathbf{0}$ & 1.94 & 12.19 & 34.14 & 66.89 & 1.7 & 10.7 & 29.95 & 58.68 & 12.37 & 12.22 & 12.27 & 12.27 \\
\hline 250 & 4.87 & 16.15 & 38.38 & 71.38 & 4.76 & 15.05 & 34.7 & 63.74 & 2.26 & 6.81 & 9.59 & 10.70 \\
\hline 500 & 8.96 & 24.37 & 48.74 & 83.23 & 8.87 & 23.63 & 45.82 & 76.69 & 1.00 & 3.04 & 5.99 & 7.86 \\
\hline 750 & 13.1 & 33.76 & 61.91 & 99.44 & 13.01 & 33.18 & 59.5 & 93.85 & 0.69 & 1.72 & 3.89 & 5.62 \\
\hline
\end{tabular}




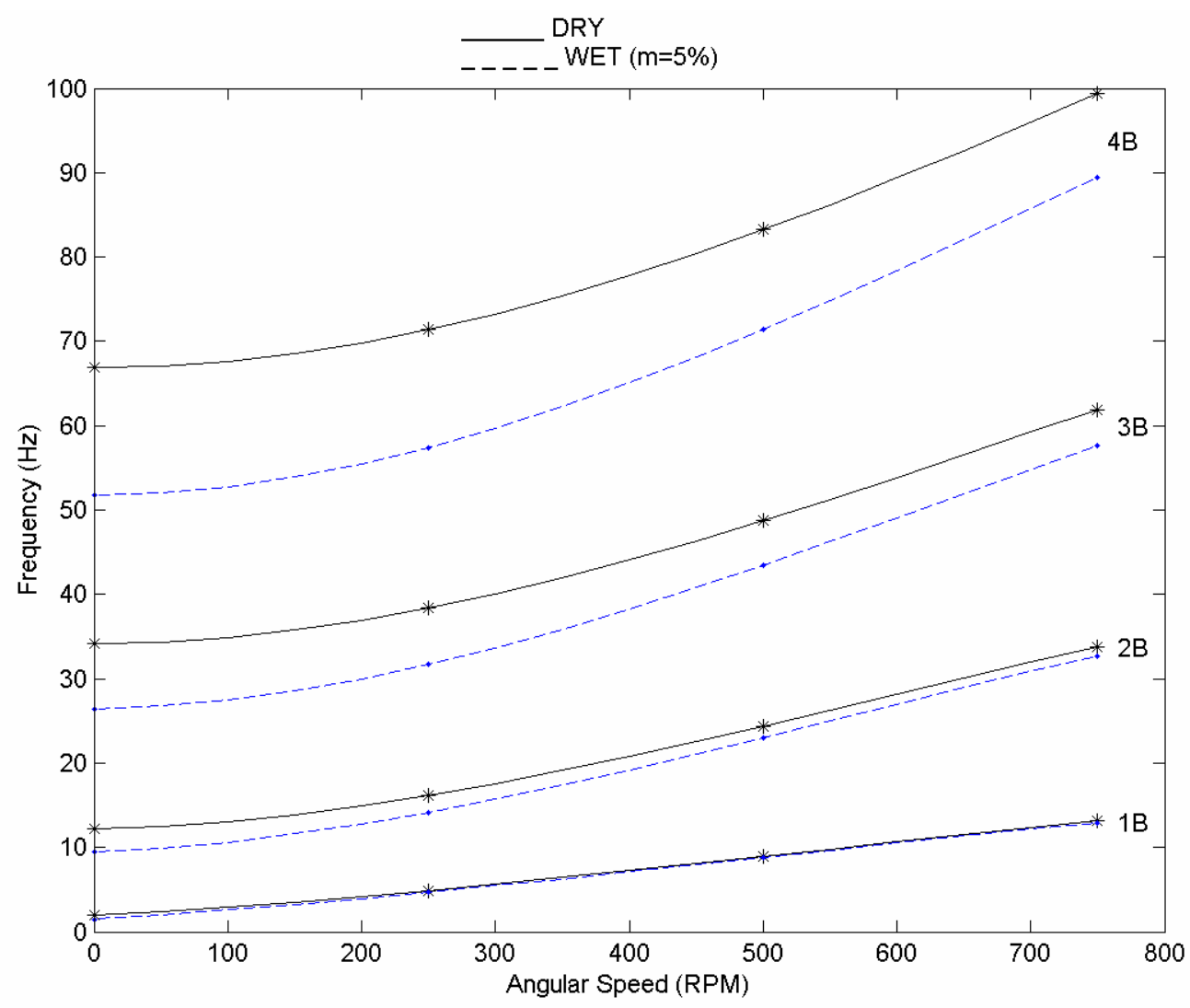

Figure 4.6 Influences of rotational speed and moisture content on natural frequencies of S-glass/epoxy beam, $[15]_{24} \mathbf{T}=90{ }^{\circ} \mathrm{C}$

Table 4.18 Influences of rotational speed and moisture content on natural frequencies of S-glass/epoxy beam, $[15]_{24}, T=90{ }^{\circ} \mathrm{C}$

\begin{tabular}{|c|c|c|c|c|c|c|c|c|c|c|c|c|}
\hline \multirow{2}{*}{$\begin{array}{l}\text { Angular } \\
\text { Speed } \\
\text { (RPM) }\end{array}$} & \multicolumn{4}{|c|}{ Dry Condition (Hz) } & \multicolumn{3}{c|}{$\begin{array}{c}\text { Hygrothermal (Hz) } \\
\text { m=5\% }\end{array}$} & \multicolumn{5}{c|}{ \% Reduction } \\
\cline { 2 - 14 } & 1B & 2B & 3B & 4B & 1B & 2B & 3B & 4B & 1B & 2B & 3B & 4B \\
\hline $\mathbf{0}$ & 1.94 & 12.19 & 34.14 & 66.89 & 1.5 & 9.43 & 26.42 & 51.75 & 22.68 & 22.64 & 22.61 & 22.63 \\
\hline $\mathbf{2 5 0}$ & 4.87 & 16.15 & 38.38 & 71.38 & 4.68 & 14.18 & 31.68 & 57.42 & 3.90 & 12.20 & 17.46 & 19.56 \\
\hline $\mathbf{5 0 0}$ & 8.96 & 24.37 & 48.74 & 83.23 & 8.8 & 23.05 & 43.5 & 71.43 & 1.79 & 5.42 & 10.75 & 14.18 \\
\hline $\mathbf{7 5 0}$ & 13.1 & 33.76 & 61.91 & 99.44 & 12.94 & 32.73 & 57.6 & 89.38 & 1.22 & 3.05 & 6.96 & 10.12 \\
\hline
\end{tabular}


Now a beam of $15^{\circ}$-ply orientation, [15]24, is considered and the results for $\mathrm{m}=2 \%$ are presented in Figure 4.5 and Table 4.17 while the ones for $\mathrm{m}=5 \%$ in Figure 4.6 and Table 4.18. The raw values of the natural frequencies for all the dry and wet cases are lower for the $15^{\circ}$-beam than the corresponding values for the $0^{\circ}$-beam, as expected, since the material stiffness contribution of the matrix has a higher percentage and thus reducing the beam stiffness. The hygrothermal effect, in terms of the percent decrease, is much more pronounced for the $15^{\circ}$-beam and still much higher for the non-rotating beam than the rotating beam.

The results for the $30^{\circ}$-beam and $45^{\circ}$-beam are presented in Figures 4.7-10 and Tables 4.19-22. As the ply orientation increases, the raw values of the natural frequencies for all the dry and wet cases decrease. The percentage reduction in the natural frequency due to the hygrothermal conditions $(\mathrm{m}=2 \%)$ increases with the ply orientation for the non-rotating beam from about $1.5 \%$ for the $0^{\circ}$-beam to about $18 \%$ for the $45^{\circ}$-beam; the corresponding range for the $\mathrm{m}=5 \%$ case is approximately $3 \%-32 \%$. The percentage reduction in the rotating natural frequency does not show a direct correlation with the ply orientation; the reduction value jumps up as you go from $0^{\circ}$ to $15^{\circ}$ while it mostly decreases, though slightly, from $15^{\circ}$ to $45^{\circ}$.

The results for $\mathrm{T}=52^{\circ} \mathrm{C}$ at $\mathrm{m}=5 \%$ for different ply orientations are included in Figures 4.11-14 and Tables 4.23-26. The trends are similar to that of the $\mathrm{T}=90^{\circ} \mathrm{C}$ case. 
From the results presented in this chapter, the main conclusion that can be drawn is that the hygrothermal effect on the natural frequency is more severe on the non-rotating beam than on the rotating beam. As the rotational speed increases the percentage reduction in the natural frequency decreases for all the cases considered. This is because the beam stiffness reduction due to hygrothermal exposure is more than mitigated by the increase in stiffness due to the centrifugal effect. 


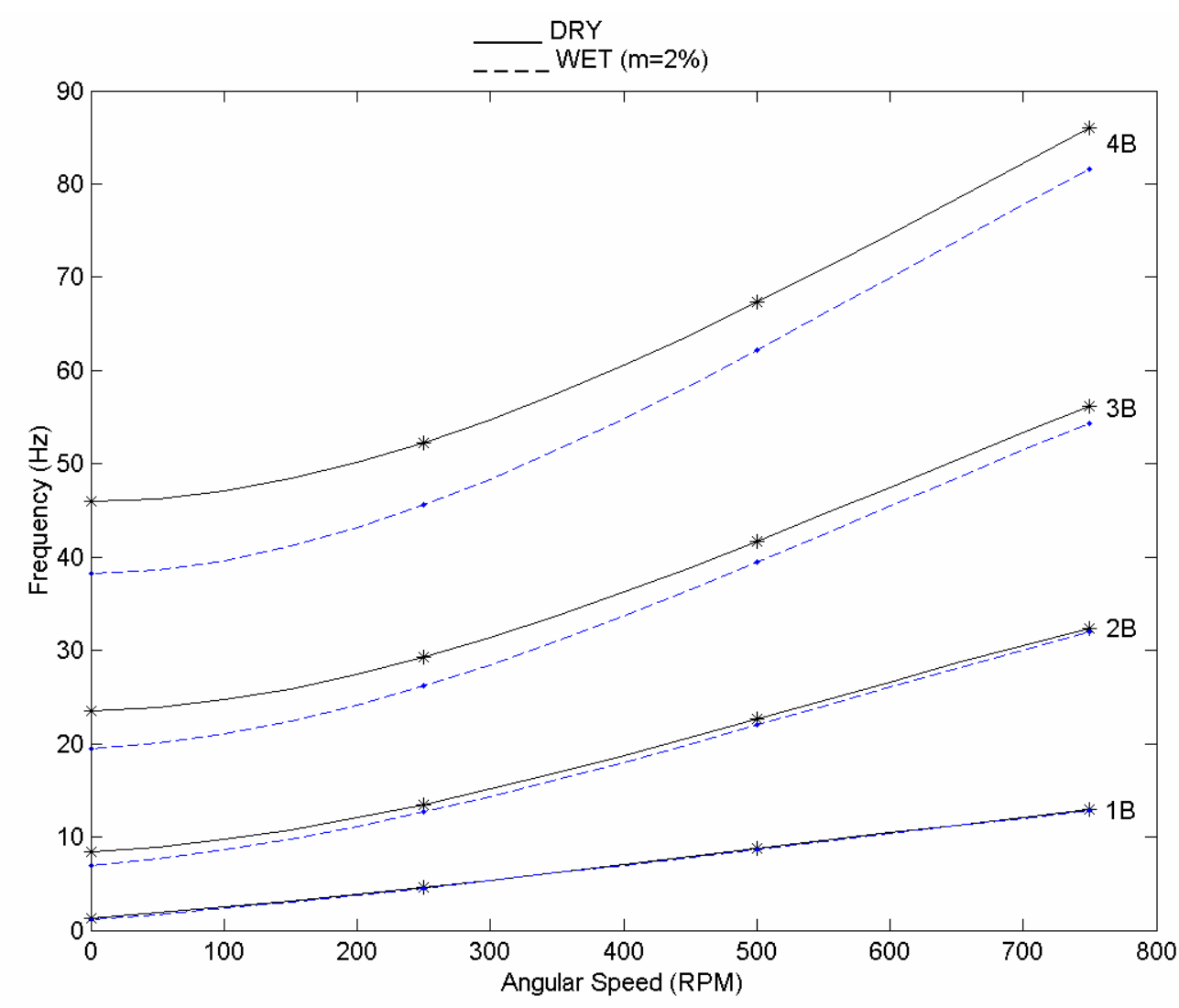

Figure 4.7 Influences of rotational speed and moisture content on natural frequencies of S-glass/epoxy beam, $\left[\mathbf{3 0}_{\mathbf{2 4}}, \boldsymbol{T}=90^{\circ} \mathrm{C}\right.$

Table 4.19 Influences of rotational speed and moisture content on natural frequencies of S-glass/epoxy beam, $[30]_{24}, \boldsymbol{T}=90{ }^{\circ} \mathrm{C}$

\begin{tabular}{|c|c|c|c|c|c|c|c|c|c|c|c|c|}
\hline $\begin{array}{c}\text { Angular } \\
\text { Speed } \\
\text { (RPM) }\end{array}$ & \multicolumn{3}{|c|}{ Dry Condition (Hz) } & \multicolumn{3}{c|}{$\begin{array}{c}\text { Hygrothermal (Hz) } \\
\text { m=2\% }\end{array}$} & \multicolumn{4}{c|}{ \% Reduction } \\
\cline { 2 - 13 } & 1B & 2B & 3B & 4B & 1B & 2B & 3B & 4B & 1B & 2B & 3B & 4B \\
\hline $\mathbf{0}$ & 1.33 & 8.38 & 23.46 & 45.97 & 1.11 & 6.96 & 19.5 & 38.2 & 16.54 & 16.95 & 16.88 & 16.90 \\
\hline $\mathbf{2 5 0}$ & 4.61 & 13.5 & 29.26 & 52.27 & 4.53 & 12.65 & 26.16 & 45.56 & 1.74 & 6.30 & 10.59 & 12.84 \\
\hline $\mathbf{5 0 0}$ & 8.75 & 22.62 & 41.71 & 67.3 & 8.67 & 22 & 39.44 & 62.2 & 0.91 & 2.74 & 5.44 & 7.58 \\
\hline $\mathbf{7 5 0}$ & 12.9 & 32.41 & 56.18 & 85.99 & 12.82 & 31.98 & 54.32 & 81.56 & 0.62 & 1.33 & 3.31 & 5.15 \\
\hline
\end{tabular}




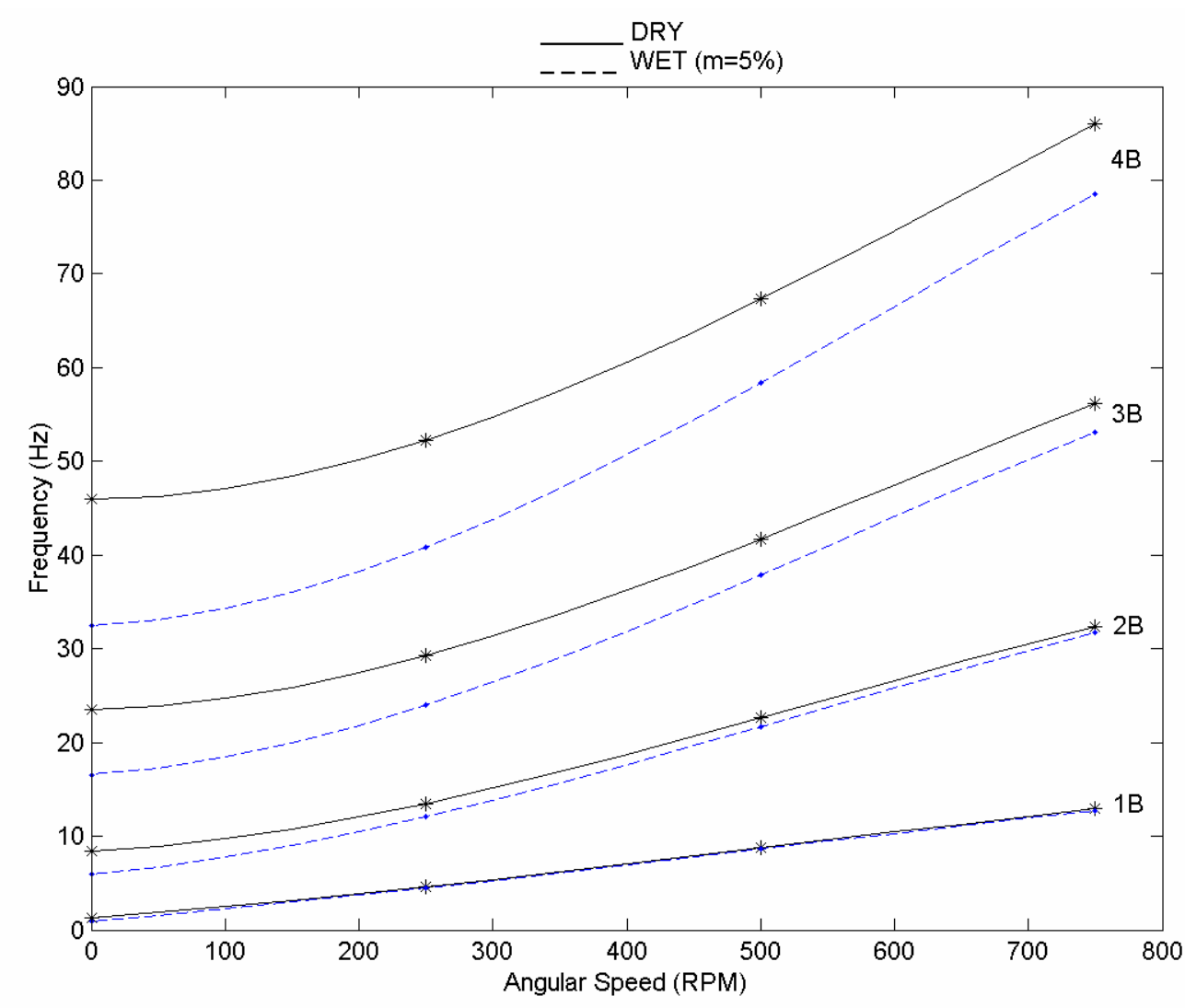

Figure 4.8 Influences of rotational speed and moisture content on natural frequencies of S-glass/epoxy beam, $\left[\mathbf{3 0}_{\mathbf{2 4}}, \boldsymbol{T}=90^{\circ} \mathrm{C}\right.$

Table 4.20 Influences of rotational speed and moisture content on natural frequencies of S-glass/epoxy beam, $[30]_{24}, T=90{ }^{\circ} \mathrm{C}$

\begin{tabular}{|c|c|c|c|c|c|c|c|c|c|c|c|c|}
\hline \multirow{2}{*}{$\begin{array}{l}\text { Angular } \\
\text { Speed } \\
\text { (RPM) }\end{array}$} & \multicolumn{3}{|c|}{ Dry Condition (Hz) } & \multicolumn{3}{c|}{$\begin{array}{c}\text { Hygrothermal (Hz) } \\
\text { m=5\% }\end{array}$} & \multicolumn{5}{c|}{ \% Reduction } \\
\cline { 2 - 13 } & 1B & 2B & 3B & 4B & 1B & 2B & 3B & 4B & 1B & 2B & 3B & 4B \\
\hline $\mathbf{0}$ & 1.33 & 8.38 & 23.46 & 45.97 & 0.94 & 5.92 & 16.57 & 32.48 & 29.32 & 29.36 & 29.37 & 29.35 \\
\hline $\mathbf{2 5 0}$ & 4.61 & 13.5 & 29.26 & 52.27 & 4.47 & 12.1 & 24.02 & 40.84 & 3.04 & 10.37 & 17.91 & 21.87 \\
\hline $\mathbf{5 0 0}$ & 8.75 & 22.62 & 41.71 & 67.3 & 8.62 & 21.71 & 37.91 & 58.42 & 1.49 & 4.02 & 9.11 & 13.19 \\
\hline $\mathbf{7 5 0}$ & 12.9 & 32.41 & 56.18 & 85.99 & 12.76 & 31.68 & 53.05 & 78.51 & 1.09 & 2.25 & 5.57 & 8.70 \\
\hline
\end{tabular}




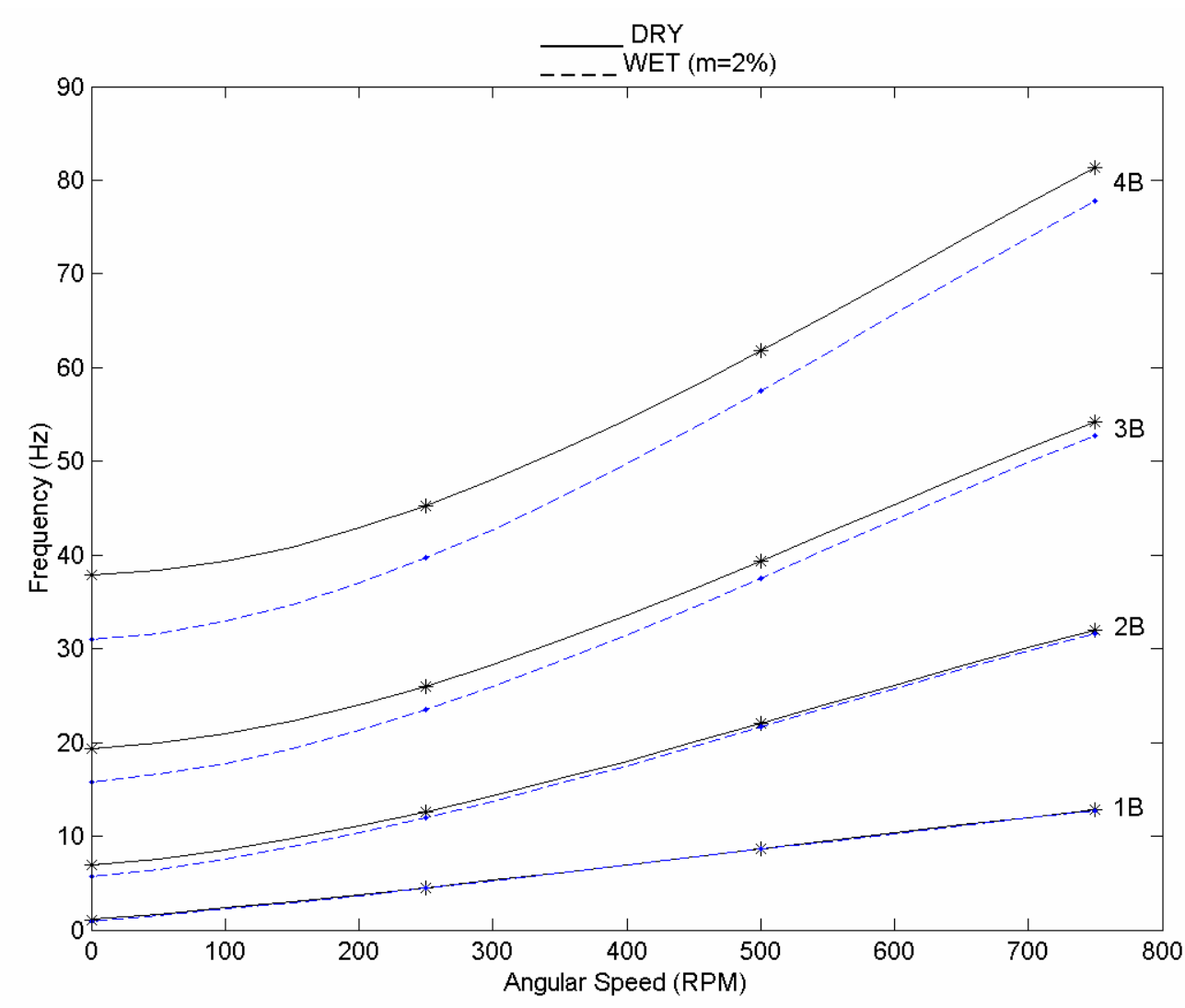

Figure 4.9 Influences of rotational speed and moisture content on natural frequencies of S-glass/epoxy beam, $[45]_{24}, \boldsymbol{T}=90{ }^{\circ} \mathrm{C}$

Table 4.21 Influences of rotational speed and moisture content on natural frequencies of S-glass/epoxy beam, $[45]_{24}, T=90{ }^{\circ} \mathrm{C}$

\begin{tabular}{|c|c|c|c|c|c|c|c|c|c|c|c|c|}
\hline \multirow{2}{*}{$\begin{array}{l}\text { Angular } \\
\text { Speed } \\
\text { (RPM) }\end{array}$} & \multicolumn{4}{|c|}{ Dry Condition (Hz) } & \multicolumn{3}{c|}{$\begin{array}{c}\text { Hygrothermal (Hz) } \\
\text { m=2\% }\end{array}$} & \multicolumn{5}{c|}{ \% Reduction } \\
\cline { 2 - 14 } & 1B & 2B & 3B & 4B & 1B & 2B & 3B & 4B & 1B & 2B & 3B & 4B \\
\hline $\mathbf{0}$ & 1.1 & 6.9 & 19.32 & 37.86 & 0.9 & 5.65 & 15.82 & 31 & 18.18 & 18.12 & 18.12 & 18.12 \\
\hline $\mathbf{2 5 0}$ & 4.52 & 12.62 & 26.03 & 45.28 & 4.45 & 11.96 & 23.49 & 39.67 & 1.55 & 5.23 & 9.76 & 12.39 \\
\hline $\mathbf{5 0 0}$ & 8.67 & 22.05 & 39.35 & 61.81 & 8.6 & 21.63 & 37.55 & 57.55 & 0.81 & 1.90 & 4.57 & 6.89 \\
\hline $\mathbf{7 5 0}$ & 12.82 & 31.97 & 54.26 & 81.4 & 12.76 & 31.63 & 52.76 & 77.79 & 0.47 & 1.06 & 2.76 & 4.43 \\
\hline
\end{tabular}




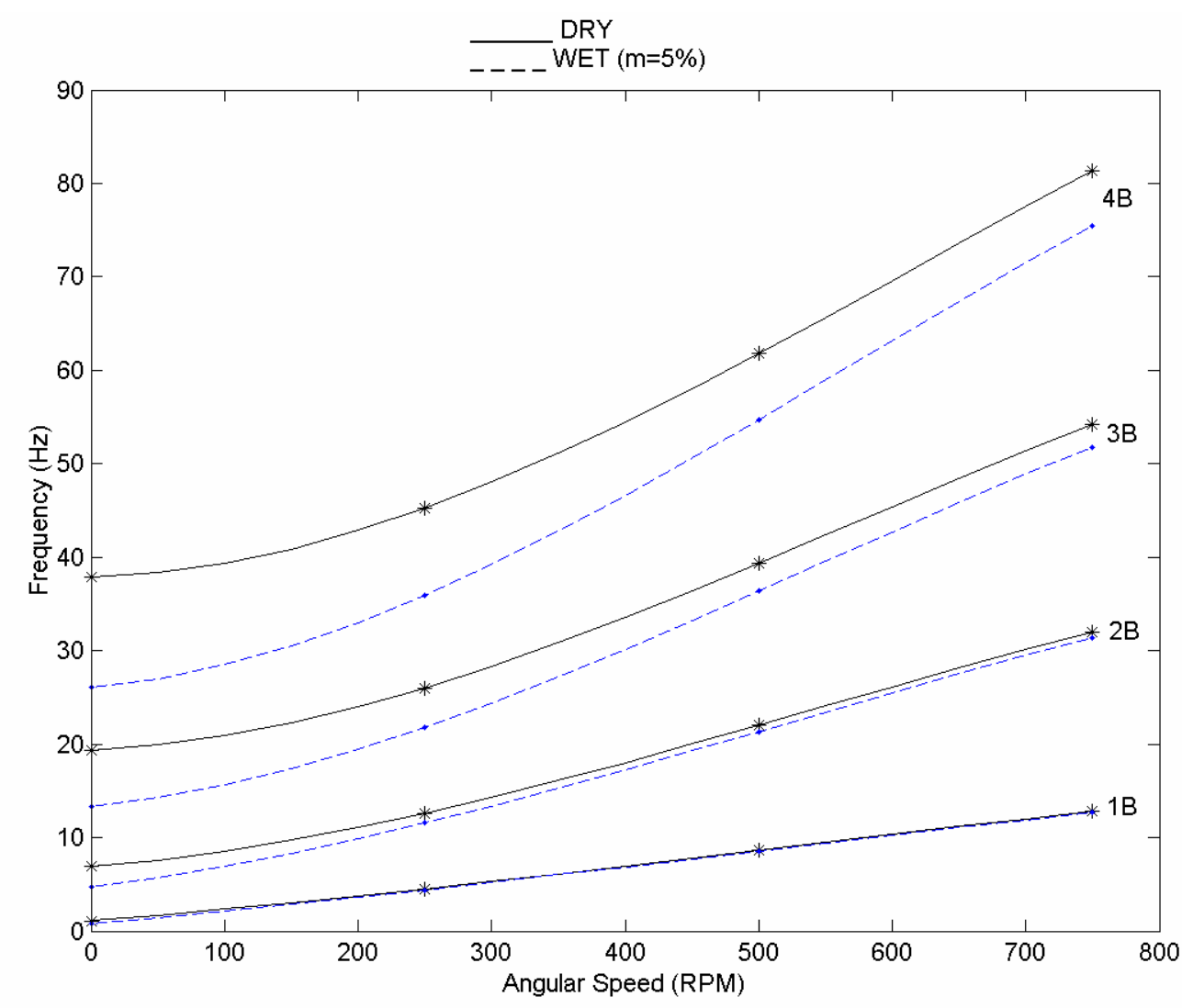

Figure 4.10 Influences of rotational speed and moisture content on natural frequencies of S-glass/epoxy beam, $[45]_{24}, T=90{ }^{\circ} C$

Table 4.22 Influences of rotational speed and moisture content on natural frequencies of S-glass/epoxy beam, $[45]_{24}, T=90{ }^{\circ} \mathrm{C}$

\begin{tabular}{|c|c|c|c|c|c|c|c|c|c|c|c|c|}
\hline \multirow{2}{*}{$\begin{array}{l}\text { Angular } \\
\text { Speed } \\
\text { (RPM) }\end{array}$} & \multicolumn{4}{|c|}{ Dry Condition (Hz) } & \multicolumn{4}{|c|}{$\begin{array}{c}\text { Hygrothermal }(\mathrm{Hz}) \\
\mathrm{m}=5 \%\end{array}$} & \multicolumn{4}{|c|}{ \% Reduction } \\
\hline & 1B & 2B & 3B & 4B & 1B & 2B & 3B & 4B & 1B & 2B & 3B & 4B \\
\hline $\mathbf{0}$ & 1.1 & 6.9 & 19.32 & 37.86 & 0.75 & 4.7 & 13.33 & 26.12 & 31.82 & 31.88 & 31.00 & 31.01 \\
\hline 250 & 4.52 & 12.62 & 26.03 & 45.28 & 4.4 & 11.55 & 21.84 & 35.92 & 2.65 & 8.48 & 16.10 & 20.67 \\
\hline 500 & 8.67 & 22.05 & 39.35 & 61.81 & 8.56 & 21.36 & 36.37 & 54.75 & 1.27 & 3.13 & 7.57 & 11.42 \\
\hline 750 & 12.82 & 31.97 & 54.26 & 81.4 & 12.71 & 31.4 & 51.78 & 75.39 & 0.86 & 1.78 & 4.57 & 7.38 \\
\hline
\end{tabular}




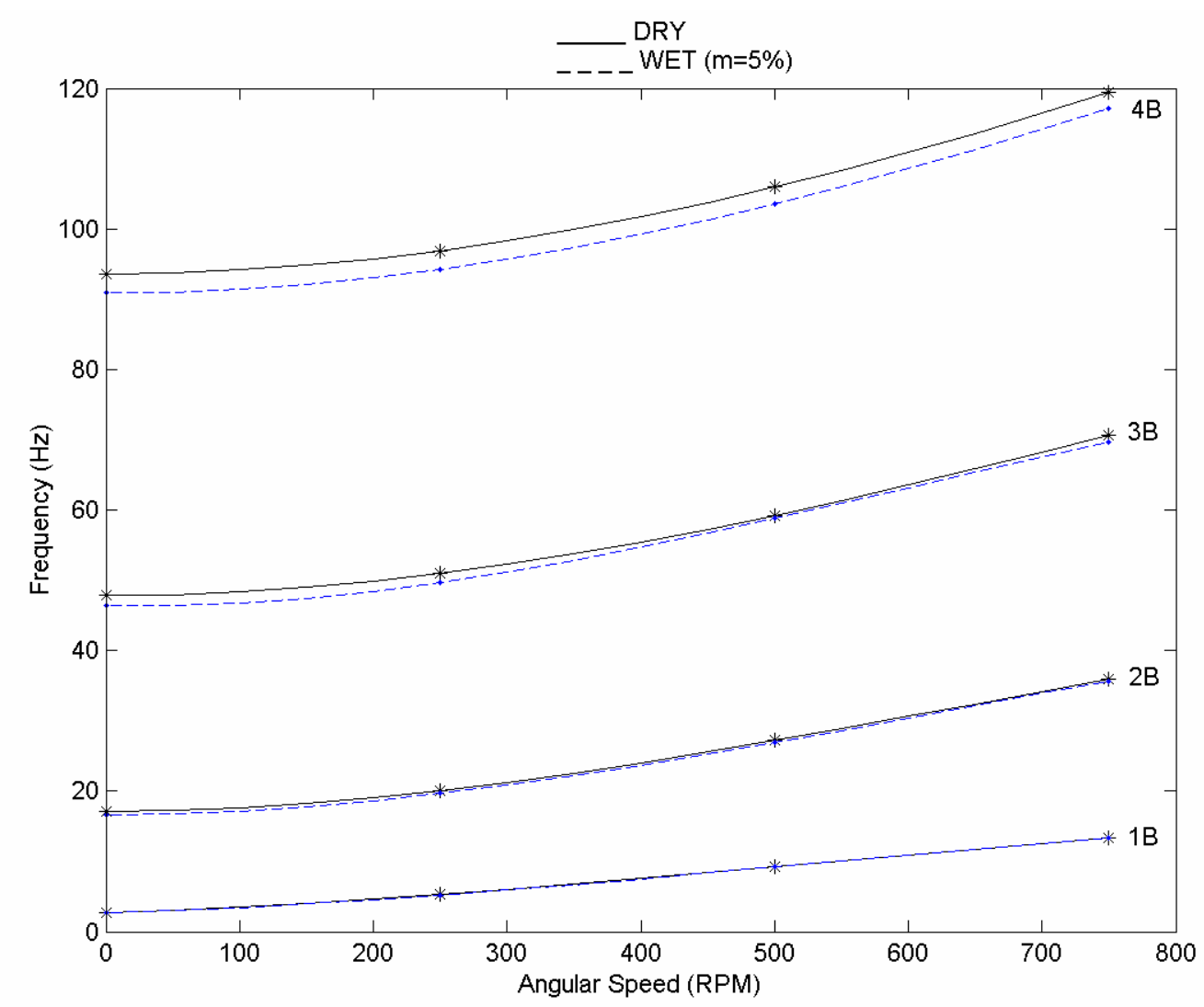

Figure 4.11 Influences of rotational speed and moisture content on natural frequencies of S-glass/epoxy beam, $[0]_{24}, T=52{ }^{0} \mathrm{C}$

Table 4.23 Influences of rotational speed and moisture content on natural frequencies of S-glass/epoxy beam, $[0]_{24}, T=52{ }^{0} C$

\begin{tabular}{|c|c|c|c|c|c|c|c|c|c|c|c|c|}
\hline $\begin{array}{l}\text { Angular } \\
\begin{array}{l}\text { Speed } \\
\text { (RPM) }\end{array}\end{array}$ & \multicolumn{4}{|c|}{ Dry Condition (Hz) } & \multicolumn{4}{c|}{$\begin{array}{c}\text { Hygrothermal (Hz) } \\
\text { m=5\% }\end{array}$} & \multicolumn{4}{c|}{ \% Reduction } \\
\cline { 2 - 13 } & 1B & 2B & 3B & 4B & 1B & 2B & 3B & 4B & 1B & 2B & 3B & 4B \\
\hline $\mathbf{0}$ & 2.72 & 17.08 & 47.81 & 93.63 & 2.64 & 16.59 & 46.43 & 90.91 & 2.94 & 2.87 & 2.89 & 2.91 \\
\hline $\mathbf{2 5 0}$ & 5.26 & 20.1 & 50.93 & 96.89 & 5.21 & 19.68 & 49.63 & 94.25 & 0.95 & 2.09 & 2.55 & 2.72 \\
\hline $\mathbf{5 0 0}$ & 9.25 & 27.19 & 59.21 & 105.99 & 9.21 & 26.87 & 58.8 & 103.55 & 0.43 & 1.18 & 0.69 & 2.30 \\
\hline $\mathbf{7 5 0}$ & 13.36 & 35.93 & 70.67 & 119.39 & 13.33 & 35.68 & 69.68 & 117.17 & 0.22 & 0.70 & 1.40 & 1.86 \\
\hline
\end{tabular}




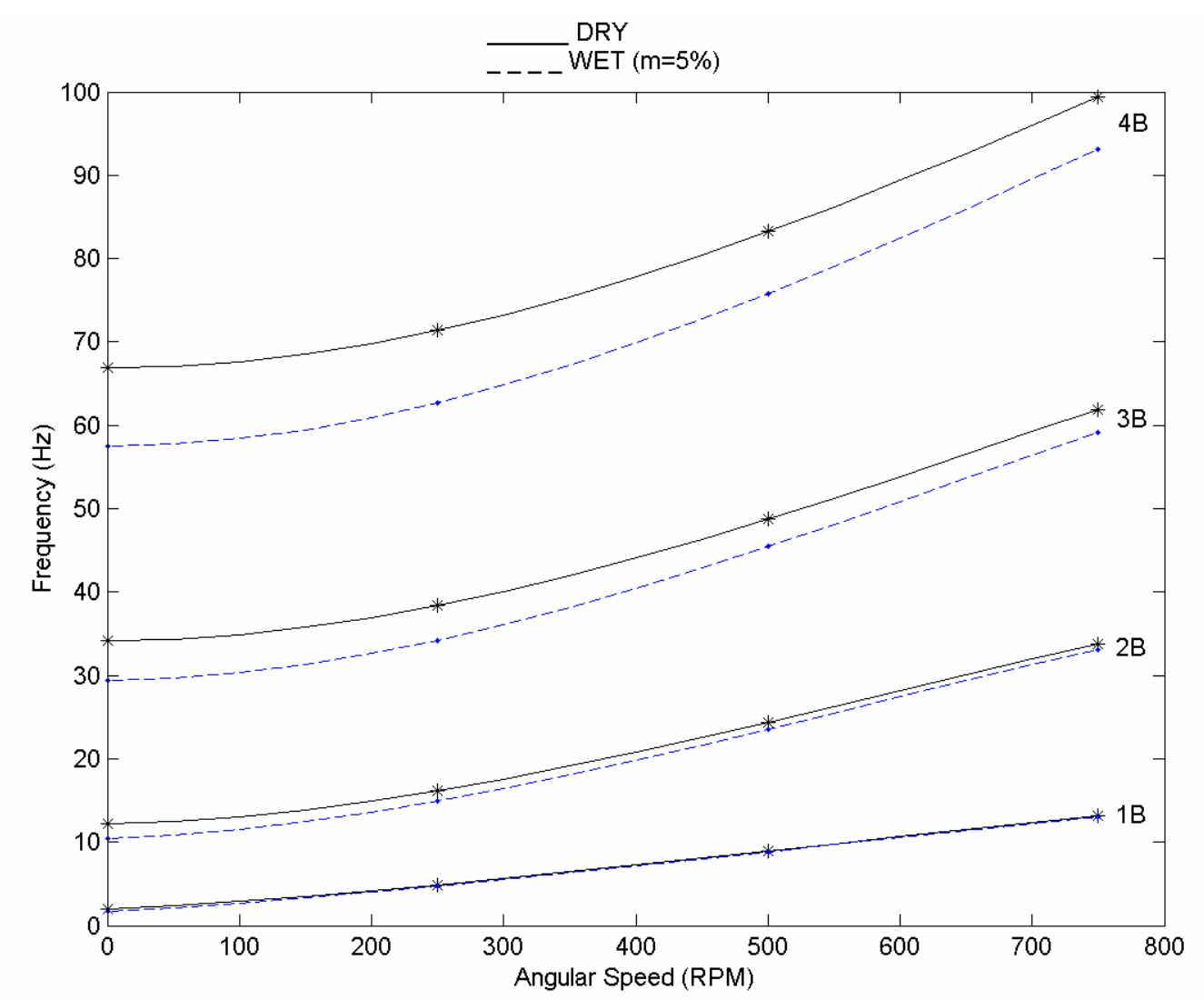

Figure 4.12 Influences of rotational speed and moisture content on natural frequencies of S-glass/epoxy beam, $[15]_{24}, T=52^{0} \mathrm{C}$

Table 4.24 Influences of rotational speed and moisture content on natural frequencies of S-glass/epoxy beam, $[15]_{24}, T=52{ }^{\circ} C$

\begin{tabular}{|c|c|c|c|c|c|c|c|c|c|c|c|c|}
\hline \multirow{2}{*}{$\begin{array}{l}\text { Angular } \\
\text { Speed } \\
\text { (RPM) }\end{array}$} & \multicolumn{4}{|c|}{ Dry Condition (Hz) } & \multicolumn{4}{|c|}{$\begin{array}{c}\text { Hygrothermal }(\mathrm{Hz}) \\
\mathrm{m}=5 \%\end{array}$} & \multicolumn{4}{|c|}{ \% Reduction } \\
\hline & $1 B$ & $2 B$ & 3B & 4B & 1B & 2B & 3B & 4B & 1B & 2B & 3B & 4B \\
\hline $\mathbf{0}$ & 1.94 & 12.19 & 34.14 & 66.89 & 1.67 & 10.49 & 29.38 & 57.56 & 13.92 & 13.95 & 13.94 & 13.95 \\
\hline 250 & 4.87 & 16.15 & 38.38 & 71.38 & 4.75 & 14.91 & 34.21 & 62.71 & 2.46 & 7.68 & 10.87 & 12.15 \\
\hline 500 & 8.96 & 24.37 & 48.74 & 83.23 & 8.86 & 23.53 & 45.44 & 75.83 & 1.12 & 3.45 & 6.77 & 8.89 \\
\hline 750 & 13.1 & 33.76 & 61.91 & 99.44 & 13.00 & 33.11 & 59.19 & 93.11 & 0.76 & 1.93 & 4.39 & 6.37 \\
\hline
\end{tabular}




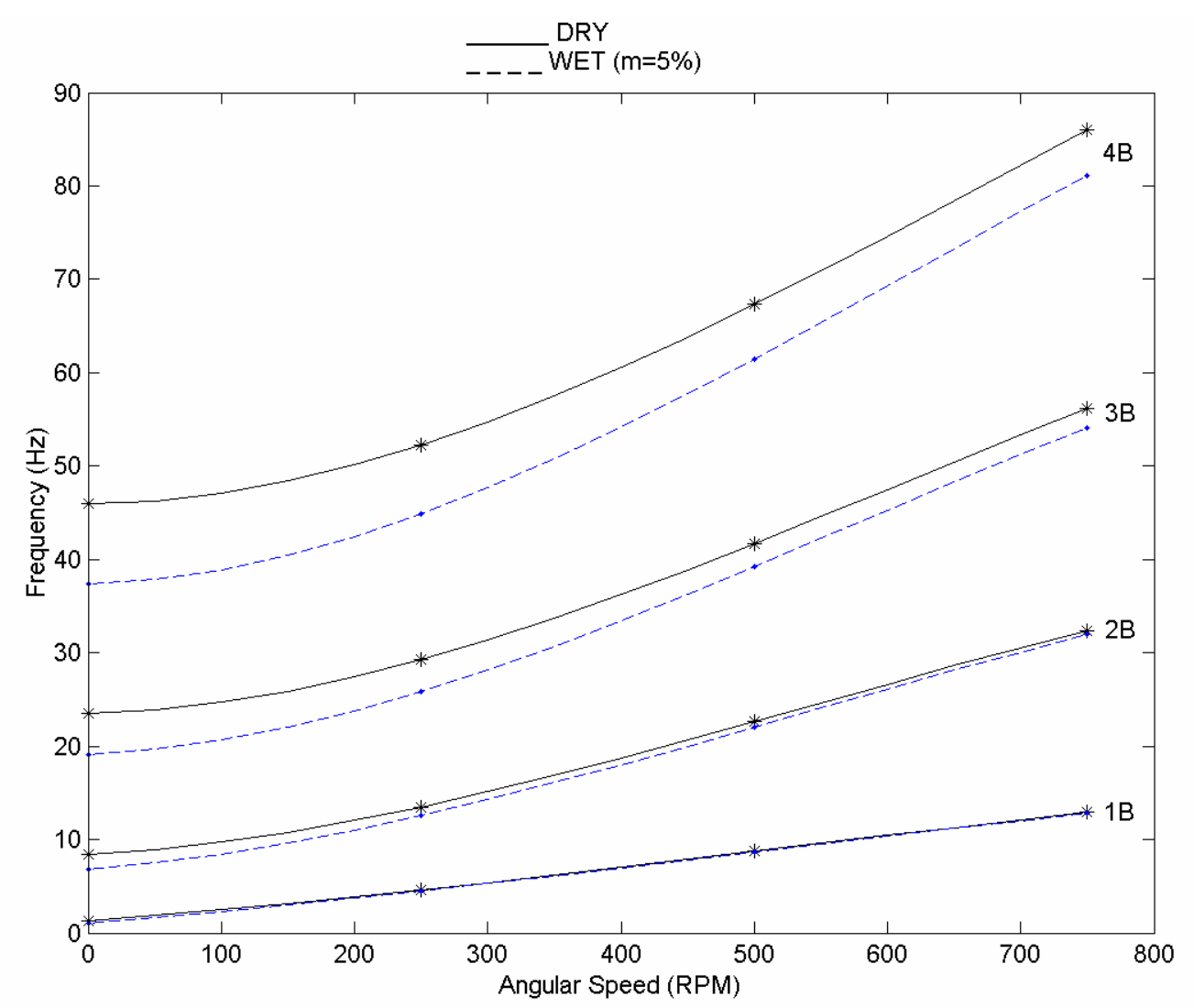

Figure 4.13 Influences of rotational speed and moisture content on natural frequencies of S-glass/epoxy beam, $[30]_{24}, T=52{ }^{\circ} \mathrm{C}$

Table 4.25 Influences of rotational speed and moisture content on natural frequencies of S-glass/epoxy beam, $[30]_{24}, T=52{ }^{\circ} \mathrm{C}$

\begin{tabular}{|c|c|c|c|c|c|c|c|c|c|c|c|c|}
\hline $\begin{array}{c}\text { Angular } \\
\text { Speed } \\
\text { (RPM) }\end{array}$ & \multicolumn{3}{|c|}{ Dry Condition (Hz) } & \multicolumn{3}{c|}{$\begin{array}{c}\text { Hygrothermal (Hz) } \\
\text { m=5\% }\end{array}$} & \multicolumn{4}{c|}{ \% Reduction } \\
\cline { 2 - 14 } & 1B & 2B & 3B & 4B & 1B & 2B & 3B & 4B & 1B & 2B & 3B & 4B \\
\hline $\mathbf{0}$ & 1.33 & 8.38 & 23.46 & 45.97 & 1.08 & 6.81 & 19.09 & 37.40 & 18.80 & 18.74 & 18.63 & 18.64 \\
\hline $\mathbf{2 5 0}$ & 4.61 & 13.5 & 29.26 & 52.27 & 4.52 & 12.57 & 25.85 & 44.88 & 1.95 & 6.89 & 11.65 & 14.14 \\
\hline $\mathbf{5 0 0}$ & 8.75 & 22.62 & 41.71 & 67.3 & 8.66 & 22.02 & 39.22 & 61.50 & 1.03 & 2.65 & 5.97 & 8.62 \\
\hline $\mathbf{7 5 0}$ & 12.9 & 32.41 & 56.18 & 85.99 & 12.81 & 31.93 & 54.13 & 81.11 & 0.70 & 1.48 & 3.65 & 5.68 \\
\hline
\end{tabular}




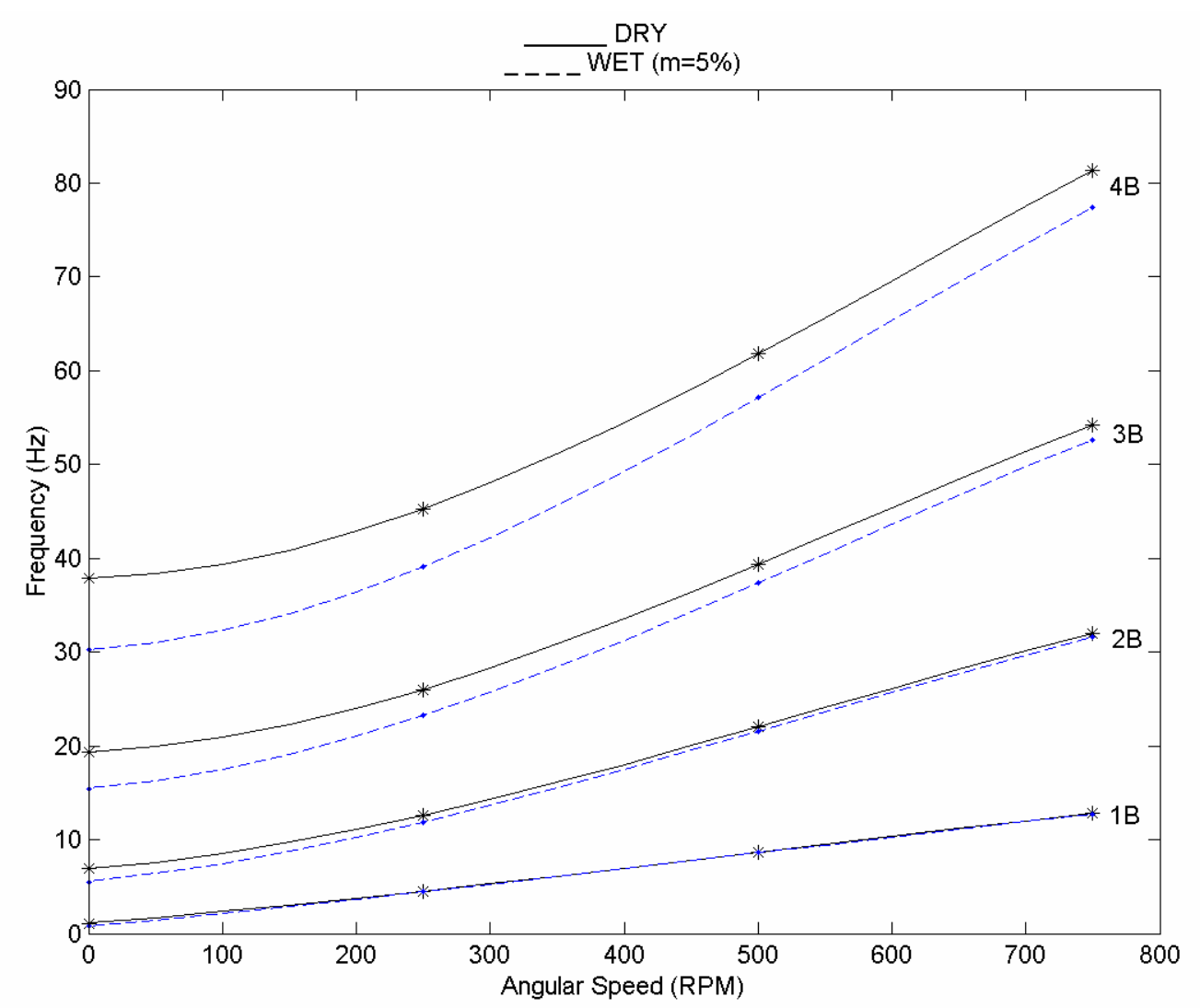

Figure 4.14 Influences of rotational speed and moisture content on natural frequencies of S-glass/epoxy beam, $[45]_{24}, T=52{ }^{0} C$

Table 4.26 Influences of rotational speed and moisture content on natural frequencies of S-glass/epoxy beam, $[45]_{24}, T=52{ }^{\circ} \mathrm{C}$

\begin{tabular}{|c|c|c|c|c|c|c|c|c|c|c|c|c|}
\hline \multirow{2}{*}{$\begin{array}{l}\text { Angular } \\
\text { Speed } \\
\text { (RPM) }\end{array}$} & \multicolumn{4}{|c|}{ Dry Condition (Hz) } & \multicolumn{4}{|c|}{$\begin{array}{c}\text { Hygrothermal (Hz) } \\
\text { m=5\% }\end{array}$} & \multicolumn{4}{|c|}{ \% Reduction } \\
\hline & 1B & $2 B$ & 3B & 4B & 1B & $2 B$ & 3B & 4B & 1B & $2 B$ & 3B & $4 B$ \\
\hline $\mathbf{0}$ & 1.1 & 6.9 & 19.32 & 37.86 & 0.8 & 5.52 & 15.47 & 30.31 & 27.27 & 20.00 & 19.93 & 19.94 \\
\hline 250 & 4.52 & 12.62 & 26.03 & 45.28 & 4.44 & 11.90 & 23.25 & 39.13 & 1.77 & 5.71 & 10.68 & 13.58 \\
\hline 500 & 8.67 & 22.05 & 39.35 & 61.81 & 8.60 & 21.59 & 37.37 & 57.14 & 0.81 & 2.09 & 5.03 & 7.56 \\
\hline 750 & 12.82 & 31.97 & 54.26 & 81.4 & 12.75 & 31.59 & 52.62 & 77.44 & 0.55 & 1.19 & 3.02 & 4.86 \\
\hline
\end{tabular}


Table 4.27 Comparison of frequency results for FSDT and CLPT, for S-Glass/Epoxy Beam, $[30]_{24}, T=90{ }^{\circ} C$

\begin{tabular}{|c|c|c|c|c|c|c|c|c|c|c|c|c|}
\hline $\begin{array}{l}\text { Angular } \\
\text { Speed } \\
\text { (RPM) }\end{array}$ & \multicolumn{4}{|c|}{$\begin{array}{c}\text { Hygrothermal (Hz) } \\
\text { m=5\% (FSDT) }\end{array}$} & \multicolumn{3}{c|}{$\begin{array}{c}\text { Hygrothermal (Hz) } \\
\text { m=5\% (CLPT) }\end{array}$} & \multicolumn{5}{c|}{ \% Reduction } \\
\cline { 2 - 13 } & 1B & 2B & 3B & 4B & 1B & 2B & 3B & 4B & 1B & 2B & 3B & 4B \\
\hline $\mathbf{0}$ & 0.94 & 5.92 & 16.57 & 32.48 & 0.94 & 5.92 & 16.58 & 32.49 & 0.00 & 0.00 & -0.06 & -0.03 \\
\hline $\mathbf{2 5 0}$ & 4.47 & 12.1 & 24.02 & 40.84 & 4.47 & 12.1 & 24.03 & 40.86 & 0.00 & 0.00 & -0.04 & -0.05 \\
\hline $\mathbf{5 0 0}$ & 8.62 & 21.71 & 37.91 & 58.42 & 8.62 & 21.73 & 37.94 & 58.47 & 0.00 & -0.09 & -0.08 & -0.09 \\
\hline $\mathbf{7 5 0}$ & 12.76 & 31.68 & 53.05 & 78.51 & 12.79 & 31.72 & 53.13 & 78.64 & -0.24 & -0.13 & -0.15 & -0.17 \\
\hline
\end{tabular}




\section{CONCLUSIONS AND RECOMMENDATIONS}

\subsection{Contributions}

1. A finite element model having five nodes and 29 degrees of freedom is presented for the free vibration analysis of a composite rotating beam based on FSDT.

2. The beam element is developed using Lagrange polynomial functions with $C^{0}$ continuity for some variables and Hermite polynomial functions with $C^{1}$ continuity for the other variables.

3. A MATLAB code is written to solve the finite element equations and generate results for free vibration characteristics.

4. A parametric study on free vibration characteristics of rotating composite cantilever beam subjected to hygrothermal conditions is conducted by varying speed of rotation, temperature, moisture content and fiber orientation.

\subsection{Conclusions}

1. An $h-p$ version, one dimensional finite element is developed and successfully implemented for free vibration analysis of symmetrically laminated composite rotating beams using first-order shear deformation theory.

2. Under hygrothermal conditions, increase in temperature and moisture content decreases the stiffness and flap-bending frequencies.

3. The hygrothermal effect on the natural frequency is more severe on the nonrotating beam than on the rotating beam 
4. As the rotational speed increases the percentage reduction in the natural frequency decreases for all the cases considered

\subsection{Recommendations}

1. Torsional and lag degrees of freedom can be introduced in to the problem formulation.

2. Shear correction factor used in the present study is an approximate value. Higher order theories could eliminate the need for approximation and can produce effective results.

3. Nonlinear analysis can be performed.

4. Hygrothermal implementation can be done by considering expansion strains caused due to temperature and moisture. 


\section{REFERENCES}

Abarcar, R.B. and Cunniff, P.F., (1972), "The vibration of Cantilever Beams of Fiber Reinforced Material,” Journal of Composite Materials, Vol. 6, pp. 504-517.

Barbero, E.J., 1998, “Introduction to Composite Materials Design”, Taylor and Francis, Philadelphia.

Bauer, H.F. and Eidel, W. (1988), "Vibration of a rotating uniform beam, part II: orientation perpendicular to the axis of rotation", Journal of Sound and Vibration, Vol. 122, pp. 357-375.

Bhat, R.B. (1986), "Transverse vibrations of a rotating uniform beam with tip mass as predicted by using beam characteristic polynomials in the Rayleigh-Ritz method", Journal of Sound and Vibration, Vol. 105, pp. 199-210.

Cairns, D.S. and Adams, D.F., (1984), "Moisture and Thermal Expansion Properties of unidirectional Composite Materials and the Epoxy Matrix", Environmental Effects on Composite Materials, Vol. 2, George S. Springer, Ed. pp.300-316.

Chamis, C.C., (1983), "Simplified Composite Micromechanics Equations for Hygral, Thermal and Mechanical Properties", NASA Technical Memorandum 83320. Prepared for the Thirty-eighth Annual Conference of the Society of the Plastics Industry, Reinforced Plastics Institute, Houston, TX, pp. 1-10.

Chandrasekaran, G., (2000), "Dynamic Analysis of a Composite Moving Beam", Master's Thesis, West Virginia University, Morgantown, WV. 
Chen, L.W., and Chen, Y.M., (1998), "Vibrations of Hygrothermal Elastic Composite Plates”, J. Engineering Fracture Mechanics, Vol. 31, No.2, pp. 209-220.

Epps, J.J., and Chandra, R., (1996), “The Natural Frequency of Rotating Composite Beams With Tip Sweep", Journal of The American Helicopter Society, Vol. 41, No.1, 2936.

Hodges and Rutkowski (1981), "Free-vibration analysis of rotating beams by a variableorder finite-element method", AIAA Journal, Vol. 19, No.11 pp. 1459-1466.

Hodges, D.H., Shang, X., and Cesnik, C.E.S., (1996), “The Finite Solution Nonlinear Intrinsic Equations for Curved Composite Beams", Journal of The American Helicopter Society, Vol. 41, No.4, 313-321.

Kavipurapu, P.K, (2005), "Forced Vibration and Hygrothermal Analysis of Composite Laminated Beams under the Action of Moving Loads", Master's Thesis, West Virginia University, Morgantown, WV.

Nagappan, G., (2004), “Analysis of Composite Moving Beams using Higher Order Shear Deformation Theory", Master's Thesis, West Virginia University, Morgantown, WV.

Reddy, J.N., (1985), "Review of the Literature on Finite-Element Modeling of Laminated Composite Plates”, Journal of Shock and Vibration Digest, Vol. 17, No. 4, pp. 3-8.

Reddy, J.N., (1997), "Mechanics of Laminated Composite Plates: Theory and Analysis", CRC Press, Boca Raton, Fla.

Shen, S.H., Zheng, J.J., and Huang, X.L.; (2004); “The Effects of Hygrothermal Conditions on The Dynamic Response of Shear Deformable Laminated Plates Resting on Elastic Foundations", Journal of Reinforced Plastics and Composites, Vol. 23, No.10, pp. 1095-1113. 
Singh, G., Rao, G.V., and Iyengar N.G.R., (1991), "Analysis of Nonlinear Vibrations of Unsymmetrically Laminated Composite Beams", AIAA Journal, Vol. 29, No. 10, pp. 1727-1735.

Sreeram, T.R., (1995), "Dynamic Analysis of a Moving Beam using h-p version Finite Element Method with Essential Conditions Applied Via Lagrange Multipliers", Master's Thesis, West Virginia University, Morgantown, WV.

Sreeram, T.R. and Sivaneri, N.T., (1997), "FE-Analysis of a Moving Beam using Lagrangian Multiplier Method", International Journal of Solids and Structures, Vol. 35, No. 28-29, pp. 3675-3694.

Stemple, A.D., Rhim, J.W., and Kim Y.H., (1995) "Vibration of Rotating Composite Beams Using a Finite Element Model with Warping Degrees of Freedom", Computational Mechanics, Vol. 16, pp. 258-265.

Upadhyay, P.C. and Lyons, J.S., (2000a), "Effect of Hygrothermal Environment on the Bending of PMC Laminates under Large Deflection”, Journal of Reinforced Plastics and Composites, Vol.19, No.6, pp. 465-491.

Upadhyay, P.C. and Lyons, J.S., (2000b), "Hygrothermal Effect on the Large Deflection Bending of Asymmetric PMC Laminates", Journal of Reinforced Plastics and Composites, Vol.19, No. 14, pp. 1094-1111.

Yildirim, V., Sancaktar, E., and Kiral, E., (1999) "Free Vibration Analysis Of Symmetric Cross-Ply Laminated Composite Beams With The Help Of The Transfer Matrix Approach", J. Communications In Numerical Methods In Engineering, 15, 651-660. 


\section{BIBLIOGRAPHY}

Chandrupatla, T.R. and Belegundu D.A., 1997, "Introduction to Finite Elements

in Engineering," Second Edition, Prentice-Hall of India Private Ltd., New Delhi, India.

Bathe, K.J., 2001, "Finite Element Procedures," Fifth Edition, Prentice-Hall of India Private Ltd., New Delhi, India.

Kattan, P.I., "Matlab Guide to Finite Elements", First Edition, Springer-Verlag Berlin Heidelberg, Inc., New York.

Reddy, J.N., 1984, "Energy and variational methods in applied mechanics: with an introduction to the finite element method," Wiley, New York. 